San Jose State University

SJSU ScholarWorks

Master's Theses

Master's Theses and Graduate Research

Fall 2010

\title{
Aircraft Deconfliction Responsibility Across En Route Sectors in NextGen Separation Assurance
}

Christopher Donald Douglas Cabrall

San Jose State University

Follow this and additional works at: https://scholarworks.sjsu.edu/etd_theses

\section{Recommended Citation}

Cabrall, Christopher Donald Douglas, "Aircraft Deconfliction Responsibility Across En Route Sectors in NextGen Separation Assurance" (2010). Master's Theses. 3848.

DOI: https://doi.org/10.31979/etd.fv4y-3tfh

https://scholarworks.sjsu.edu/etd_theses/3848

This Thesis is brought to you for free and open access by the Master's Theses and Graduate Research at SJSU ScholarWorks. It has been accepted for inclusion in Master's Theses by an authorized administrator of SJSU ScholarWorks. For more information, please contact scholarworks@sjsu.edu. 


\title{
AIRCRAFT DECONFLICTION RESPONSIBILITY ACROSS EN-ROUTE SECTORS IN NEXTGEN SEPARATION ASSURANCE
}

\author{
A Thesis \\ Presented to \\ The Faculty of the Graduate Program in Human Factors and Ergonomics \\ San José State University \\ In Partial Fulfillment \\ of the Requirements for the Degree \\ Master of Science \\ by \\ Christopher D. Cabrall
}

December 2010 
(C) 2010

Christopher D. Cabrall

ALL RIGHTS RESERVED 
The Designated Thesis Committee Approves the Thesis Titled

\begin{abstract}
AIRCRAFT DECONFLICTION RESPONSIBILITY ACROSS EN-ROUTE SECTORS
IN NEXTGEN SEPARATION ASSURANCE

by

Christopher D. Cabrall
\end{abstract}

APPROVED FOR THE DEPARTMENT OF

INDUSTRIAL AND SYSTEMS ENGINEERING

SAN JOSE STATE UNIVERSITY

December 2010

Dr. Kevin Jordan

Department of Psychology

Dr. Anthony Andre

Department of Industrial and Systems Engineering

Dr. Thomas Prevot

Senior Research Associate, San Jose State University

Research Foundation at NASA Ames Research Center 


\begin{abstract}
AIRCRAFT DECONFLICTION RESPONSIBILITY ACROSS EN-ROUTE SECTORS

IN NEXTGEN SEPARATION ASSURANCE

by Christopher D. Cabrall

The subject of the current research is a Next Generation Air Transportation

System (NextGen) concept that involves automated separation assurance developed to enable controllers to provide both safe and efficient air traffic services at much higher traffic densities than possible today. The study investigated the issue of how responsibility should be handled between controllers for the resolution of a conflict that is predicted to occur in a sector other than where it was detected. Two possibilities, a DeConflicting AirPlanes procedure (DCAP) versus a De-Conflicting AirSpace procedure (DCAS), were examined under human-in-the-loop simulations with scripted aircraft conflicts. Results showed that the DCAS procedure was preferred and that participants experienced less verbal coordination and took less time to resolve conflicts. The results, however, did not reveal significant differences among other plane performance metrics between DCAP and DCAS. These results indicate that the demands of NextGen separation assurance might still be met with ownership and coordination procedures (e.g., DCAP) similar to today. Reducing verbal coordination requirements, however, and allowing separation assurance responsibilities to extend more seamlessly across sector boundaries (e.g., DCAS) would evidently be more acceptable to controllers.
\end{abstract}




\section{ACKNOWLEDGEMENTS}

I would like to thank my thesis committee, Dr. Kevin Jordan, Dr. Anthony Andre, and Dr. Thomas Prevot, for all their support throughout the completion of my thesis. Aside from formal instruction or professional mentorship, their personable characters have taught me far more than I expected to learn.

I would also like to express enduring gratitude to all the members and associates of my group in the Airspace Operations Laboratory at NASA Ames Research Center. The opportunities for direct participation and interaction with the research and technologies afforded me here continue to impress me each and every day. The patience and guidance with which Lynne Martin, Jeffrey Homola, and Joey Mercer in particular have responded to my incessant questions are especially appreciated. More so, the kindness and comfort throughout the group has truly made the AOL feel like a second home.

I am deeply thankful for the love and encouragement of my friends and family, whether near or remote. Last, the greatest thanks are owed to my complement, Amira DeSourdis. Your support and distractions together provided me with the balance I needed to see me through this effort. In hopes that "Chris and Ami fun days" will continue to pervade difficult work and prevent it from becoming overwhelming, thank you. 


\section{TABLE OF CONTENTS}

SECTION

PAGE

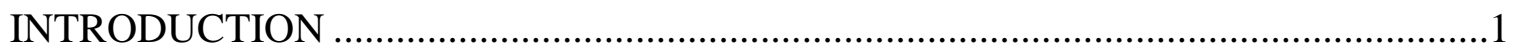

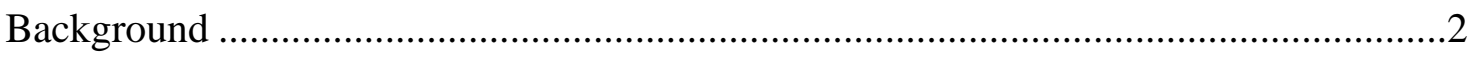

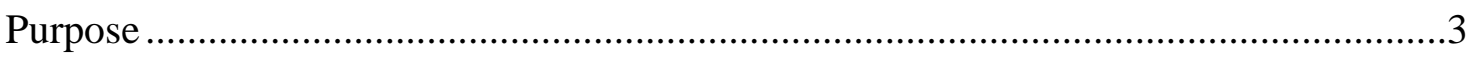

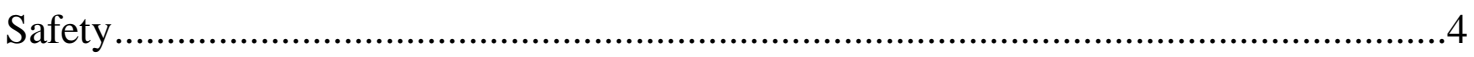

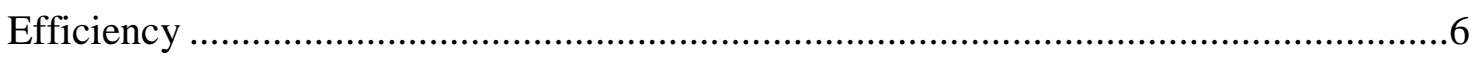

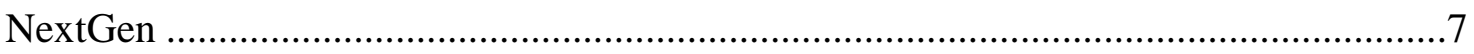

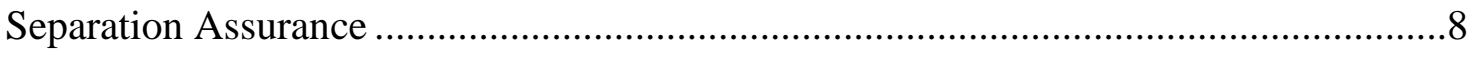

Automated Separation Assurance …………………...............................................10

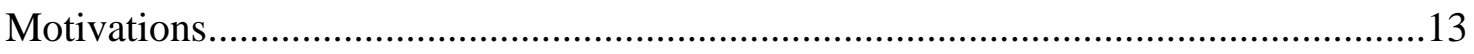

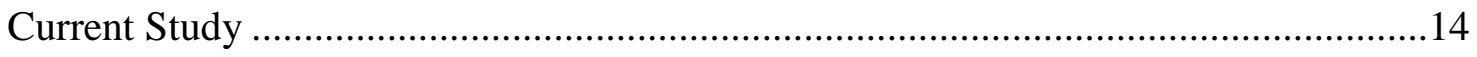

Coordination in Aviation Decision Making ..........................................................16

Research Questions and General Hypotheses ...........................................................19

Specific Hypotheses -DCAS "better" than DCAP ………...........................................20

Coordination.

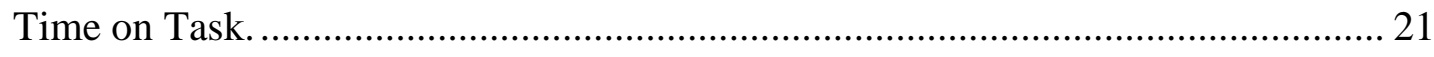

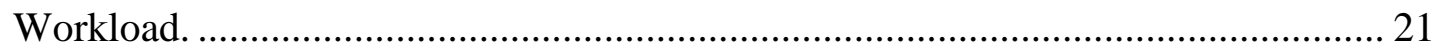




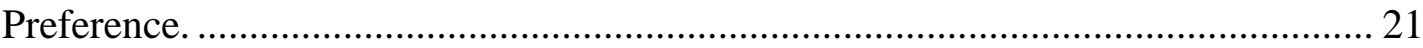

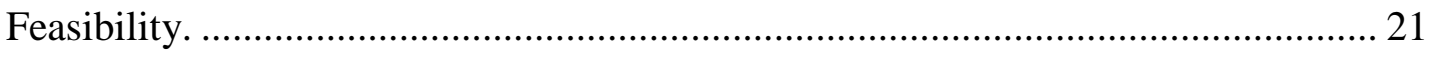

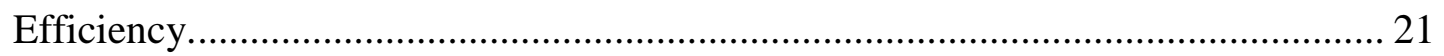

Safety

Specific Hypotheses - Interaction of procedure and traffic level ................................22

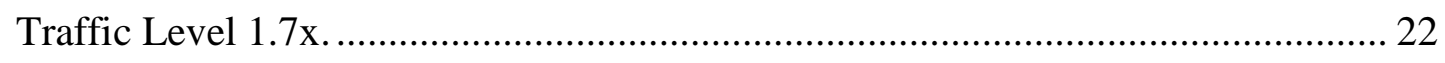

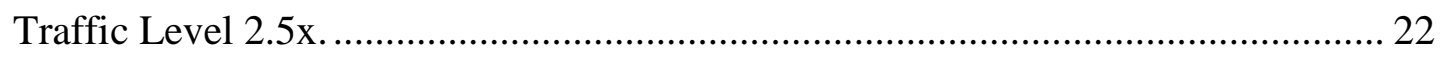

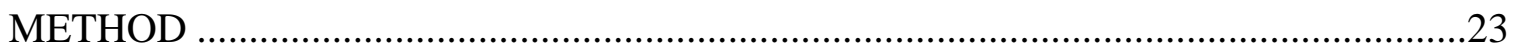

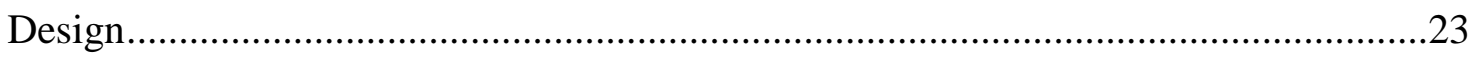

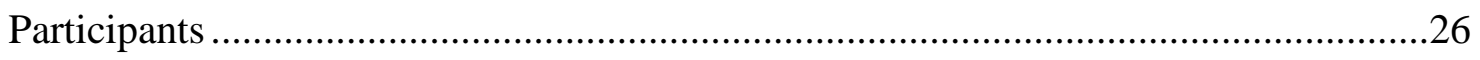

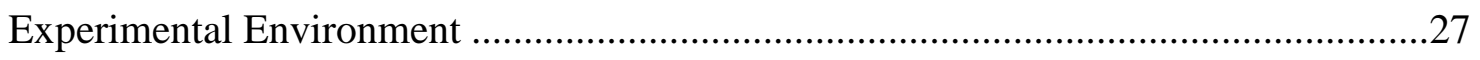

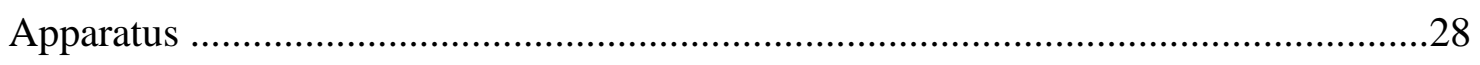

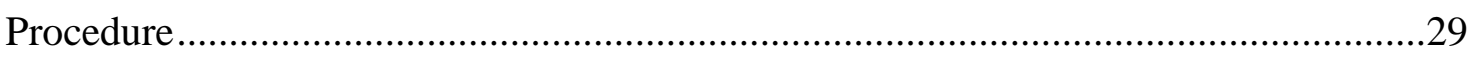

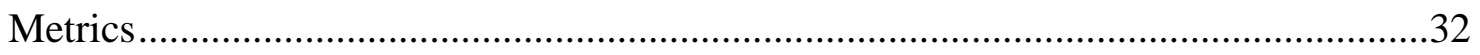

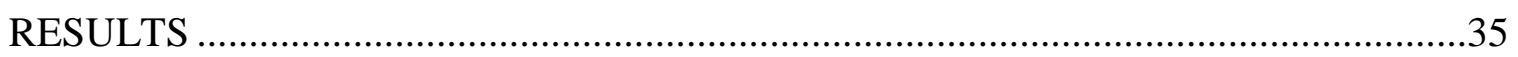

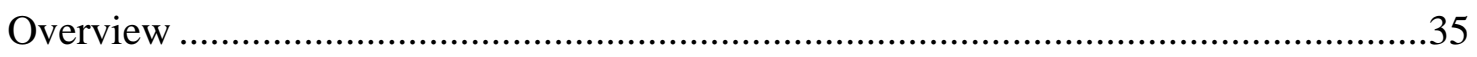

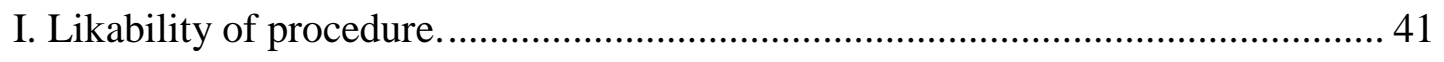

II-a. Workload (self - report). ………………………….................................. 43

II-b. Workload (supervisor assessment) ............................................................... 46

III-a. Amount of coordination (experienced). ........................................................... 47 
III-b. Amount of coordination (expected). .................................................. 48

IV-a. Likability of amount of coordination (experienced). ............................... 50

IV-b. Likability of amount of coordination (expected).........................................52

Summary - Controller Experience, Subjective ...................................................53

V-a, V-b, V-c. Verbal coordination counts, lengths and \% of run length............... 54

VI. Time on task taken to resolve conflicts. .................................................... 57

Summary - Controller Experience, Objective ......................................................58

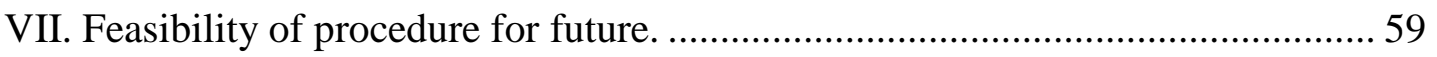

VIII-a, VIII-b. Unnecessary plane movement (experienced, expected).................. 60

Summary - Plane Performance, Subjective ....................................................62

IX-a, IX-b, IX-c. Separation Violations (LoS, O.E., Proximity Event). ................... 62

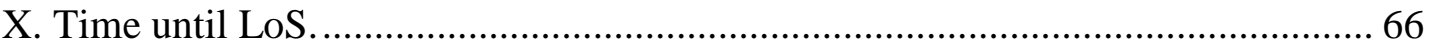

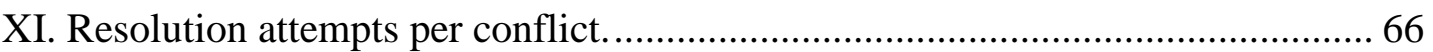

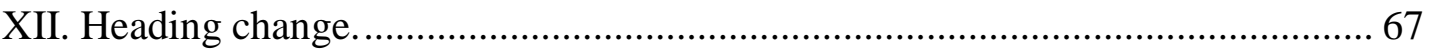

Summary - Plane Performance, Objective ..........................................................67

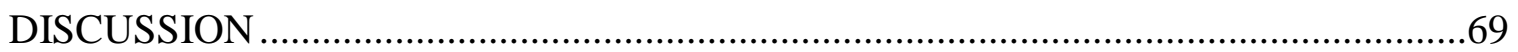

Procedure Main Effects: Differences ................................................................. 70

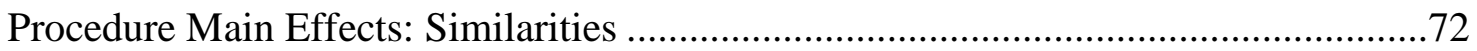

Traffic Density Main Effects: Differences and Similarities.....................................73

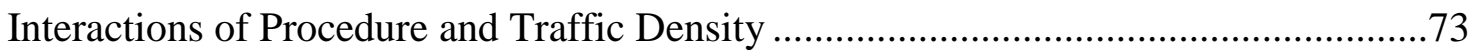




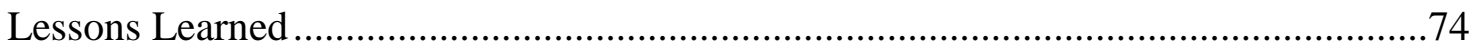

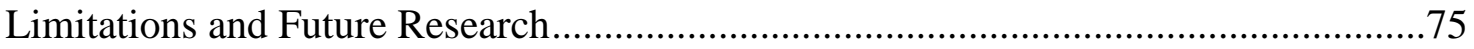

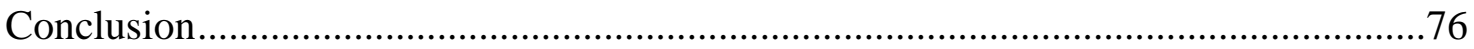

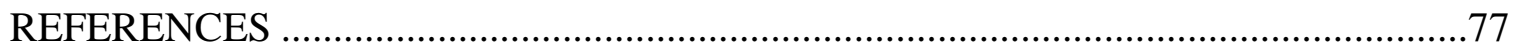

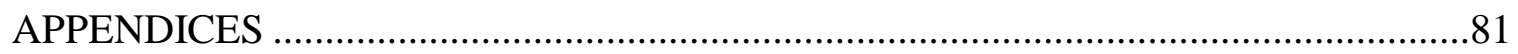

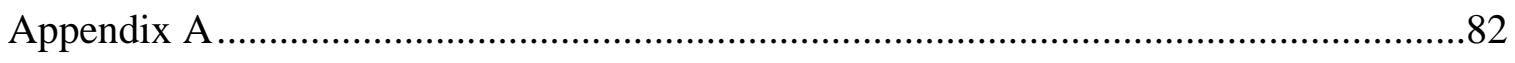

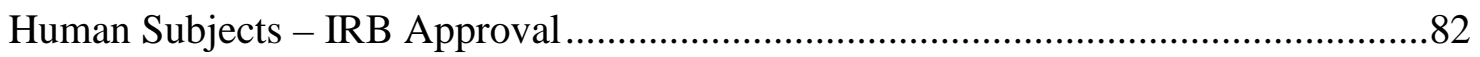

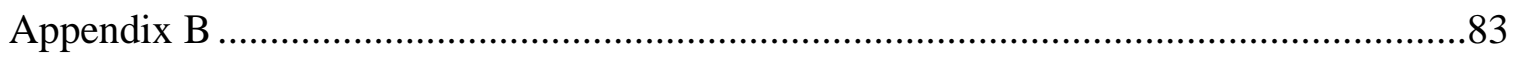

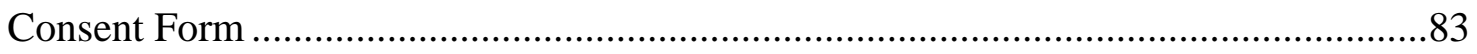

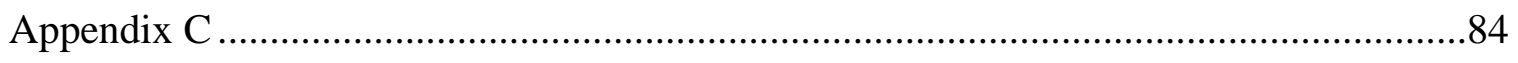

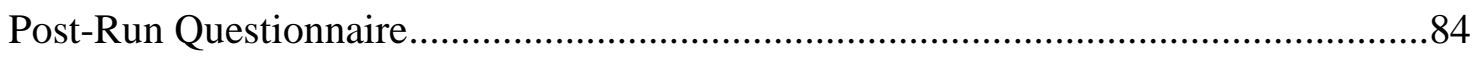

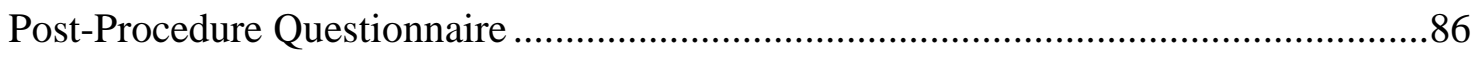

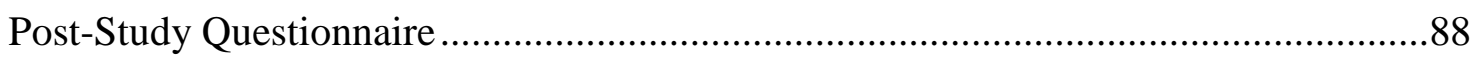

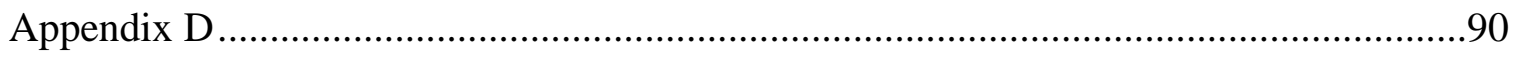

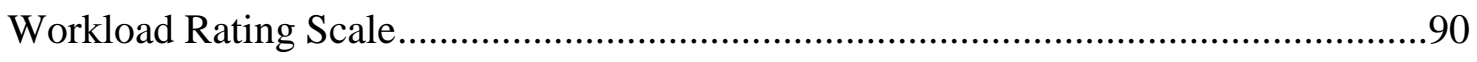




\section{LIST OF TABLES}

TABLE

PAGE

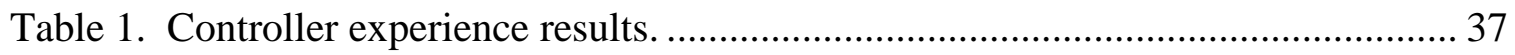

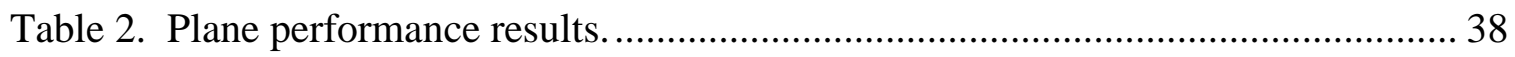

Table 3. Sub-group means, standard deviations, and interaction significance statistics . 40 


\section{LIST OF FIGURES}

FIGURE

PAGE

Figure 1. Sample of current day United States air traffic volume per en-route sector...... 2

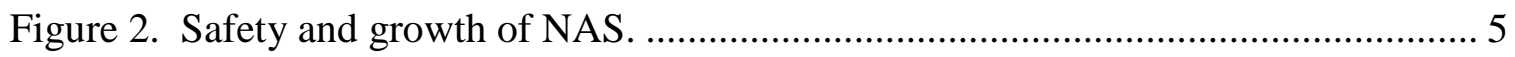

Figure 3. Current day controller display with 1x, 2x, and 3x traffic levels................... 10

Figure 4. Involvement of controllers of adjacent sectors....................................... 13

Figure 5. Experimental design test matrix........................................................ 24

Figure 6. Cases differening by number of controllers (sectors) involved...................... 25

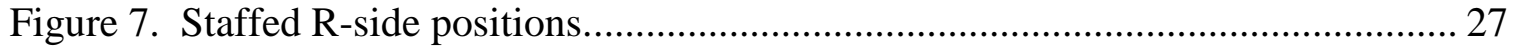

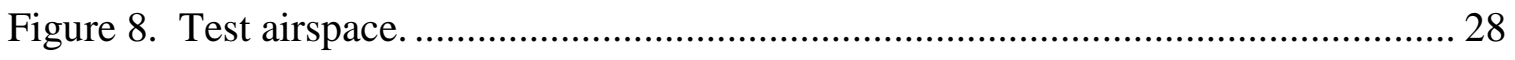

Figure 9. Conflict table, color coding, and time until LoS counter ............................. 31

Figure 10. Trial planning a trajectory amendment................................................. 32

Figure 11. Likability of procedure rating distributions........................................ 41

Figure 12. Likability of procedure significant mean comparison............................... 42

Figure 13. Average workload self-response ratings by prompt time and procedure...... 44

Figure 14. Average workload self-response ratings by prompt time and traffic density. 44

Figure 15. Workload self-response significant mean procedure comparison................. 45

Figure 16. Workload self-response significant mean density comparison. ................... 45

Figure 17. Supervisor assessed R-side workload ratings by procedure......................... 46

Figure 18. Experienced coordination rating distributions by procedure ........................ 47 
Figure 19. Expected coordination rating distributions by procedure 48

Figure 20. Expected coordination for future significant mean comparison.................... 50

Figure 21. Agreeableness of experienced coordination amount by procedure............... 51

Figure 22. Coordination agreeableness expected for future controllers. ....................... 52

Figure 23. Agreeableness of coordination for future significant mean comparison........ 53

Figure 24. Verbal coordination transmissions, color coded by participant and enumerate

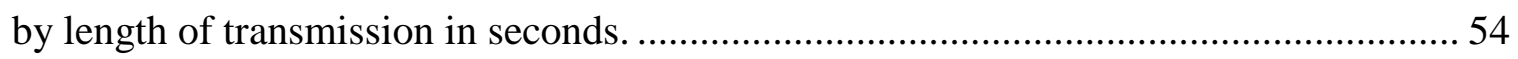

Figure 25. Interaction of world and procedure on time taken to resolve a conflict.........56

Figure 26. Significant mean comparison of time taken to resolve a scripted conflict..... 58

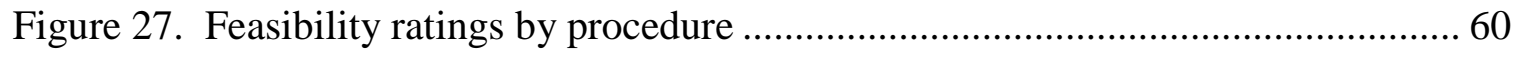

Figure 28. Experienced concern over the unnecessary movement of planes. ............... 61

Figure 29. Expected concern for future for unnecessary movement of planes............... 61

Figure 30. DCAS - Loss of separation due to late conflict detection from automation .. 64

Figure 31. DCAP - Loss of separation due to late conflict detection from automation .. 65 


\section{INTRODUCTION}

On an average day, the United States National Airspace System (NAS) sees more than 87,000 flights traverse its skies; approximately 5,000 planes are aloft at any given moment (National Air Traffic Controllers Association, 2009). To help visualize this

volume of traffic, Figure 1 shows the number of airborne aircraft at a single point in time above a geographic area about the same size as the state of Connecticut. Over the course of 2008 with a commercial fleet of 7,274 airplanes, the NAS enabled approximately 757.4 million passengers (over 2 million per day) as well as over a trillion dollars in cargo to traverse its $17,017,092$ square miles of airspace while consuming approximately 21,240 million gallons of fuel at a peak cost of \$3.83 per gallon (Federal Aviation Administration, 2009a). Simply put, the scope of the NAS spans a sizeable number of planes, miles, and money not to mention the nearly invaluable cost of human life (e.g., \$6.0 million per person, Office of the Secretary of Transportation, 2009). 


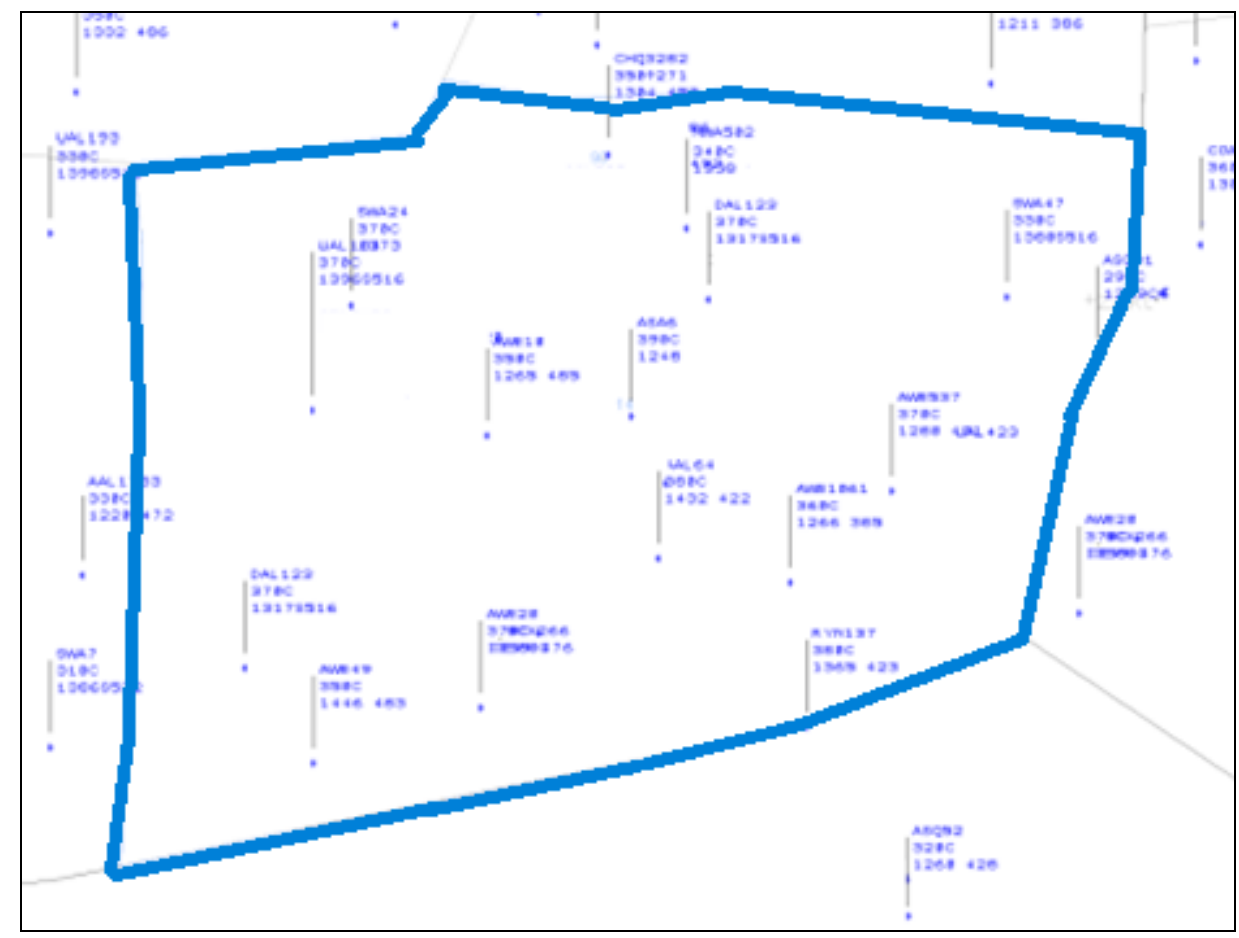

Figure 1. Sample of current day United States air traffic volume per en-route sector.

With such a significant investment, the Federal Airspace Administration (FAA) employs a vast network of more than 15,000 air traffic controllers (ATCo) devoted to its support and function. Across the U.S. and its territories, controllers staff a wide range of positions within 478 different facilities (NATCA, 2009). Despite their varied job duties or position titles, the underlying and fundamental mission statement of all these men and women is to accomplish the safe and efficient flow of traffic from origin to destination (Nolan, 2004).

\section{Background}

Unfortunately, such high responsibilities weigh on human beings and compensations such as higher wages, shorter work weeks, and better retirement benefits 
contrast against limited federal budgets. In a landmark labor-management standoff in the early 1980s, nearly 75\% of the Professional Air Traffic Controllers Organization (PATCO) walked off the job in hopes of gaining recognition and recompense for the highly stressful nature of their critical work. Such an action was in violation of federal no-strike clauses, and despite developing trends in other federal strikes (i.e., postal workers, government printing office, and library of congress employees) President Reagan fired over 11,000 air traffic controllers who went on strike. Normally graduating 1,500 persons per six month cycle, the FAA's Oklahoma City training school planned to ramp their matriculation rate to 5,500 with 45,000 people applying to the school within a month of the strike's onset (Manning, 2000). Such staffing decisions have long-term repercussions especially in a field with a mandatory retirement age of 56 years old. As a result, the mass hiring in the eighties jeopardized the turn-of-the-millennium ATCo workforce since a large proportion of employees are eligible for retirement between the years 2002 and 2012 (Nolan, 2004).

\section{Purpose}

With the looming pressures of fewer controllers available to handle increasing numbers of air traffic, and after several years of particularly disruptive service, the FAA established an Operational Evolution Partnership (OEP) in 2001 as a roadway to redesign the NAS and implement a benchmark 30\% increase in its capacity by 2013 (FAA, 2007).

Meanwhile, forecasts since have estimated demands as high as 1 billion passengers between 2012 and 2015 with that number more than doubling by 2025

(Mohler, 2008). More conservative estimates foresee 1.1 billion passengers for 2025 
(FAA, 2009a), representing a 50\% increase from today. Furthermore, the OEP projects that without improvements to the air traffic system, delays will increase $62 \%$ by 2014 , with a $27 \%$ increase in domestic traffic slated for 2016. Presently, the OEP has found that thirteen of the 35 busiest airports they have investigated are already operating at capacity and that a failure to accommodate an increase in demand could have severe economic impacts (Mohler, 2007). Most alarmingly, the OEP references studies that have shown that controllers cannot handle even a $25 \%$ increase in traffic in their busiest sectors with the use of today's tools alone (Mohler, 2008).

For the health of both the U.S. economy and the NAS alike, it is important to consider the impacts this challenge of demand poses towards controllers meeting their goals of safe and efficient flow of air traffic.

\section{Safety}

Historically, the United States NAS has been well-known for its robust level of safety. Since its inception in 1959, the Federal Aviation Administration (FAA) has simultaneously exponentially decreased the number of accidents (fatal or otherwise) while steadily increasing its numbers of flown aircraft (see Fig. 2). Thirty years ago fatal accidents on commercial jetliners occurred approximately once in every 140 million miles flown, while today 1.4 billion miles are flown for every fatal accident (i.e., a tenfold improvement in safety). Compared to other forms of transportation in the year 2000, commercial aviation had 163 fatalities while highways posted 41,800 , boats 801 , railways 770, and bicycles 738 fatalities. It has been reported that fewer people have died in 
commercial airplane accidents in the U.S. over the past 60 years than are killed in auto accidents in a typical three-month period (Boeing, 2009).

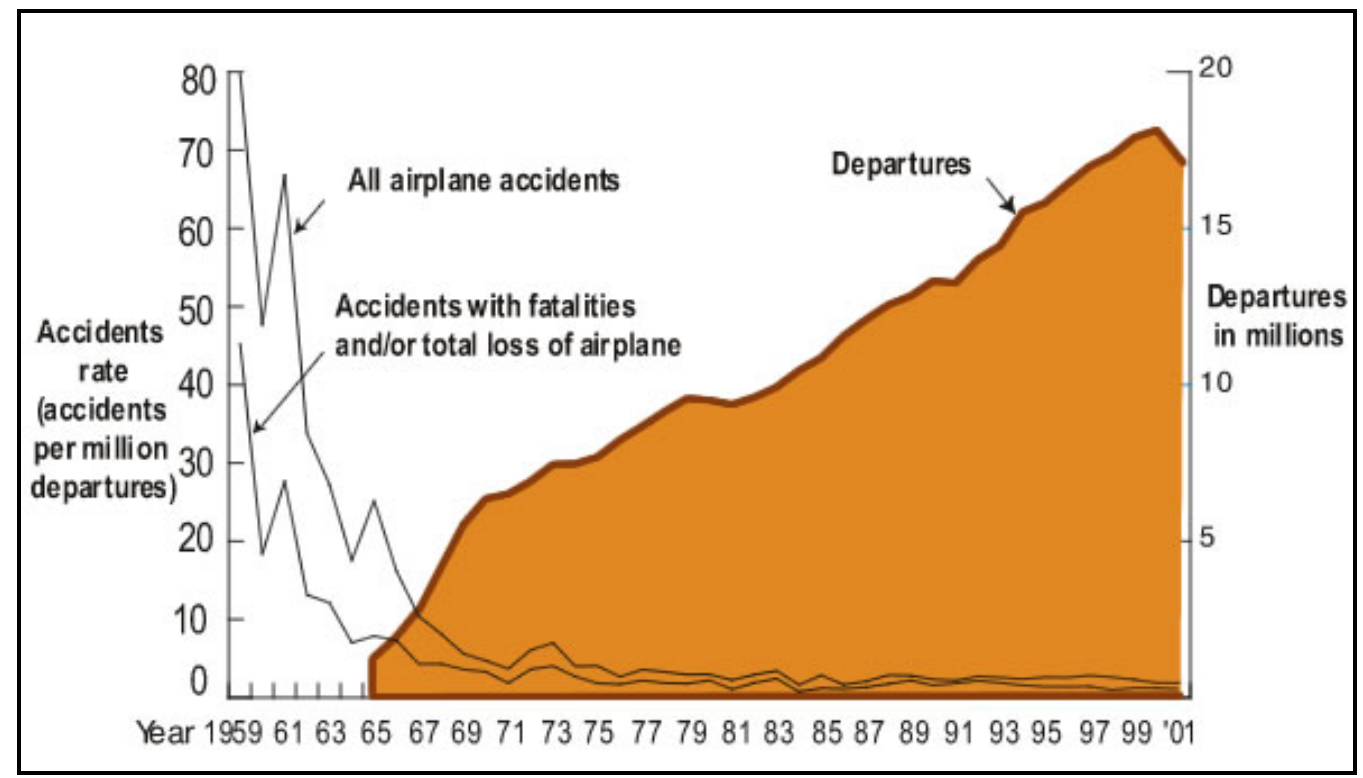

Figure 2. Safety and growth of NAS.

As others have put it, a person could board an aircraft each day for 36,000 years before being involved in a fatal accident (Barnett, 2001).

Reasons for air travel's uniquely high caliber of safety no doubt include the extensive amount of research and effort put in by manufacturers, pilots, civil aviation associations, government agencies, and regulatory authorities. In other words, such safety does not just happen, but rather is designed to be that way. An immense set of strict policies and procedures have been previously defined for air traffic control operations, an example of which is the $600+$ paged 7110.65 publication document commonly regarded as the "ATC Bible" (FAA, 2008a). With demand forecasts indicating greater than normal strains on the NAS in the near future, it becomes all the 
more pertinent to research system design decisions, and to revisit and revise that Bible in light of the new tools and technologies that will be necessary if controllers are to be able to accommodate the additional traffic.

\section{Efficiency}

Another problem perhaps more commonly and publically recognized within air travel than that of safety, is the issue of efficiency. At the turn of the new millennium the FAA faced historic delays and disruptions to its air transportation services. In the year 2000, about 3.5 of every 100 scheduled flights were cancelled and of those remaining, nearly a quarter were delayed (Bureau of Transportation Statistics, 2009). Hordes of stranded passengers frequented news television programs alongside statistics reporting alarming levels of increases in delays and cancellations over the previous years. Amid a season of hearings, panels, and public statements about the delay problem, Monte Belger, the acting deputy administrator of the FAA, stated on PBS that he felt the entire air transportation system was in a sort of crisis with the increases in demand surpassing the capacity of its airports (MacNeil/Lehrer Productions, 2000).

While most obvious to consumers at airports, these problems are not exclusive to the terminal environment. Delay is also a pertinent an issue for aircraft in between airports, as they follow the majority of their planned routes at altitude and level flight. Complimentary with research aimed to address capacity problems at airports, the present research is oriented around capacity problems of airspace. Interestingly, this issue is not most directly related to constraints in physical capacity (i.e., there is plenty of room for many more aircraft in the sky). Instead, the bottleneck for meeting forecasted levels of 
demands for airspace has been identified to be the mental resources of the human controllers operating the system. Capacities in human cognition (e.g., memory, attention, decision-making, etc.) are the principle limiting factor to future levels of traffic, because people are naturally constrained by a fixed amount of information/objects that they are able to process at a given time. For this reason, the FAA uses a number known as the Monitor Alert Parameter (MAP) that establishes a trigger value to provide notification that efficiency may be degraded during specific periods of time for a specific area (FAA, 2008b). Current operating procedures set the MAP value at around 15 - 18 aircraft per controller. It is easy to see how tripling or even doubling this number over the next 15 years could bog down the system without taking the precautions to research useful tools and procedures to supplement a controller's taxed mental resources.

In sum, to meet increases in demand, research is needed to design and implement the tools and operating methods to enable today's controller to meet the challenges of tomorrow and continue to uphold their golden rule of ensuring safe and efficient air travel.

\section{NextGen}

In 2003, Congress enacted the Vision 100 - Century of Aviation Reauthorization Act (Public Law 108-176) and established the Joint Planning and Development Office (JPDO) to manage work related to the wide-ranging transformation of the US NAS into the Next Generation Air Transportation System (NextGen). Consisting of members from the FAA, the Department of Defense (DOD), the Department of Transportation (DOT), 
the National Aeronautics and Space Administration (NASA), the Department of Commerce (DOC), the Department of Homeland Security (DHS), and the Office of Science and Technology Policy, the JPDO was made responsible for supervising and coordinating the national vision statement for an air system capable of meeting potential air traffic demand by 2025 through a multiagency research and development effort. One output of that effort is the continual development of a Concept of Operations (ConOps) document that identifies key research and policy issues for NextGen (Joint Planning and Development Office, 2009).

Amid the diversity of ideas and initiatives within the ConOps, one underlying characterization JPDO uses to describe NextGen is the utilization of optimized aircraft trajectories. Essentially with advanced computational support, aircraft will be able to identify and adhere to trajectories that simultaneously meet the safety, comfort, schedule, efficiency, and environmental impact requirements of the user and the system. While flying along their optimal routes however, aircraft still need to be kept at safe distances from one another and as much as the challenge exists for a controller to find a conflictfree route, another challenge is to find the best conflict-free route (e.g., move aircraft the least from their pre-determined routes) to achieve that safety. The focus of the current research is a NextGen concept of separation management within the high altitude (at or above 29,000 feet) en-route environment.

\section{Separation Assurance}

The NAS is divided into 21 different en route Air Route Traffic Control Centers (ARTCC) that cover the Continental U.S. Each ARTCC's area of responsibility, which 
average more than 100,000 square miles and generally extend over a number of states, is further sub-divided into two to seven different sectors (FAA, 2009b). Each sector is staffed by at least one on radar position ("R-side") ATCo who takes active control over each aircraft in his/her sector and issues clearances to pilots to keep their aircraft separate from other traffic, expedite traffic flows, and provide additional services as available. Being actively involved with each individual aircraft, today's controllers are responsible for both the manual detection and manual resolution of any potential losses of separation (LoS, i.e., two aircraft passing each other in the en-route environment within a distance that is less than five nautical miles laterally and 1000 feet vertically). As a two-step process, a controller first projects along the flight plan of each of his/her aircraft to identify or "detect" a predicted LoS (i.e., a "conflict") and then decides upon and executes a clearance to an aircraft to remove and "resolve" that conflict.

However, this manual process can only be performed for a very limited number of aircraft (i.e., a sector's MAP value) and as the number of aircraft increases, conflicts become harder to discriminate and the solution space becomes more limited (see Fig 3). Traffic levels at twice (2x) and three times (3x) the present day levels cannot be managed with conventional manual air traffic control separation assurance techniques (Prevot, Homola, \& Mercer, 2008). 


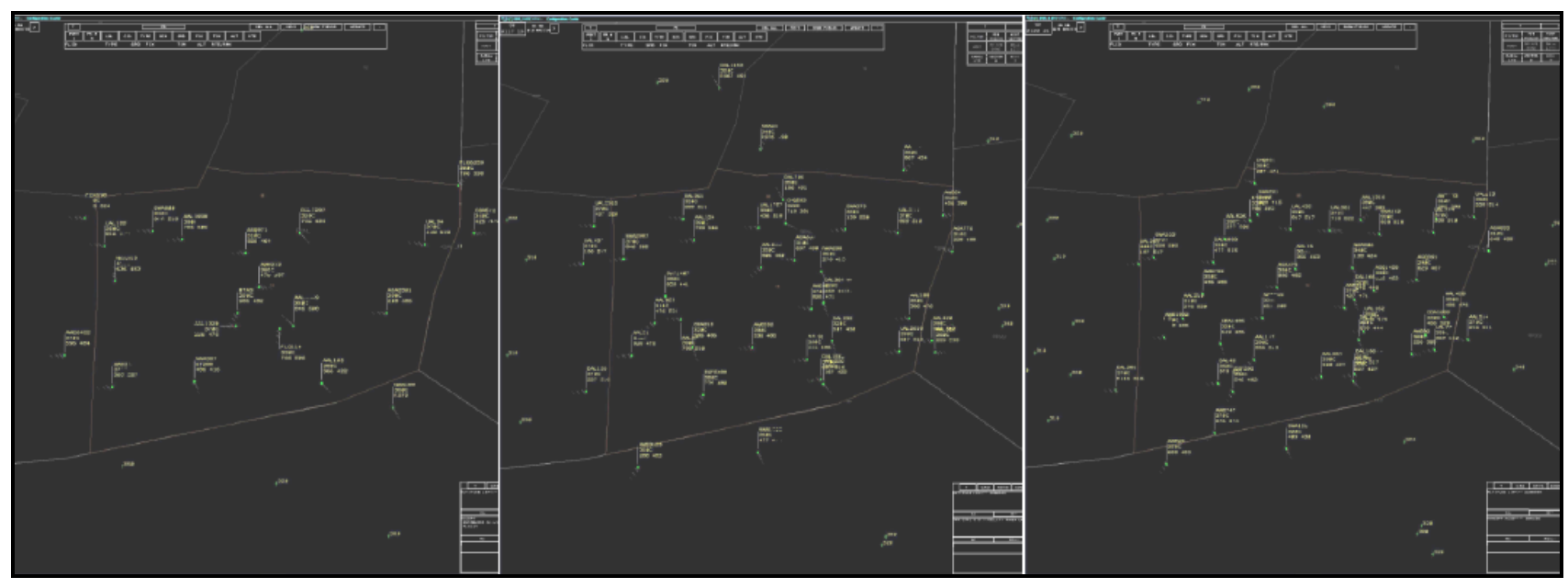

Figure 3. Current day controller display with $1 \mathrm{x}, 2 \mathrm{x}$, and 3x traffic levels.

\section{Automated Separation Assurance}

For these reasons, research is being conducted with the intended application of helping to overcome or supplement previously mentioned human limitations in separation management. While promising airborne approaches are investigated and developed elsewhere (Barhydt and Kopardekar, 2005), the present study contributes to that regarding a ground-based automated separation assurance focus (Erzberger, 2006; Farley and Erzberger, 2007; Erzberger and Heere, 2008; Homola, 2008; McNally and Thipphavong, 2008; Prevot, Homola, Mercer, Mainini, \& Cabrall, 2009; Erzberger, Lauderdale, \& Chu, 2010; Prevot et al., 2010; Wing et al., 2010). For NextGen, automated separation assurance is envisioned to include both computerized conflict detection and resolution algorithms. Conflict detection automation can scan for and then flag predicted conflicts to a controller. Conflict resolution automation can aid a controller in the identification, representation, and transmission of a conflict-free 
trajectory to the aircraft in conflict. Such algorithms function through iterative loops that take the flight data from the conflicting aircraft, the surrounding traffic, as well as information about other hazards and constraints as input to compute, prioritize, recommend, and/or select preferred resolution trajectories and maneuvers.

With such layers of automation in operation, a controller would be able to resolve a conflict by requesting an optimal resolution trajectory from the automation and/or perform what are called trial plans via click and drag operations on a provisional trajectory that the automation continuously probes for conflicts. One other principle feature of automated separation assurance would be a component for the transmission of resolution trajectories (route changes, altitude clearances, descent speed profiles, etc.) to an aircraft's flight management system (FMS) via datalink rather than through verbal clearances alone.

Automated separation assurance poses significant challenges before its benefits can be actualized, and the human factors issues associated with the controller's changed work environment must be given careful attention. Up until and including recent advances, controllers have primarily operated under a protocol of ownership-oriented procedures characterized by protecting aircraft within specific sectors of airspace. With technological advancements (i.e., integrated automated conflict detection), however and the adoption of more trajectory-oriented procedures, controllers will be increasingly encouraged to work cooperatively across sector boundaries for well-planned, nominally conflict-free flows of traffic (Leiden \& Green, 2000). To achieve NextGen en-route separation assurance (SA) benefits, the provision of new decision support tool 
technologies alone will presumably not be enough to enable the transition to strategic planning if a controller's mindset, procedures, and responsibilities are not likewise updated from a tactical environment.

Automated conflict detection entails a problem of inter-sector boundary event responsibility (compared to manual intra-sector jurisdiction) by nature of an automated probe's ability to see and alert to conflicts that will occur across a sector border and hence beyond traditional boundaries. For example, referencing Figure 4, in a preconflict probe environment the "ATCo 1" is primarily responsible for aircraft entering and flying within sector 1 , and ensuring that no conflicts occur between these aircraft (smaller aircraft in Figure 4). With advanced strategic conflict probing and alerting, it becomes possible for "ATCo 1" to be alerted to a conflict that would occur in the sector of "ATCo 2", which he/she might otherwise not have been able to see or be concerned with (aircraft A and aircraft B in Figure 4). Furthermore, in many situations overhead coordination costs can exist whenever the resolution planning ATCo is not the same as the resolution implementing ATCo. 


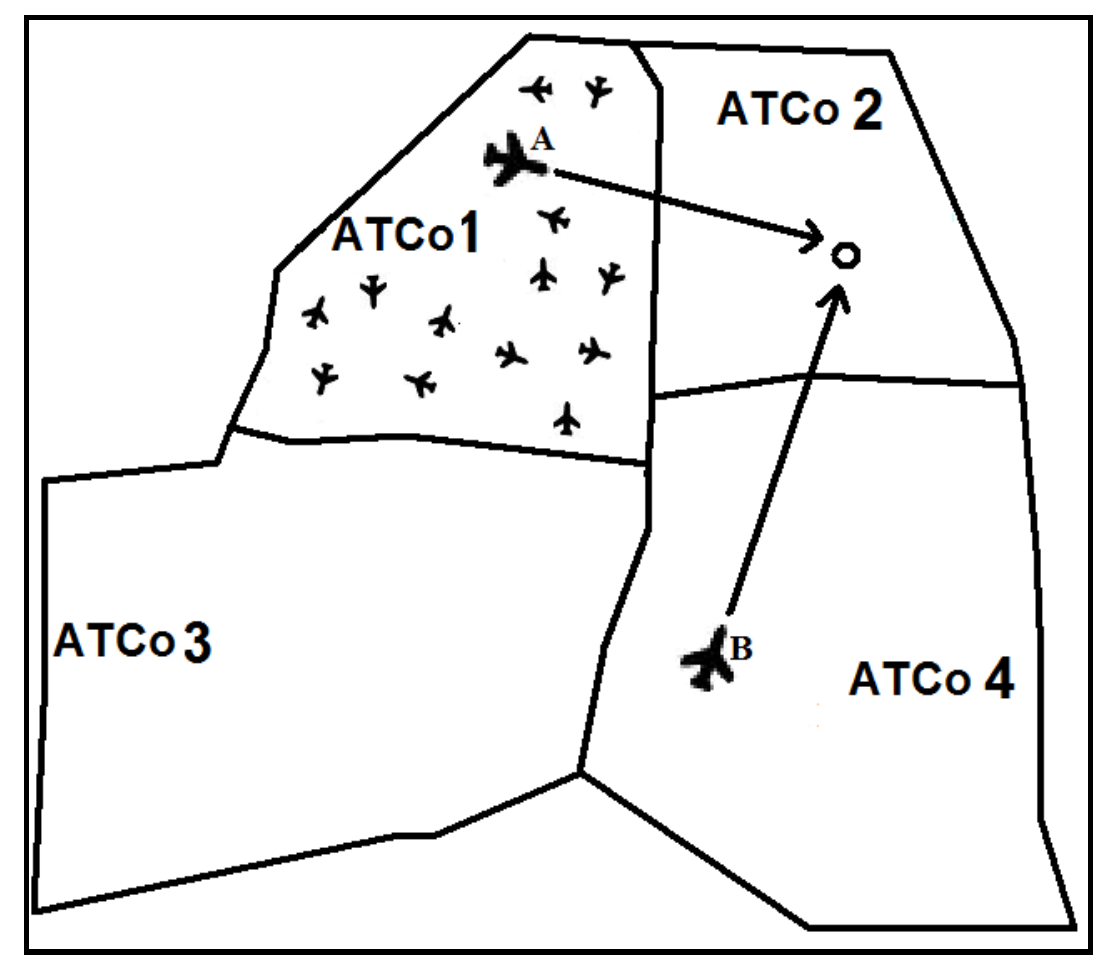

Figure 4. Involvement of controllers of adjacent sectors.

\section{Motivations}

The procedures and technologies examined in the present study depart from current day procedures in a number of important ways. First, the technologies are different. The current study examined automation-assisted conflict detection and resolution implementations via an interactive interface directly integrated within an Rside's primary display (DSR). With such layers of automation in operation, the R-side controller was able to resolve a conflict by requesting an optimal resolution trajectory from the automation and/or performing trial plan routes via click and drag operations, to identify a provisional trajectory that the automation continuously probed for conflicts (Prevot et al., 2009). Second, the responsibilities are different. Current day operations 
require that the responsibility for conflict detection resides with the controller and not the automation. In the present study this responsibility was shifted to the automation. This radical paradigm shift results in a complete redesign of procedures, controller workstations, and human/automation interaction philosophy. Third, the air ground communication mechanisms are different. Present day operational prototypes allow for a great reduction of verbal coordination between controllers through the use of digital transmission/reception of inter-sector coordinated trial plans among controllers. The current study also extended this capability to include aircraft as well. This assumed component allowed for the transmission of resolution trajectories (route changes, altitude clearances, descent speed profiles, etc.) to an aircraft's flight management system via datalink rather than verbal clearances alone.

Last, prior research has not yet evaluated inter-sector coordination issues in a highly automated NextGen environment. Single sector studies have shown general benefits (e.g., Prevot et al., 2010), but left out the coordination issues associated with automating conflict detection and resolution in high density traffic environments. Therefore, this study examined critical operational issues that need to be considered before an informed determination of the feasibility and effectiveness of highly automated air traffic control operations can be made.

\section{Current Study}

The illustrated conflict between aircraft A and aircraft B in Figure 4 could be alerted (via advanced automation detection algorithms) to different controllers depending on different procedural responsibilities. A basic question arises then as to who of these 
controllers should be responsible for the deconfliction of such an alert (i.e., both resolution planning and implementation). The current study addressed this issue of deconfliction responsibility for en-route controllers working within an automated separation assurance environment. Of the many different combinations where multiple aircraft could be conflicting across multiple sector boundaries, a simple dichotomy between adjacent sectors was established first to explore the differences between two general operational procedures. Note that in either procedure both ground-ground and air-ground data communications technology was assumed that enabled controllers to coordinate with one another and with airplanes directly through the digital transmission/reception of trajectory clearances.

In the DeConflicting AirPlanes (DCAP) procedure, resolution responsibility is tied to the ATCo(s) of the sector(s) where aircraft are located at the time the conflict is detected and made into an alert; hence ATCo focus is on protecting their set of owned airplanes from conflicts. Under DCAP, the automation alerts an ATCo whenever any of his/her currently owned airplanes are predicted to lose separation minima (regardless of where that LoS will occur). Referring again to Figure 1, in DCAP, "ATCo 1" is responsible for maintaining a conflict free trajectory for airplane A and "ATCo 4" for airplane B, with any necessary coordination to determine which or both aircraft need to be issued a clearance.

In the DeConflicting AirSpace (DCAS) procedure, resolution responsibility is tied to the ATCo of the sector where the potential LoS is predicted to occur; hence the ATCo focus is on deconflicting an area of airspace. Under DCAS, the automation alerts the 
ATCo of any conflicts that result in a LoS within their individual airspace of responsibility (regardless of airplanes' current location). In DCAS in Figure 1, “ATCo 2 " is solely responsible for deconflicting alerts to $\operatorname{LoS}$ in his/her airspace and so would issue a conflict-probed clearance to airplanes A and/or B even while they are currently flying through sectors 1 and/or 4 (with optional ATCo-ATCo coordination).

As a second factor, two different future levels of traffic densities were chosen to represent the environment under which these operating procedures could take place because there are differences in the amount of traffic forecasted for the future NAS - up to three times present day traffic levels - and also because any increase will occur over time rather than immediately (JPDO, 2009). The different traffic density levels used here assumed a baseline Monitor Alert Parameter (MAP) value of about 18 aircraft per sector as a baseline, and represented levels of $1.7 \mathrm{x}$ and $2.5 \mathrm{x}$ traffic, or about 30 or 45 planes respectively per sector.

\section{Coordination in Aviation Decision Making}

Because one of the largest underlying differences between the DCAP and DCAS procedures is the number of controllers involved for a conflict, between controller coordination and effective team dynamics was of principle interest to the current study. Previous research from the Crew Resource Management (CRM) framework provides a promising context for anticipating how the between controller interactions would play out. As developments in 1950's aircraft technology enhanced and stabilized airframe and engine reliably, attention shifted to other sources of aviation risk and "pilot error" grew to be identified as the largest contributor. As a reaction to a growing recognition that these 
"pilot errors" were primarily reflective of failures in team communication and coordination rather than deficiencies in individual skills, e.g., "stick -and-rudder proficiency" (Cooper, White, \& Lauber, 1980; Murphy, 1980), CRM emerged as a convergence of concepts, attitudes, and practical approaches for achieving effective human performance in a team context. Moving away from the aviation domain's traditional individualistic emphasis on pilot performance, CRM underscored the importance of task delegation, situation awareness, leadership, use of available resources including other crewmembers, interpersonal communications, and the process of building and maintaining an effective team relationship on the flightdeck (Helmreich \& Foushee, 2010). Initially CRM denoted “Cockpit Resource Management," but because its principles generalized so well to areas outside of the cockpit, it was re-dubbed "Crew Resource Management" to reflect its application to team dynamics in general.

A plausible assumption to make from CRM is that agreement between team members' shared mental models would better enable teams to achieve their goals (Orasanu, 2010) and that these shared mental models should increase with the extent of communication and collaboration (Payne, 2008). However, in a study with pilot dyad teams performing missions in a PC-based flight simulator, Mathieu, Heffner, Goodwin, Salas, and Cannon-Bowers (2000) found that, contrary to their hypothesis, convergence of mental models did not increase over time in spite of increased amounts of coordination; instead it was stable within their dyads. In reviewing the former as well as other studies on shared mental models, Payne (2008) posits that there must be team situations in which role differentiation is critical for success, suggesting that task mental 
models should not so much be "shared" as "distributed" to allow for effective team performance. What becomes most important in such situations then is not the specifics of shared task knowledge but that individuals' knowledge about who knows what is accurate. In other words, it may not be necessary for team members to both know the same thing (e.g., what the other is thinking or doing) but that a team member can trust that another has the requisite information or knowledge that makes his or her actions appropriate. Orasanu (2010) notably points out that the intent of communication training in CRM is not simply to get crews to talk more. Because high levels of talk contribute to workload, instead what is desired is the definition of the problem, plans, strategies, and relevant information, i.e., the context of the problem needs to be considered.

Illustratively, Orasanu (2010) charts an aviation decision process model that begins with a threat or problem event and progresses in accordance with the conditions of the context to result in one of four different courses of action for the decision maker: "apply rule," "choose option," "create novel solution," or "gather more information." The contexts of the first two courses of action involve problems that are familiar and/or have readily available condition-action rules, whereas the contexts of the last two involve problems that are either not understood or where no options are available. Anecdotally, it is not hard to imagine how contexts that call for the last two courses of action could be facilitated by the involvement of another person, whereas those of the first could be hindered by unnecessary coordination, i.e., when standard operating procedures can be applied. 
Looking at the experimental tasks of the present study, the controller participants would be expected to regard the scripted conflict problems as familiar and with multiple condition-action rules available (as they were to be detected by the automation with sufficient time ahead of a LoS). From their professional training and years of experience of "working traffic," they assumedly have internalized a vast array of mappings between aircraft-aircraft conflict orientations and respective solutions. Furthermore, the level of automation assumed in the experimental concept is such that conflict-free resolutions were available to be automatically generated and displayed on-demand to the controller at any point in time. With an assumed rate of approximately one conflict per minute (based on the simulated levels of traffic complexity) and an a priori trust in the automation functions, it was expected that less coordination could actually serve the controllers better in resolving their sector-boundary spanning conflicts because they could trust that movements of aircraft made by other controllers were all being continuously probed and cleared of conflicts before being implemented.

\section{Research Questions and General Hypotheses}

The primary research question of interest was which deconfliction responsibility procedure, DCAP or DCAS, would better enable a NextGen ATCo to perform his/her separation assurance duties. These two operational procedures were explored across two different levels of traffic densities forecasted for NextGen. The DCAS procedure limits the number of responsible controllers for conflict detection and resolution to just one person in all conflict cases and so reduces the potential ambiguity of responsibility. 
Thus, it was hypothesized that the DCAS would prove to be a better standard operating procedure in the automated separation assurance environment than DCAP, both in terms of controller experience and plane performance.

Under similar levels of ATC automation and technology in prior research, where responsibility procedures for inter-sector conflicts were at the time unspecified but consistent with those outlined by DCAP (Homola, 2008), results showed tolerable levels of separation violations, delay, and workload at the lowest density of about 30 aircraft per controller. However, there were increases in these areas as the number of aircraft per controller increased to about 60 . As an additional hypothesis for the current study, it was predicted that controllers would be able to satisfactorily meet their duties under either procedure in the lower traffic density of about 30 aircraft per controller but would exhibit degradation with the DCAP procedure as the density was increased to about 45 aircraft per controller. In other words, an interaction effect was hypothesized between traffic density and procedure such that DCAS would be effective under either traffic density (1.7x or $2.5 x)$ but that DCAP would only be effective under the $1.7 x$ density.

\section{Specific Hypotheses -DCAS "better" than DCAP}

A range of hypotheses were considered to account for various outcomes of operation under the two different procedures and included aspects of coordination, time on task, workload, preference, feasibility, efficiency, and safety.

Coordination. Controllers would voluntarily coordinate more with each other in DCAP than in DCAS both in the number and length of ATCo to ATCo transmissions. Furthermore, they would be cognizant of this difference in amount of coordination 
between the procedures both for themselves and in the amounts they expected future controllers to engage in.

Time on Task. Controllers would solve the scripted conflicts faster in the DCAS procedure than in the DCAP procedure.

Workload. Controller workload would be less in the DCAS procedure than in the DCAP procedure, both in terms of their self-reported workload ratings as well as those assessed by the supervisor position.

Preference. Controller preference ratings would indicate greater preference for the amounts of coordination they experienced under the DCAS procedure versus the amount of coordination they experienced under the DCAP procedure. Furthermore, the participants would anticipate that future NextGen controllers would also prefer the DCAS procedure coordination levels more than the DCAP procedure coordination levels.

Feasibility. Controllers would judge the DCAS procedure to be more feasible than the DCAP procedure.

Efficiency. Controller concern for the in-efficient movement of planes would be greater in the DCAP procedure than in the DCAS procedure. More resolution attempts would be made for a given scripted conflict under the DCAP procedure than under the DCAS procedure. Heading change clearances issued to resolve conflicts for planes in DCAP would be larger than those in DCAS.

Safety. Planes would be kept more safely apart in the DCAS procedure than in the DCAP procedure showing fewer Losses of Separation overall, as well as fewer 
Operational Errors and Proximity Events. Additionally, the time remaining until predicted Loss of Separation would be lower in DCAP than in DCAS.

\section{Specific Hypotheses - Interaction of procedure and traffic level}

Traffic Level 1.7x. Controllers will show acceptable levels of coordination, time on task, workload, preference, feasibility, efficiency, and safety for both the DCAP and DCAS procedures under the $1.7 \mathrm{x}$ traffic density conditions.

Traffic Level 2.5x. Controllers will show acceptable levels of coordination, time on task, workload, preference, feasibility, efficiency and safety for the DCAS procedure under the $2.5 x$ traffic density conditions, but these levels would be negatively elevated for the DCAP procedure. 


\section{METHOD}

\section{Design}

The current study employed a 2 × 2 within-subjects design with operational method (DCAP, DCAS) and traffic level (1.7x, 2.5x) as independent variables. Operational method contrasted two different possibilities for controller responsibility for conflict resolution and traffic level contrasted two different forecasted airspace traffic densities as multiples of present day traffic levels. All experimental data were collected from Human-in-the-Loop simulations conducted with the Multi Aircraft Control System (MACS) simulation platform within the Airspace Operations Laboratory (AOL) at NASA Ames Research Center (Airspace Operations Laboratory, 2008, Prevot et al., 2010). All scripted conflicts were presented in two independent but equivalent "Worlds" with teams

of four sector controllers and one supervisor running simultaneously in each World. Data was collected from participants across eight 15 minute runs. Each trial was run under either DCAP or DCAS, consisted of either a $1.7 x$ or $2.5 x$ traffic density, and included a minimum of three pre-scripted conflicts per R-ride ATCo (see Fig. 5). All ATCo positions were staffed by a local cadre of recently retired controllers who had both extensive experience in air traffic control with the R-Side position and with the Multi Aircraft Control System NextGen prototype software; thus representing a sample that would have the appropriate skills for the simulated environment and experimental concept. 


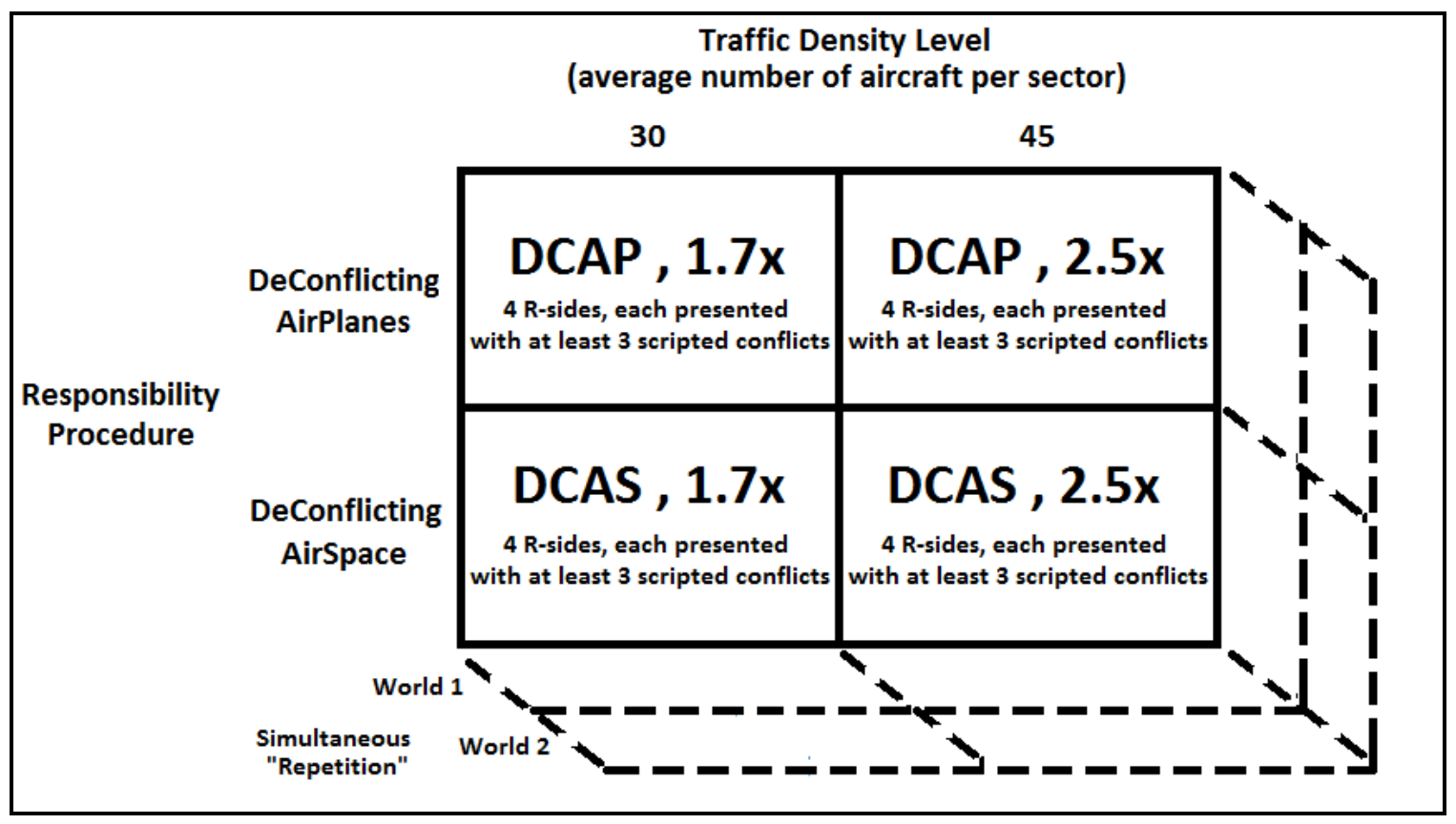

Figure 5. Experimental design test matrix.

Operational method levels were distributed between Worlds evenly such that per participant, half of the trials were conducted under the DCAP procedure with the other half conducted under the DCAS procedure. Likewise, half of all the trials for a participant were run with $1.7 \mathrm{x}$ traffic and the other half were run with $2.5 \mathrm{x}$ traffic. Learning or carry-over ordering effects were controlled for by devoting a full half day to training in which the participants received ample exposure and experience with each manipulated factor level. Furthermore in this vein, counter-balancing was applied where feasible. Across the eight runs, each of the eight experimental R-side ATCo participants was presented with at least 24 conflicts resulting in a total of 192 scripted conflicts available for analyses between the two different factors. Lastly, each participant was given 15 minute breaks in between runs and 45 minutes for lunch. In all, approximately 1.5 days of participation was required of each controller. 
As a starting point for looking at adjacent sector resolution responsibility, three of the four basic conflict cases (see Fig. 6) used in the qualitative evaluation of various conflict and flow rate conformance concepts in the Leiden and Green (2000) research were operationally examined in the current study. Case A, the intra-sector case, was left out because the DCAP and DCAS responsible controller would be the same person. However, cases B - External, C - External Intruder, and D - Inter-sector needed to be purposefully represented in the traffic to span the differences in the number of controllers and sectors involved.

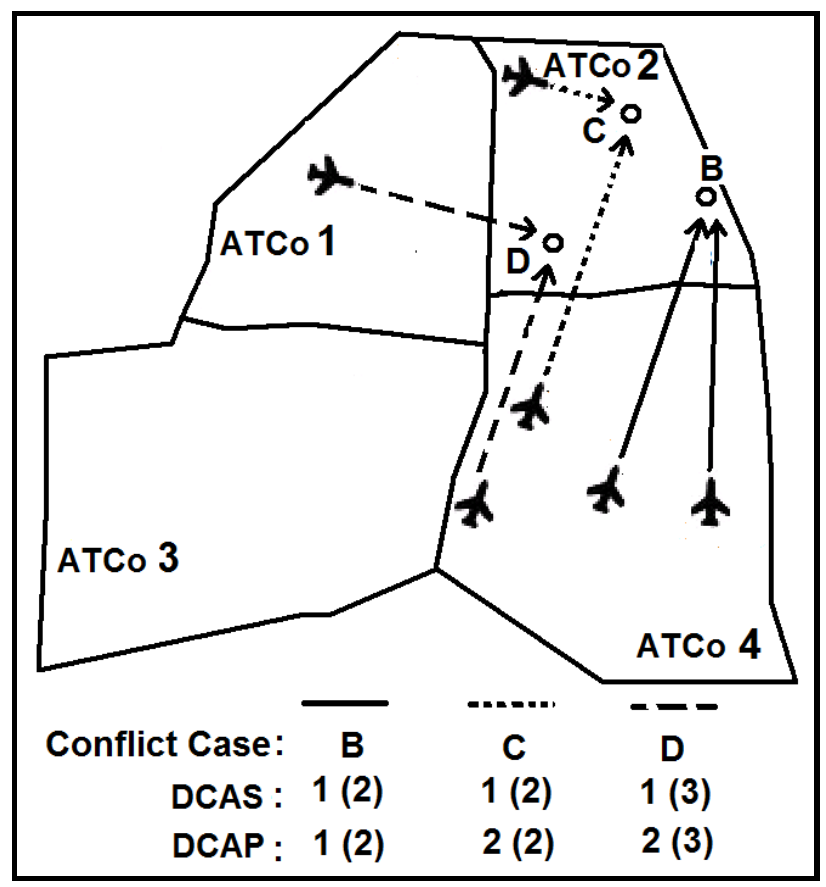

Figure 6. Cases differening by number of controllers (sectors) involved.

Conflicts were pre-scripted into the traffic scenarios to represent the three conflict cases of interest as well as a realistic proportion of conflict geometries between aircraft at level, climb/descent, or overtaking, generally representative of today's numbers of these geometries. In all experimental conditions, controllers performed routine separation tasks 
with the aid of automated conflict detection and resolution. This level of automation included manual conflict resolution with a highly responsive trial planning tool that was integrated with data link, the conflict detection function, and an interactive auto-resolver that was available for the R-side to use. The controllers were able to use the autoresolver to request a conflict resolution trajectory and uplink it unchanged, modify the resolution trajectory using the trial planner and then uplink it, or cancel the modification.

\section{Participants}

After receipt of the proper approvals (Appendix A), a total of 14 ATC positions (eight R-sides, two supervisors, four confederates) and eight aircraft simulation stations were staffed in the study. Aircraft in the simulation were largely automated and operated by a mix of general aviation pilots and aviation students. All ATC positions were operated by a local cadre of recently retired controllers. These men and women were aged between 45 and 65 and had extensive experience in air traffic control (on the R-Side position). Furthermore, from their participation in prior simulation studies with MACS (Multi Aircraft Control System), their familiarity with the software usage and automation prototype environment was key. Participants that met the above requirements needed little training on the non-experimental portions of the software they encountered in the present study because they had all interacted with it before. Without this knowledge, an extensive amount of training would be needed, requiring more time and financial resources. As this type of person has demonstrated exceptional skills when working the en route display with and without various levels of automation, the external validity of the present study relied heavily on the experiences of this particular participant set. 


\section{Experimental Environment}

The participants were tested in a room that resembles the dark rooms of an ARTCC, with several DSR workstations situated next to each other (see Fig. 7).

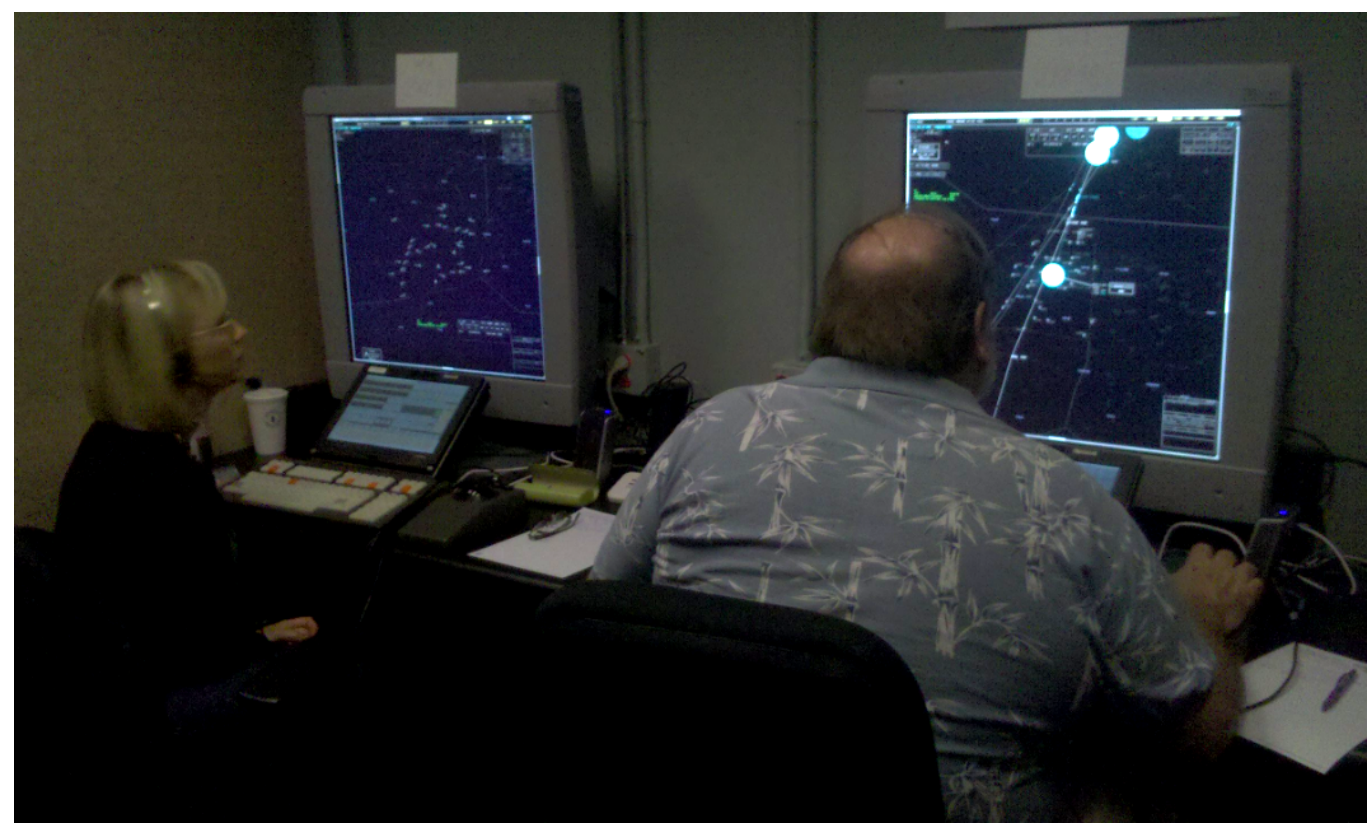

Figure 7. Staffed R-side positions.

The airspace used for the simulations was modeled after four adjacent en route sectors: sectors 98 and 90 of the Kansas City ARTCC (ZKC) and sectors 80 and 91 of the Indianapolis ARTCC (ZID). The traffic through the test sectors used in the scenarios averaged a present day and locally representative mixture of approximately $65 \%$ overflights and 35\% transitioning aircraft between the altitudes of 18,000 and 45,000 feet. The four sectors are shown in Figure 8. 


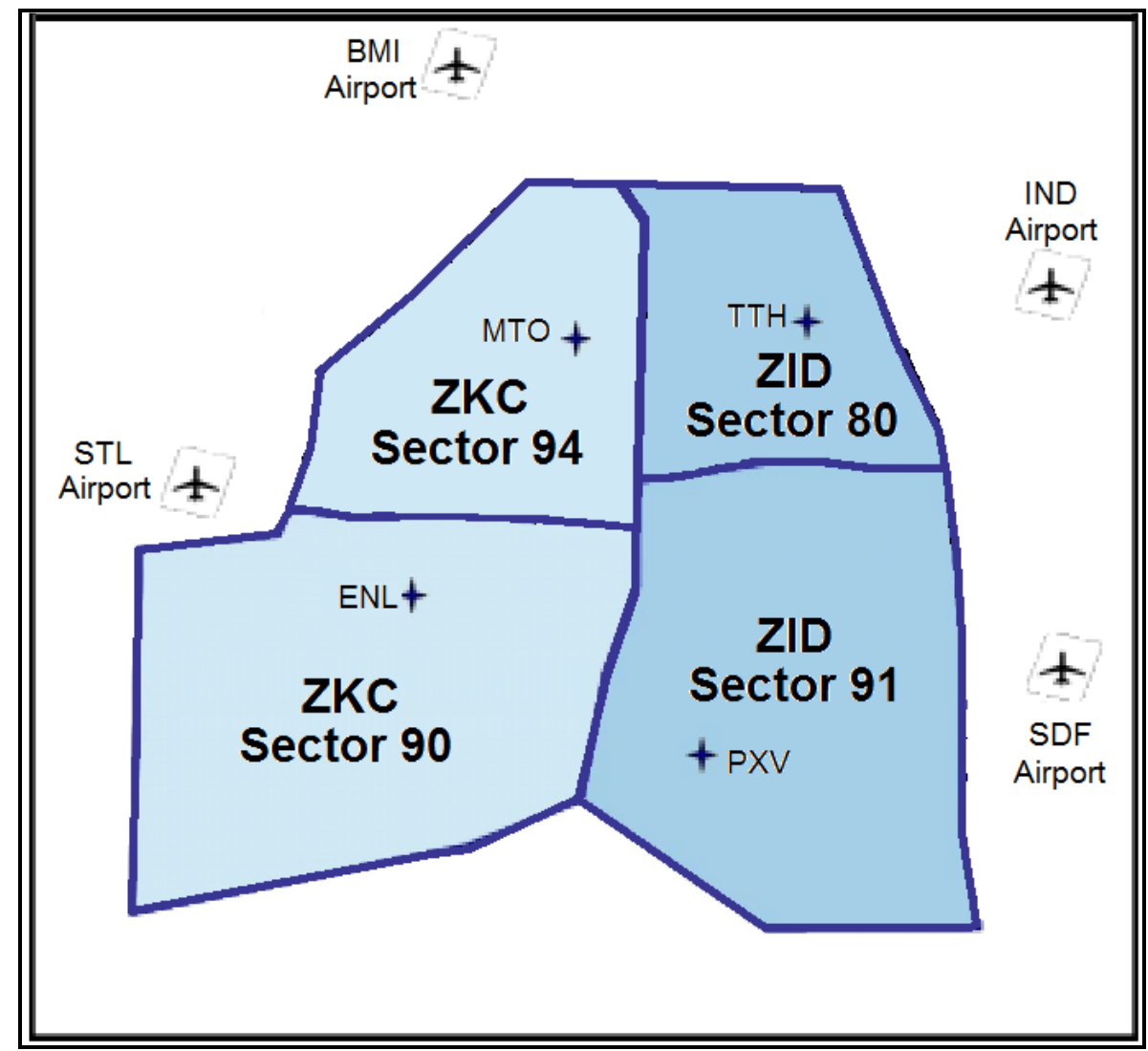

Figure 8. Test airspace.

\section{Apparatus}

The AOL equipment was set up to replicate the equipment used in the FAA's ARTCCs and used the MACS JAVA software as its primary simulation platform. Each workstation consisted of: Dell Precision PC, model T7400, Vista Ultimate (SP1), Intel® Xeon® CPU - X5482 @ 3.20GHz (2), 8GB RAM, 64bit system; Cortron, Inc. Keyboard, model 109-50008C; Measurement Systems, Inc. Trackball, PN XCL250-1; Dell mouse, model MOA8BO; Barco ISIS (MDP-471) display; Toshiba Portege M700 Tablet PC; Plantronics headset; Delcom Products food pedal, model 803653. Eight identically 
configured workstations were used for the eight R-side test participants. Further details on the emulation and experimental implementation can be found in AOL (2008) and Prevot et al. (2010). Lastly, TechSmith Camtasia screen capture software recorded video files of all visible screen events while audio recording software captured all voice activity on a VSCS communication systems emulation.

\section{Procedure}

After reading, agreeing with and signing the consent form (Appendix B), all 14 ATCo participants were briefed together on the purpose of the study. Each of the two different operating procedures (DCAP vs. DCAS) were introduced and explained at length. It was made clear that during the DCAP procedure, their conflict list table and display would highlight aircraft conflict pairs whenever at least one of those aircraft was under their track control ownership. Conversely, in the DCAS procedure it was explained that table alerts and highlighting would occur only when the point at which the aircraft were predicted to conflict resided within their individual sector of airspace. Additionally, it was emphasized that under the DCAS procedure, each ATCo would exclusively be shown conflicts that no one else was being shown; whereas in the DCAP procedure another ATCo might be shown the same conflict depending on the specific geometries and ownership states. In regards to resolution procedures, it was instructed that they should strive to adhere as closely possible to present day standards and methods with the exception that they were provided data-link channels for communicating aircraft trajectories both between ATCo and planes, as well as ATCo and ATCo. Finally, it was also explained that under the DCAP procedure an ATCo could only send trajectory 
amendments without coordinating with another ATCo to aircraft within their track control/ownership whereas in the DCAS procedure this restriction would not exist, and ATCo could reach beyond the boundaries of their sectors to move aircraft with no requirement to coordinate this with another ATCo. Coordination responsibilities (when and how much) then, were generally left up to their own discretion. Participant questions were solicited and answered until all were comfortable in their understanding of the differing display characteristics and corresponding responsibilities under each of the procedures.

Participants were then broken into two teams, each consisting of four R-side controllers, one supervisor, and two supporting confederate "ghost" roles to handle the aircraft surrounding the test sectors. Each team was run through eight 15 minute practice runs (half under DCAP and half under DCAS, switching between the procedures every other run). Traffic densities were staggered and alternated within these blocks. The focus and intent of the trial runs was to ensure that the controllers could learn to clearly distinguish and execute both of the different operating procedures.

Next, participants were run through eight different experimental 15 minute scenarios with scripted conflicts. During a scenario, controllers were asked to perform all of their duties as normal but with the addition of using the automated tools to resolve conflicts. Conflict alerts appeared on their screens in a conflict alert table list, via color coded highlighting of aircraft and via magenta colored time until LoS counters that appeared in the first line of a flight's expanded data block (see Fig 9). 


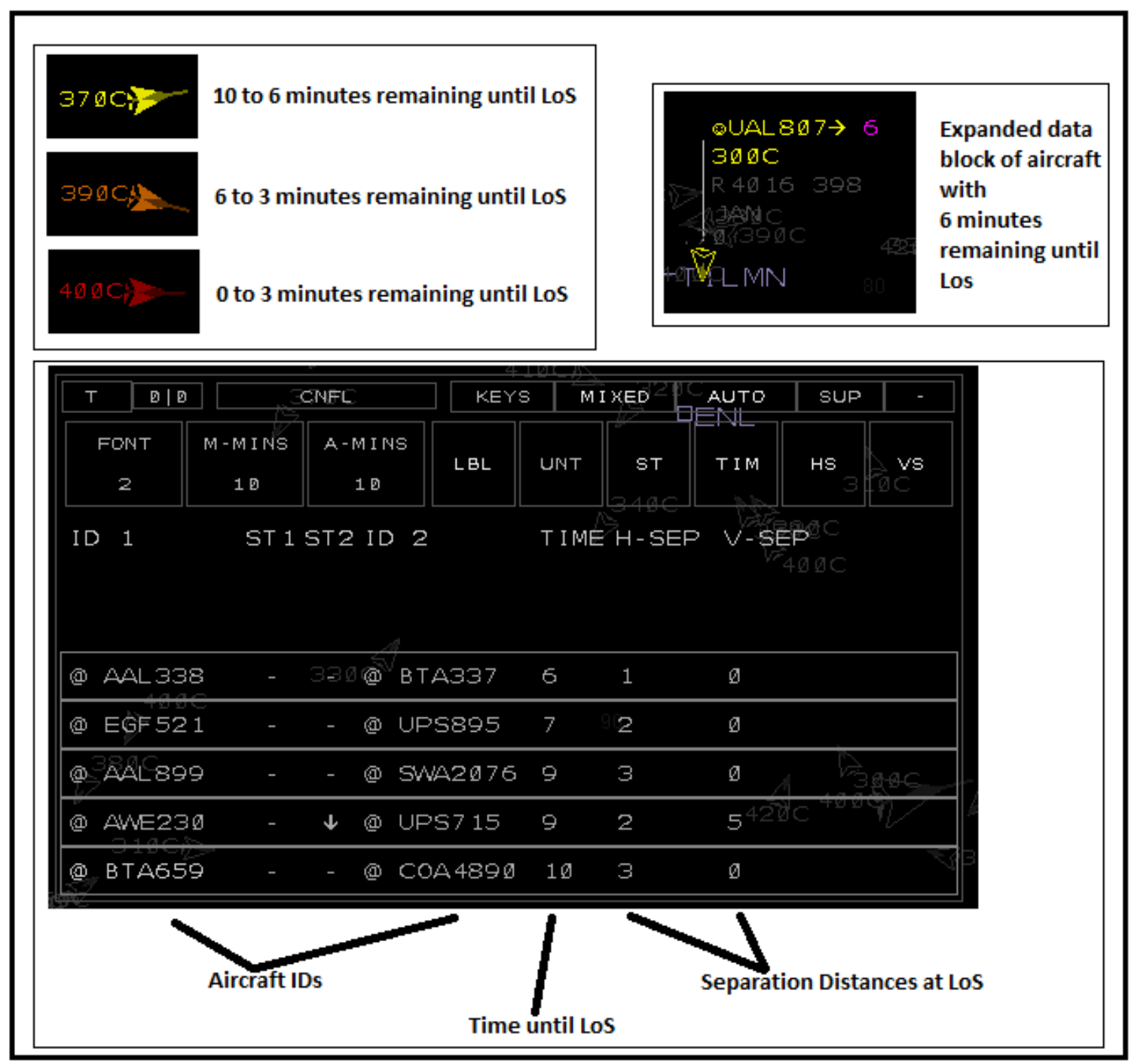

Figure 9. Conflict table, color coding, and time until LoS counter.

All provisional trajectory amendment trial plans were integrated directly on the primary radar screen and were continuously probed for conflicts (see Fig. 10). The blue shaded areas indicate that a conflict is present and exactly where it will occur as the trial plan trajectory line is moved in real time. 


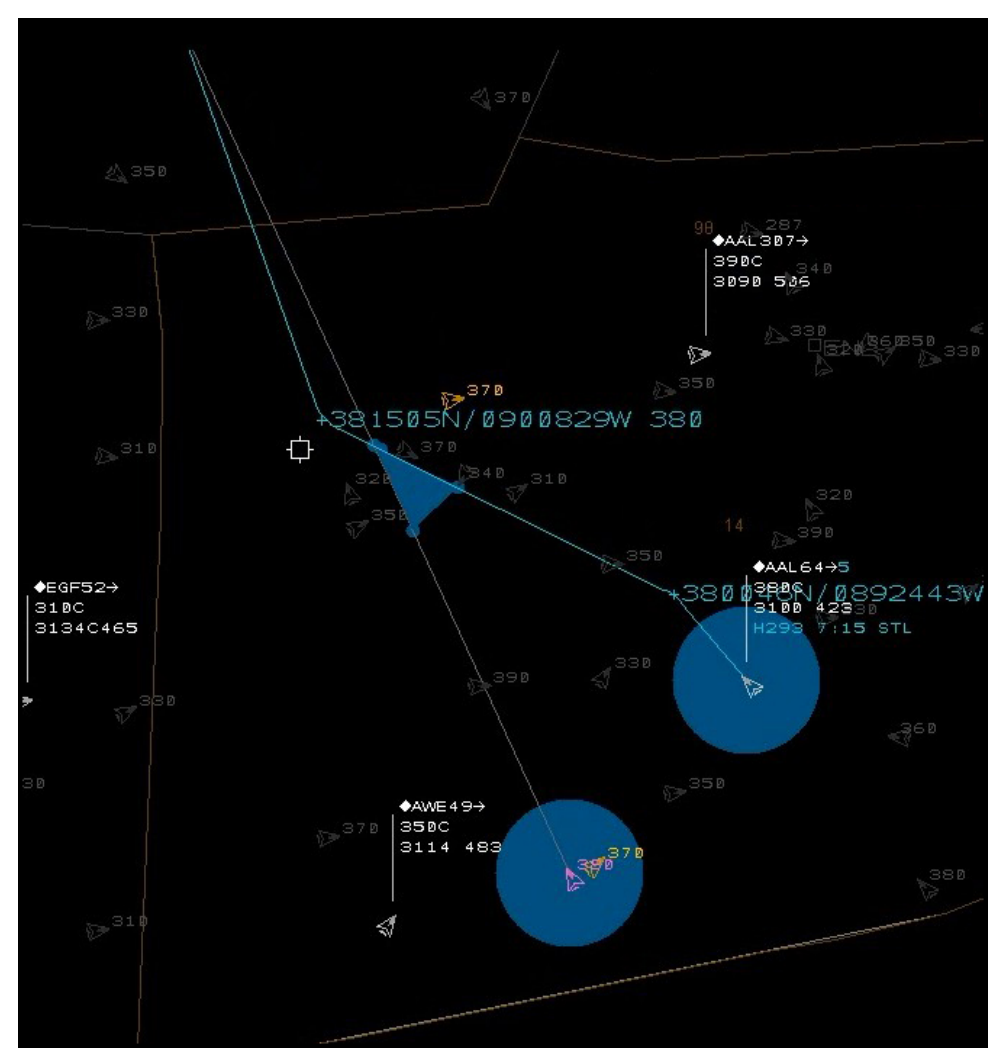

Figure 10. Trial planning a trajectory amendment.

\section{Metrics}

The metrics of the study were chosen to address the overarching goals of ATC, i.e., the accomplishment of safe and efficient travel. In addition, general usability metrics were also measured. All objective data were calculated from internal MACS software output logs, and all subjective data were collected from computerized questionnaires administered at the end of a run, end of a DCAP/DCAS procedure block, and at the end of the study (see Appendix C).

Safety metrics included number of LoS as operational errors (O.E.) and proximity events (P.E.) and minimum time until LoS. Legal separation was defined as it is today in the en-route environment with a minimum required distance of 5 miles laterally and 
1,000 feet vertically between aircraft. Two types of $\operatorname{LoS}$ were categorized in the simulation according to simulated buffers such that, if aircraft came closer than 4.5 miles of one another laterally and 800 feet vertically, it was counted as an operational error, whereas, if aircraft came between 5 and 4.5 miles of one another laterally and under 800 feet vertically, it was counted as a proximity event. Additionally, the time until LoS counter was recorded to capture how much time remained for a given conflict prediction before it would become a LoS.

Efficiency metrics included the number of resolutions issued and the sum of lateral heading changes for scripted conflict aircraft pairs. Participants were also asked to rate amount of concern for aircraft being moved un-necessarily or counter-productively both for themselves individually as well as what they anticipated for future ATCo of NextGen. Last, in regards to both safety and efficiency, ATCo were also asked to rate the feasibility of either procedure.

General usability metrics included workload ratings, time on task, amount, and agreeableness of verbal coordination, and agreeableness of the procedures in general. Workload ratings were collected on a 6-point scale from "Very Low" to "Very High." The unlabeled numeric scale was presented at the top of an ATCo display every three minutes with a corresponding auditory bell, and remained highlighted in yellow until a response was made by clicking on top of it or through use of dedicated function keys (i.e., F1 through F6). Through rehearsals with prior simulations, this group of participants already had mastered the practice of internalizing the values and response procedure for the particular workload rating scale shown in Appendix D. For each 
scripted conflict pair, time on task was measured as the time taken from the first detection to the last resolution as the summing of segments represented by each separate attempt (for the cases where multiple resolutions were sent) rather than as an elapsed total. Amount of coordination was measured objectively from recorded audio files (in seconds) as well as subjectively through rating scales (1 to 5). Agreeableness ratings for coordination and for procedures in general were also measured with 1-to -5 scales. 


\section{RESULTS}

All data were examined with a $2 \times 2$ repeated measures ANOVA with the independent variables of procedure (DCAP or DCAS) and traffic density (1.7x or 2.5x); with the exception of questions from the post-procedure and post-simulation surveys, which were analyzed via ANOVA with the procedure factor alone. For the few data sets that violated assumptions underlying an ANOVA, i.e., homogeneity of variance or normalized distributions, descriptive statistics are compared and reported, and remaining factors are examined independently. Last, while the subjective data were collected via Likert-like ordinal scales and thus traditionally in violation of parametric analysis, recent reviews and research show common use of ANOVA for such data and support its treatment of such as interval by its underlying nature (Jaccard \& Wan, 1996; Homola, 2008; Prevot et al., 2009; Mainini, 2009).

\section{Overview}

The results are grouped into two general categories for ease of interpretation: metrics regarding effects on controllers and metrics regarding effects on planes. Tables 1 and 2 separate the results according to these groupings, identifying their general type and scale as well as providing their means, standard deviations, and values of statistical significance.

In general, Table 1 shows that the experiences of the controllers were affected by the type of procedure (DCAS vs. DCAP). When asked to be responsible for deconflicting an area of airspace rather than a set of currently owned aircraft, controllers objectively did not find it necessary to coordinate their inter-sector deconfliction 
clearances with their adjacent sector partner and were faster at resolutions.

Correspondingly, the controller participants subjectively reported lower experienced and expected levels of future coordination under the DCAS procedure; and rated their workload there lower and preferences higher than under the DCAP procedure. Results from metric numerals III-a., IV-a., V-a., V-b., and V-c., were applied to ANOVA, however the interpretation of the value of statistical significance need be reflected in light of a lack of variance by the participants in one procedure vs. the other. In the DCAS procedure, the participants did not coordinate their resolutions across the sector boundaries and were determinedly sure of this absence and their preference for it. Procedural significance is more clearly seen, then, in the descriptive statistics of these data than from inferential analyses derived from comparisons of variance. 
Table 1. Controller experience results.

\begin{tabular}{|c|c|c|c|c|c|c|}
\hline \multicolumn{7}{|c|}{ Subjective } \\
\hline Scale & DCAP & DCAS & Sig. & $1.7 x$ & $2.5 x$ & Sig. \\
\hline \multicolumn{7}{|l|}{ I. Likability Procedure } \\
\hline \multicolumn{7}{|l|}{ Preference Metric } \\
\hline Rating ( 1 = Loved it, 5 = Hated it) & $3.20(1.03)$ & $1.30(.48)$ & $.000^{* *}$ & $\cdots$ & $\ldots$ & $\cdots$ \\
\hline \multicolumn{7}{|l|}{ Ila. Workload (Self Report) } \\
\hline \multicolumn{7}{|l|}{ Workload Metric } \\
\hline Rating ( 1 = Very low, 6 = Very high) & $2.45(1.23)$ & $1.65(.83)$ & $.000^{* *}$ & $1.93(1.02)$ & $2.16(1.20)$ & $.034^{*}$ \\
\hline \multicolumn{7}{|l|}{ IIb. Workload (Supe Report) } \\
\hline \multicolumn{7}{|l|}{ Workload Metric } \\
\hline Rating ( 1 = Very low, 6 = Very high) & $3.28(1.22)$ & $2.20(.72)$ & $.000^{* *}$ & $2.35(.91)$ & $3.31(1.20)$ & $.000^{*}$ \\
\hline \multicolumn{7}{|l|}{ IIla. Coordination Amt. (actual) } \\
\hline \multicolumn{7}{|l|}{ Coordination Metric } \\
\hline Rating ( 1 = Very little, $5=$ Very much) & $2.23(1.05)$ & $1.00(.00)$ & $.000^{* * \wedge}$ & $2.08(1.06)^{\sim}$ & $2.44(1.03)^{\sim}$ & $.302^{\sim}$ \\
\hline \multicolumn{7}{|l|}{ IIIb. Coordination Amt. (expected) } \\
\hline \multicolumn{7}{|l|}{ Coordination Metric } \\
\hline Rating ( 1 = Very little, $5=$ Very much) & $3.70(1.16)$ & $1.60(.97)$ & $.000^{* *}$ & $\cdots$ & $\ldots$ & $\cdots$ \\
\hline \multicolumn{7}{|l|}{ IVa. Likability Coordination Amt. (actual) } \\
\hline \multicolumn{7}{|l|}{ Preference Metric } \\
\hline Rating ( 1 = Loved it, 5 = Hated it) & $2.37(1.15)$ & $1.00(.00)$ & $.000^{* * \wedge}$ & $2.25(1.07)^{\sim}$ & $2.56(1.15)^{\sim}$ & $0.387^{\sim}$ \\
\hline \multicolumn{7}{|l|}{ IVb. Likability Coordination Amt. (expected) } \\
\hline \multicolumn{7}{|l|}{ Preference Metric } \\
\hline Rating ( 1 = Loved it, 5 = Hated it) & $3.10(.88)$ & $1.70(.82)$ & $.002^{* *}$ & $\ldots$ & $\ldots$ & $\ldots$ \\
\hline \multicolumn{7}{|c|}{ Objective } \\
\hline Scale & DCAP & DCAS & Sig. & $1.7 x$ & $2.5 x$ & Sig. \\
\hline \multicolumn{7}{|l|}{ Va. Verbal Coordination Transmissions } \\
\hline \multicolumn{7}{|l|}{ Coordination Metric } \\
\hline Count & $7.90(4.65)$ & $0.00(.00)$ & $.000^{* * \wedge}$ & $7.67(5.39)^{\sim}$ & $8.25(4.03)^{\sim}$ & $.859^{\sim}$ \\
\hline \multicolumn{7}{|l|}{ Vb. Length of Coordination Transmission } \\
\hline \multicolumn{7}{|l|}{ Coordination Metric } \\
\hline Seconds & $10.32(3.44)$ & $0.00(.00)$ & $.000^{* * \wedge}$ & $9.20(3.75)^{\sim}$ & $11.99(2.44)^{\sim}$ & $.231^{\sim}$ \\
\hline \multicolumn{7}{|l|}{ Vc. Transmission to Run Length Ratio } \\
\hline \multicolumn{7}{|l|}{ Coordination Metric } \\
\hline$\%$ & $10 \%(.07)$ & $00 \%(.00)$ & $.000^{* * \wedge}$ & $9 \%(.08)^{\sim}$ & $11 \%(.06)^{\sim}$ & $.659^{\sim}$ \\
\hline \multicolumn{7}{|l|}{ VI. Time on Task' } \\
\hline \multicolumn{7}{|l|}{ Time Metric } \\
\hline Seconds & $67.58(46.63)$ & $40.45(37.45)$ & $.000^{* *}$ & $54.50(46.46)$ & $53.24(42.26)$ & .887 \\
\hline means (S.D.); $p=. x X X$ & & & & & & \\
\hline ' = Scripted conflict pairs only & & & & & & \\
\hline$* \quad=$ Significant at .05 & & & & & & \\
\hline$* *$ = Significant at .01 & & & & & & \\
\hline$\wedge$ = Significance assumed from descriptives & & & & & & \\
\hline$\sim$ = DCAS data omitted due to absence of verba & al coordinatic & on transmissic & ons & & & \\
\hline
\end{tabular}


Table 2. Plane performance results.

\begin{tabular}{|c|c|c|c|c|c|c|}
\hline \multicolumn{7}{|c|}{ Subjective } \\
\hline Scale & DCAP & DCAS & Sig. & $1.7 x$ & $2.5 x$ & Sig. \\
\hline \multicolumn{7}{|l|}{ VII. Feasibility for Future } \\
\hline \multicolumn{7}{|l|}{ Feasibility Metric } \\
\hline Rating ( $1=$ Entirely, $5=$ Not at all $)$ & $2.50(.97)$ & $2.10(.99)$ & .375 & $\ldots$ & $\ldots$ & $\ldots$ \\
\hline \multicolumn{7}{|l|}{ VIIla. Unecessary Plane Movement (actual) } \\
\hline \multicolumn{7}{|l|}{ Efficiency Metric } \\
\hline Rating ( $1=$ Not concerned, 5 =Very concerned $)$ & $2.23(1.10)$ & $1.90(1.22)$ & .200 & $1.96(1.05)$ & $2.22(1.31)$ & .330 \\
\hline \multicolumn{7}{|l|}{ VIIIb. Unecessary Plane Movement (expected) } \\
\hline \multicolumn{7}{|l|}{ Efficiency Metric } \\
\hline Rating ( 1 = Not concerned, 5 =Very concerned ) & $3.40(1.27)$ & $2.60(.97)$ & .129 & $\ldots$ & $\ldots$ & $\ldots$ \\
\hline \multicolumn{7}{|c|}{ Objective' } \\
\hline Scale & DCAP & DCAS & Sig. & $1.7 x$ & $2.5 x$ & Sig. \\
\hline \multicolumn{7}{|l|}{ IXa. Separation Violations (LoS)' } \\
\hline \multicolumn{7}{|l|}{ Safety Metric } \\
\hline Count & 1 & 1 & $\ldots$ & 0 & 2 & $\ldots$ \\
\hline \multicolumn{7}{|l|}{ IXa. Separation Violations (Operational Error)' } \\
\hline \multicolumn{7}{|l|}{ Safety Metric } \\
\hline Count & 1 & 1 & $\ldots$ & 0 & 2 & $\ldots$ \\
\hline \multicolumn{7}{|l|}{ IXa. Separation Violations (Proximity Event)' } \\
\hline \multicolumn{7}{|l|}{ Safety Metric } \\
\hline Count & 0 & 0 & $\ldots$ & 0 & 0 & $\ldots$ \\
\hline \multicolumn{7}{|l|}{ x. Time until LoS' } \\
\hline \multicolumn{7}{|l|}{ Safety Metric } \\
\hline Minutes & $7.14(1.97)$ & $7.32(2.26)$ & .643 & $7.32(2.01)$ & $7.14(2.23)$ & .603 \\
\hline \multicolumn{7}{|l|}{ XI. Resolution Attempts per Conflict' } \\
\hline \multicolumn{7}{|l|}{ Efficiency Metric } \\
\hline Count & $\mid 1.31(.61)$ & $1.32(.57)$ & .945 & $1.37(.64)$ & $1.26(.53)$ & .209 \\
\hline \multicolumn{7}{|l|}{ XII. Heading Change' } \\
\hline \multicolumn{7}{|l|}{ Efficiency Metric } \\
\hline Degrees & ||26.58(14.63) & $25.85(12.67)$ & .595 & $26.16(12.52)$ & $26.27(14.81)$ & .792 \\
\hline \multicolumn{7}{|l|}{ means (S.D.); $p=. X X X$} \\
\hline $\begin{aligned} 1 & =\text { Scripted conflict pairs only } \\
* & =\text { Significant at } .05\end{aligned}$ & & & & & & \\
\hline
\end{tabular}

As seen generally in Table 2, however, controllers were able to provide non-

differential service to aircraft no matter the procedure they were operating under.

Objectively, the resolution clearances they sent to planes were not more frequent, of

greater magnitude, nor closer to time of predicted LoS. Instead controllers were able to

keep planes apart equally in either the DCAP or the DCAS procedure. Subjectively, they 
also expressed similar opinions as to any concern for counter-productive or unnecessary movement of planes between the procedures and did not rate one procedure as ultimately more feasible than the other.

In regards to the traffic density manipulation, only the workload metrics showed significant differences. Seemingly evident differences in the number of separation violations between the $1.7 \mathrm{x}(0)$ and $2.5 \mathrm{x}$ ( 2 ) traffic densities were not pursued as both were investigated and determined to be in violation of conceptual assumptions (discussed further in the LoS sub-section).

Table 3 displays the sub-group means, standard deviations, and interaction statistics for the metrics that are meaningful in interpreting the traffic density and procedure interaction hypothesis regarding acceptability and performance for both procedures under either traffic density. In general, under the $1.7 x$ traffic density conditions, averages appear on the more desirable lower half of subjective rating scales and within tolerable objective limits in terms of minutes to LoS, counts of resolution attempts, and degrees of heading change. Furthermore, the sub-group values of DCAS under the $2.5 \mathrm{x}$ density conditions do not appear to dramatically depart from those for either procedure in the $1.7 \mathrm{x}$ conditions. While the subjective ratings of DCAP within the $2.5 \mathrm{x}$ traffic density consistently ranked further to the negative aspect end of the scales than any other sub-group, it should be noted that no significant interactions were obtained between the procedure and traffic density factors on any measured data. 
Table 3. Sub-group means, standard deviations, and interaction significance statistics.

\begin{tabular}{|c|c|c|c|c|c|}
\hline \multicolumn{6}{|c|}{ Acceptability } \\
\hline Scale & 1.7x-DCAP & 1.7x-DCAS & 2.5x-DCAP & 2.5x-DCAS & $\begin{array}{c}\text { Interaction } \\
\mathrm{F}, \mathrm{p}\end{array}$ \\
\hline \multicolumn{6}{|l|}{ Ila. Workload (Self Report) } \\
\hline \multicolumn{6}{|l|}{ Workload Metric } \\
\hline Rating ( 1 = Very low, 6 = Very high) & $2.23(1.10)$ & $1.61(.84)$ & $2.67(1.33)$ & $1.68(.83)$ & $2.37, .125$ \\
\hline \multicolumn{6}{|l|}{ Ilb. Workload (Supe Report) } \\
\hline \multicolumn{6}{|l|}{ Workload Metric } \\
\hline Rating ( 1 = Very low, 6 = Very high) & $2.79(1.02)$ & $1.92(.50)$ & $4.00(1.16)$ & $2.62(.81)$ & $1.53, .220$ \\
\hline \multicolumn{6}{|l|}{ IIla. Coordination Amt. (actual) } \\
\hline \multicolumn{6}{|l|}{ Coordination Metric } \\
\hline Rating ( 1 = Very little, 5 = Very much) & $2.08(1.06)$ & $1.00(.00)$ & $2.44(1.03)$ & $1.00(.00)$ & $\ldots$ \\
\hline \multicolumn{6}{|l|}{ IVa. Likability Coordination Amt. (actual) } \\
\hline \multicolumn{6}{|l|}{ Preference Metric } \\
\hline Rating (1 = Loved it, 5 = Hated it) & $2.25(1.07)$ & $1.00(.00)$ & $2.56(1.15)$ & $1.00(.00)$ & $\ldots$ \\
\hline \multicolumn{6}{|c|}{ Performance } \\
\hline Scale & 1.7x-DCAP & 1.7x-DCAS & 2.5X-DCAP & 2.5x-DCAS & $\begin{array}{c}\text { Interaction } \\
\mathrm{F}, \mathrm{p} \\
\end{array}$ \\
\hline \multicolumn{6}{|l|}{ VIIla. Unecessary Plane Movement (actual) } \\
\hline \multicolumn{6}{|l|}{ Efficiency Metric } \\
\hline Rating ( $1=$ Not concerned, $5=$ Very concerned) & $2.08(.93)$ & $1.83(1.17)$ & $2.44(1.32)$ & $2.00(1.32)$ & $.12, .725$ \\
\hline \multicolumn{6}{|l|}{ X. Time until LoS' } \\
\hline \multicolumn{6}{|l|}{ Safety Metric } \\
\hline Minutes & $7.33(1.69)$ & $7.31(2.29)$ & $6.96(2.22)$ & $7.32(2.26)$ & $.41, .523$ \\
\hline \multicolumn{6}{|l|}{ XI. Resolution Attempts per Conflict' } \\
\hline \multicolumn{6}{|l|}{ Efficiency Metric } \\
\hline Count & $1.36(.68)$ & $1.38(.61)$ & $1.27(.54)$ & $1.26(.53)$ & $.01, .921$ \\
\hline \multicolumn{6}{|l|}{ XII. Heading Change' } \\
\hline \multicolumn{6}{|l|}{ Efficiency Metric } \\
\hline Degrees & $\begin{array}{c}25.21 \\
(12.80)\end{array}$ & $\begin{array}{r}27.17 \\
(12.27) \\
\end{array}$ & $\begin{array}{c}28.13 \\
(16.47) \\
\end{array}$ & $\begin{array}{c}24.57 \\
(13.05) \\
\end{array}$ & $2.02, .157$ \\
\hline
\end{tabular}

means (S.D.); $F=X . X X, p=. X X X$ 
I. Likability of procedure. At the end of the last day of the simulation study, participants were asked in their questionnaires to identify their preferences for the two procedures they experienced as well as their reasons behind their ratings (Appendix C, Post-Study Questionnaire). Rather than potentially leading participant response by only asking participants to indicate which procedure they liked better in a forced choice format, by design, two different ratings were elicited independently for each procedure, allowing for the unique outcome that they might hate both or love both.

The likability of procedure was rated on a 1 to 5 scale (Hate it (1) - Love it (5)) for both procedures [DCAP $(\mathrm{M}=3.20, \mathrm{SD}=1.03), \mathrm{DCAS}(\mathrm{M}=1.30, \mathrm{SD}=0.48)]$. While the controller participants on average responded only slightly on the dislike side of the scale for the DCAP procedure, they responded much more consistently on the "loved it" extremity for the DCAS procedure. The analyses showed a significant effect of the manipulation of procedure on expressed likability preference $[\mathrm{F}(1,18)=27.77, \mathrm{p}<.001]$, such that the DCAS procedure was given more favorable preference ratings than the DCAP procedure. Frequency distributions of rating responses for preference can be seen in Figure 11 and the significant mean comparison in Figure 12.

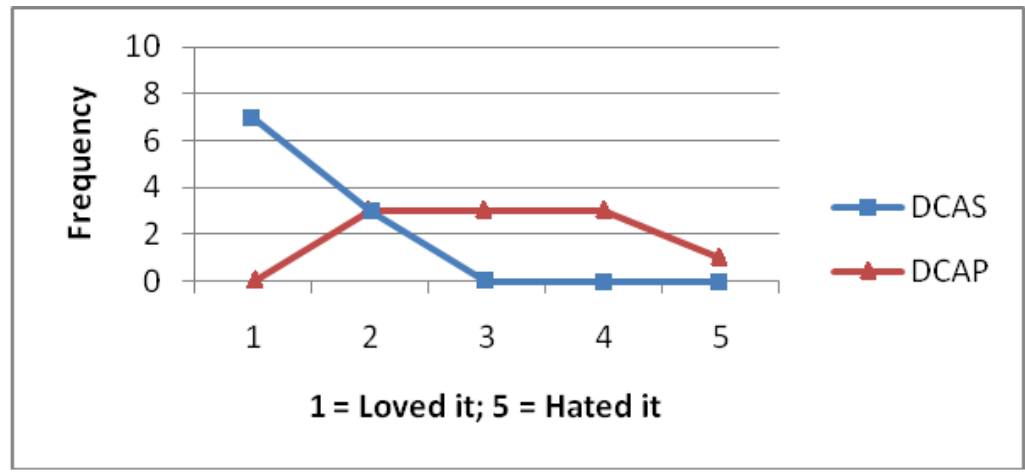

Figure 11. Likability of procedure rating distributions. 


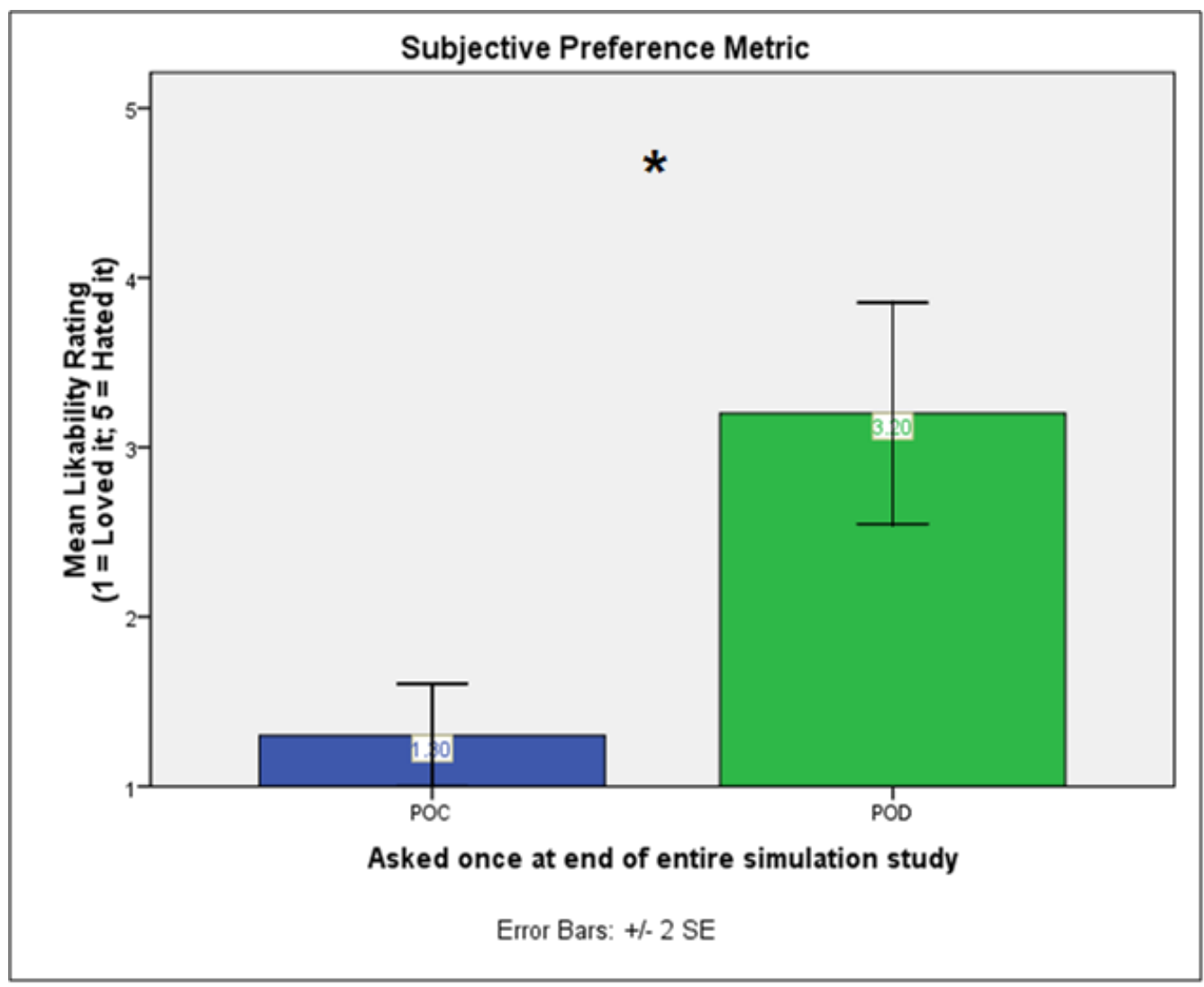

Figure 12. Likability of procedure significant mean comparison. 
II-a. Workload (self - report). Throughout each 15 minute run, workload prompts appeared every three minutes in the margin at the top of controller participants' primary display and lasted for forty seconds for each prompt. The participants tested had been previously highly exposed to the prompt and practiced at responding with their answers (Appendix D), and in this simulation there were 304 workload responses to 320 prompts, indicative of a $96.2 \%$ response rate. The $3.8 \%$ omission rate was not directly associable with any systematic imbalance, but instead appeared to be spread in an apparently random distribution between participants and conditions.

Workload ratings were made on a 1 to 6 scale ((Very Low (1) - Very High (6)) with averages computed per each controller for each run While average ratings for all manipulations fell below the halfway point on the workload scale, ratings associated with the DCAS procedure were the lowest. The analyses showed a significantly lower average workload rating in the DCAS procedure $(\mathrm{M}=1.65, \mathrm{SD}=0.83)$ than the DCAP procedure $(\mathrm{M}=2.45, \mathrm{SD}=1.23),[\mathrm{F}(1,300)=45.35, \mathrm{p}<.001]$, as well as a lower workload average in the $1.7 x$ traffic density $(M=1.93, S D=1.02)$ than in the $2.5 x$ traffic density $(M=$ 2.16, $\mathrm{SD}=1.20),[\mathrm{F}(1,300)=4.52, \mathrm{p}<.05]$. No significant interaction between procedure and traffic level was found for controller self-reported workload $[\mathrm{F}(1,300)=$ 2.37, $\mathrm{p}=.125]$. Average workload response ratings per timed prompt for procedure and traffic density can be seen in Figures 13 and 14, with significant mean comparisons in Figures 15 and 16. 


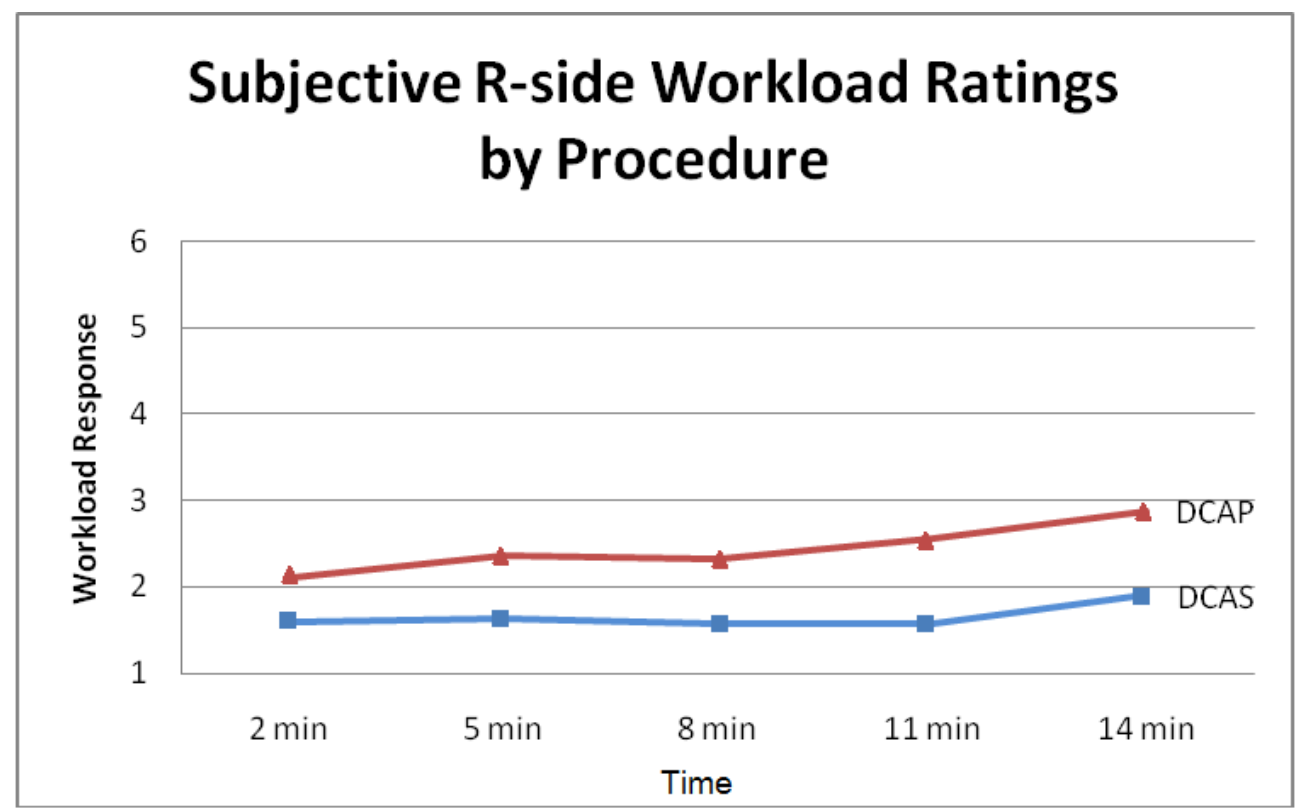

Figure 13. Average workload self-response ratings by prompt time and procedure.

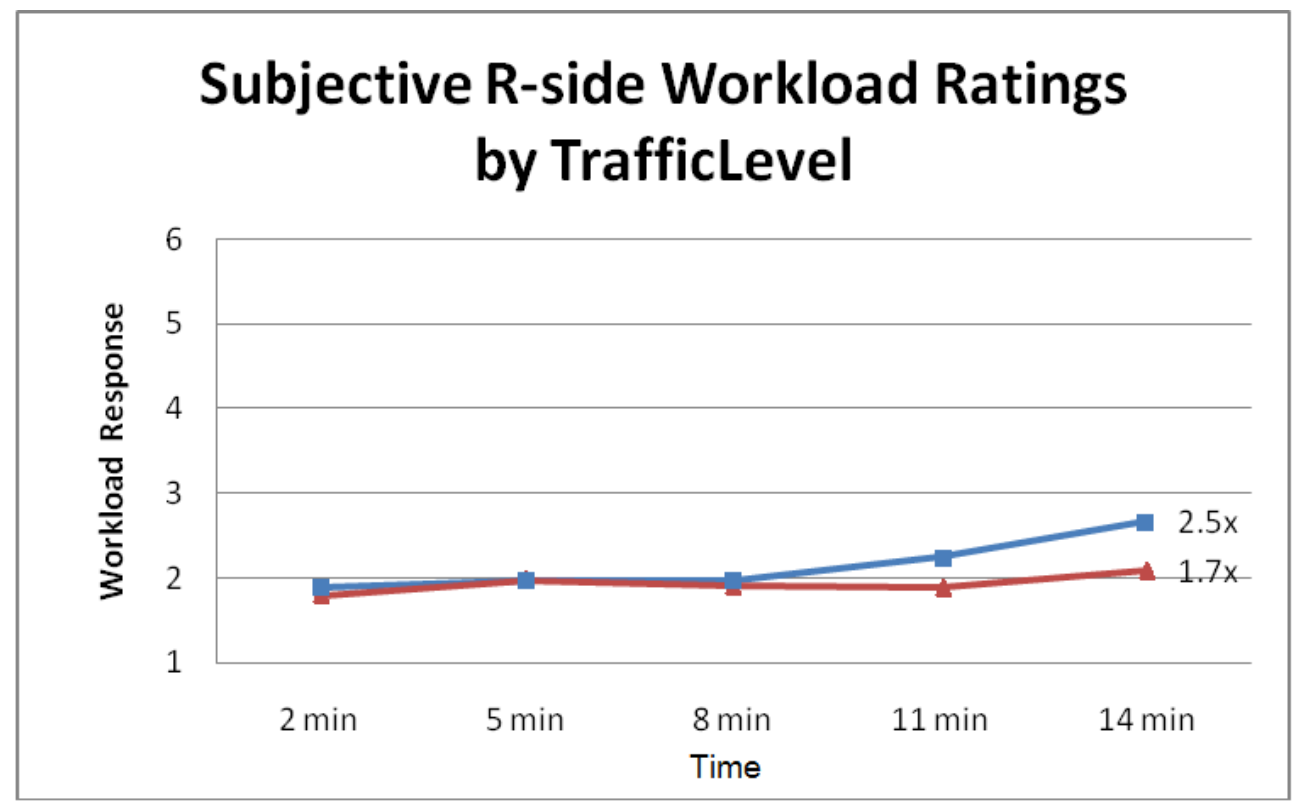

Figure 14. Average workload self-response ratings by prompt time and traffic density. 


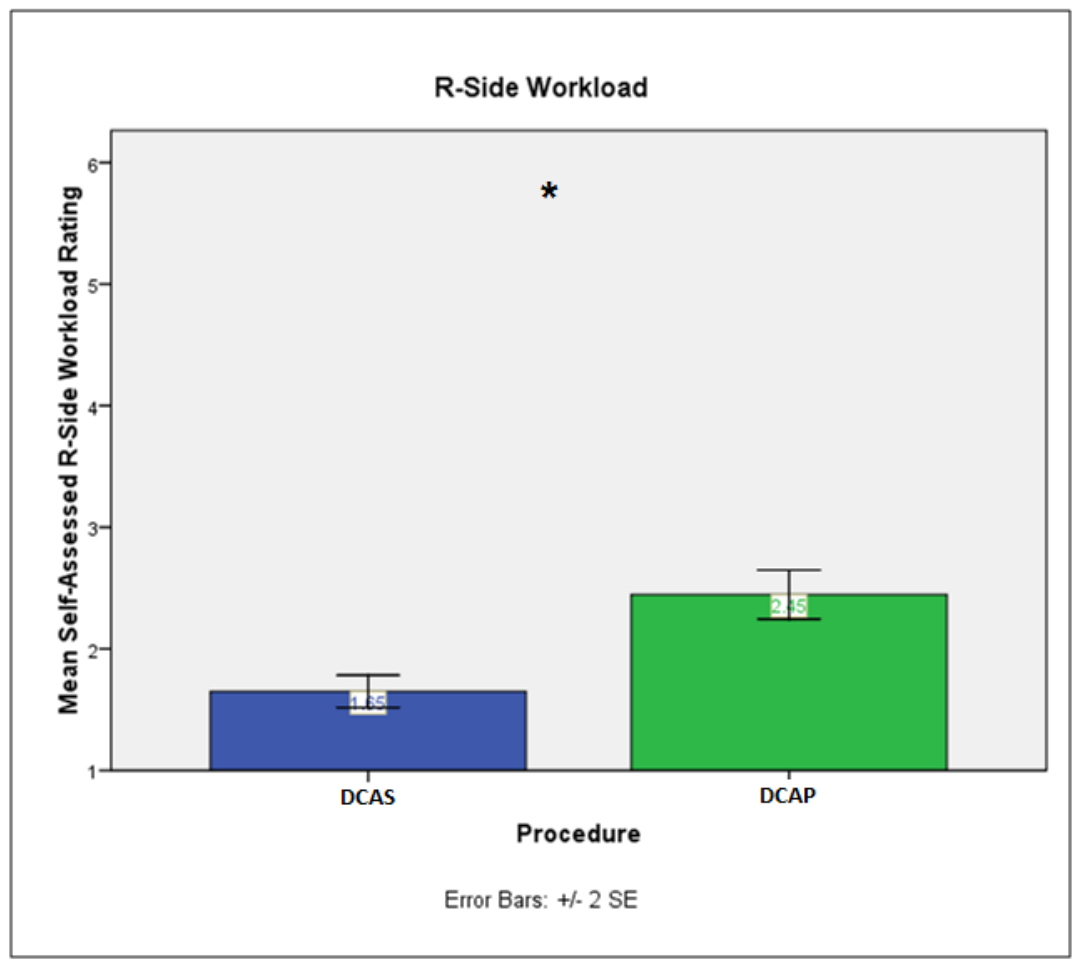

Figure 15. Workload self-response significant mean procedure comparison.

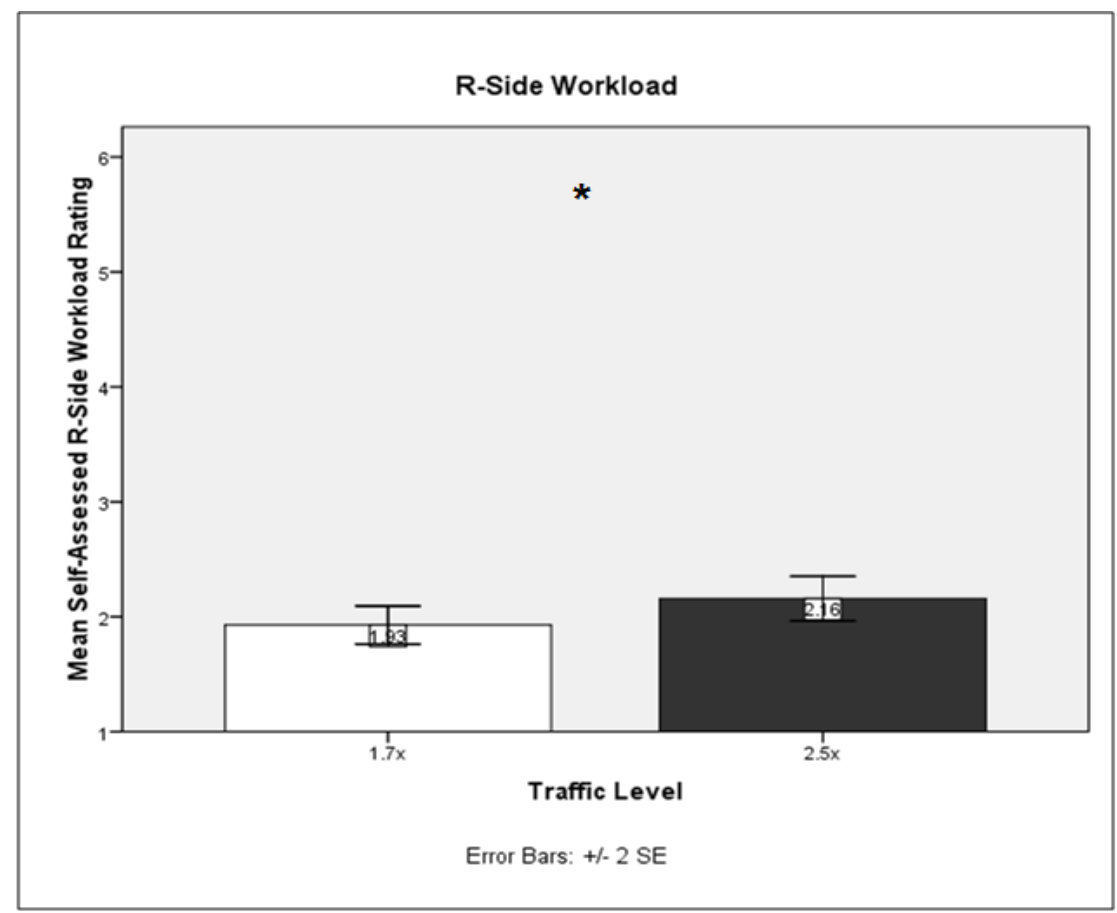

Figure 16. Workload self-response significant mean density comparison. 
II-b. Workload (supervisor assessment). Two participant controllers staffed a supervisor position for each of the two different sets of four radar controller positions and were asked to provide a single workload rating for each R-side representing their average workload for the entirety of the just completed run. These ratings were made on the same 1 to 6 scale ((Very Low (1) - Very High (6)) as the R-side self-reported workload ratings.

Figure 17 shows that the supervisors gave higher frequencies of ratings at the lower end of the workload scale (i.e., 1 to 2) for the DCAS procedure compared to the DCAP procedure, as well as lower frequencies for DCAS compared to DCAP for mid to high workload ratings.

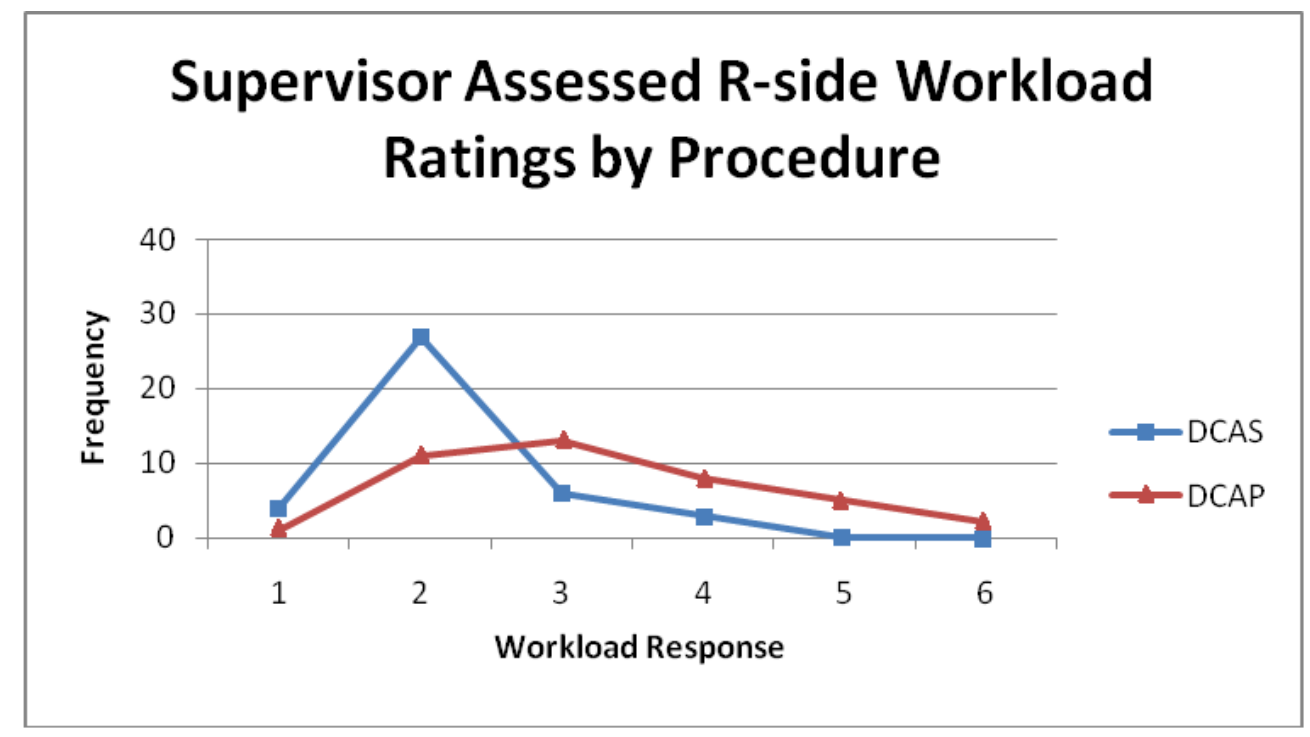

Figure 17. Supervisor assessed R-side workload ratings by procedure.

As with the self-reported workload ratings, the analyses showed the supervisors to have assessed their controllers to have significantly less workload in the DCAS procedure $(\mathrm{M}=2.20, \mathrm{SD}=.72)$ than in the DCAP procedure $(\mathrm{M}=3.28, \mathrm{SD}=1.22),[\mathrm{F}(1,76)=$ $31.02, \mathrm{p}=.000]$ as well as less in the $1.7 \mathrm{x}$ traffic density $(\mathrm{M}=2.35, \mathrm{SD}=.91)$ than in the 
$2.5 \mathrm{x}$ traffic density $(\mathrm{M}=3.31, \mathrm{SD}=1.20),[\mathrm{F}(1,76)=22.51, \mathrm{p}=.000]$. Likewise, no interaction for supervisor assessed workload was found between procedure and traffic density $[\mathrm{F}(1,76)=1.53, \mathrm{p}=.220]$.

III-a. Amount of coordination (experienced). After each run, controller participants were asked to rate the amount of verbal coordination they had just experienced. These ratings were made on a 1 to 6 scale ((Very Little (1) - Very Much (5)). Verbal coordination entailed the discussion, negotiation or otherwise sharing of information between controllers as to who had taken or would take action with what planes. While the ratings varied among participants in the DCAP procedure from 1 to 4 $(\mathrm{M}=2.23, \mathrm{SD}=1.05)$, the ratings were consistently at minimum in the DCAS procedure $(\mathrm{M}=1.00, \mathrm{SD}=0)$ and procedural differences in perceived amount of coordination experienced are clearly seen in Figure 18.

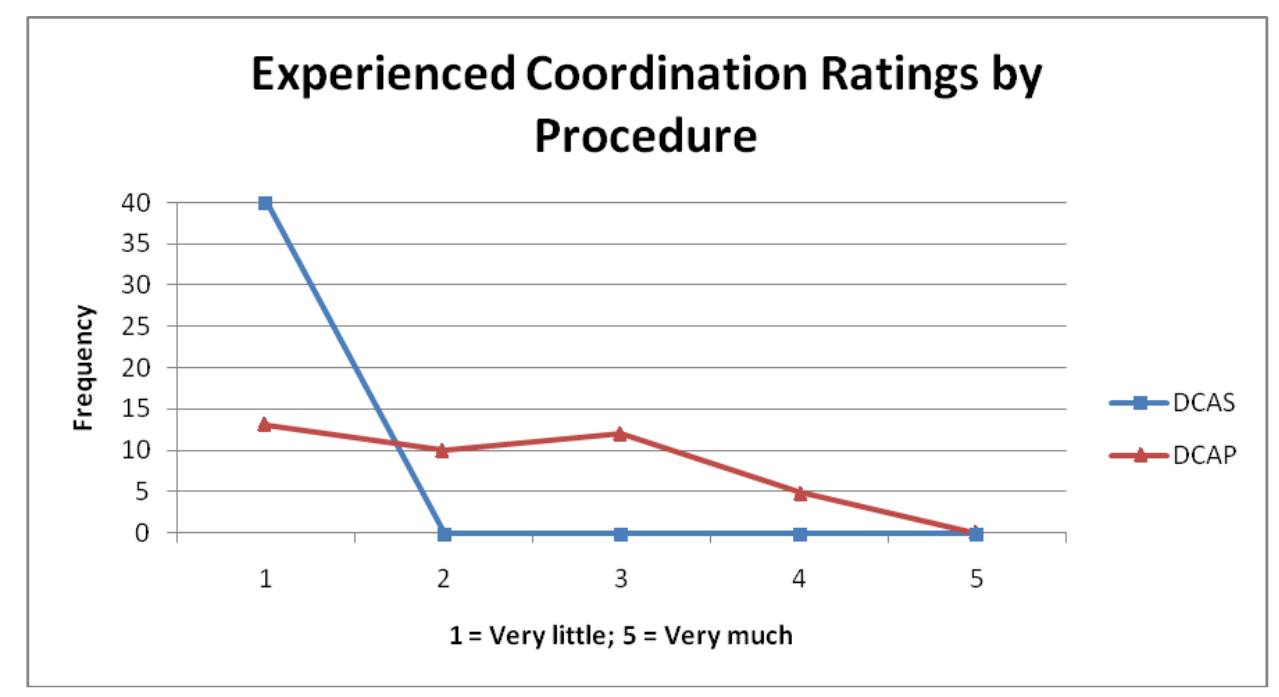

Figure 18. Experienced coordination rating distributions by procedure.

Submitting these data to the analyses returned a significant main effect of procedure with controller participants rating their experienced coordination lower in the 
DCAS procedure than in the DCAP procedure $[\mathrm{F}(1,76)=55.50, \mathrm{p}<.001]$. This statistic however, is only provided as a guideline as participants were ultimately invariant in their experienced coordination ratings, and hence, the assumption of homogeneity of variance between conditions was not met.

In regards to the factor of traffic density, the analyses did not obtain a significant effect between the $1.7 \mathrm{x}$ and $2.5 \mathrm{x}$ levels in the amount of experienced coordination $[\mathrm{F}(1,38)=1.10, \mathrm{p}=.302]$

III-b. Amount of coordination (expected). After each procedure controller participants were also asked to rate the amount of verbal coordination they expected future controllers of NextGen to experience under either of the given procedures. These ratings were made on the same 1 to 5 scale ((Very Little (1) - Very Much (5)) and their frequency distributions are seen in Figure 19.

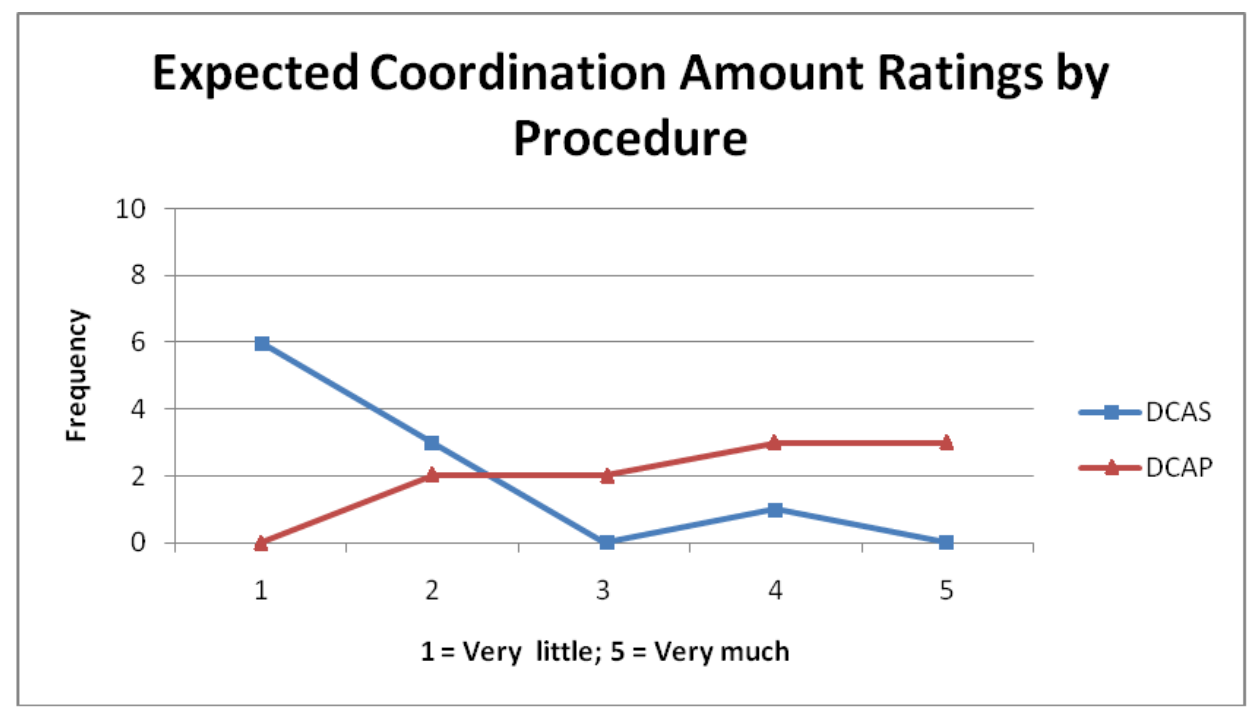

Figure 19. Expected coordination rating distributions by procedure. 
Descriptively, this plot interestingly varies from Figure 18 not only because the ratings for DCAS stray above "1" and in one case even as high as "4", but also because the expected amount of coordination ratings for DCAP diverge from those of DCAS at the right side of the chart. For their actual experienced amount of coordination, participant ratings appear to converge on the high end of the scale but in spite of their personal experiences in the simulation, it is interesting to note the allowance for the possibility of greater coordination amounts in their expectations for others. Themselves experiencing no coordination in the DCAS procedure and some in the DCAP procedure, controller participants anticipated the possibility for some amount of coordination under DCAS and up to very much under DCAP. Still, in general, the experienced and expected amount of coordination measure results were more similar than dissimilar. Last, the DCAP procedure $(\mathrm{M}=3.70, \mathrm{SD}=1.16)$ showed higher ratings of expected coordination amounts for future controllers of NextGen than the DCAS procedure $(\mathrm{M}=1.60, \mathrm{SD}=$ $.97)$, and the analyses found this difference to be significant $[\mathrm{F}(1,18)=19.36, \mathrm{p}=<.001]$. Figure 20 illustrates this significant comparison of mean expected amount of coordination ratings for the two procedures. 


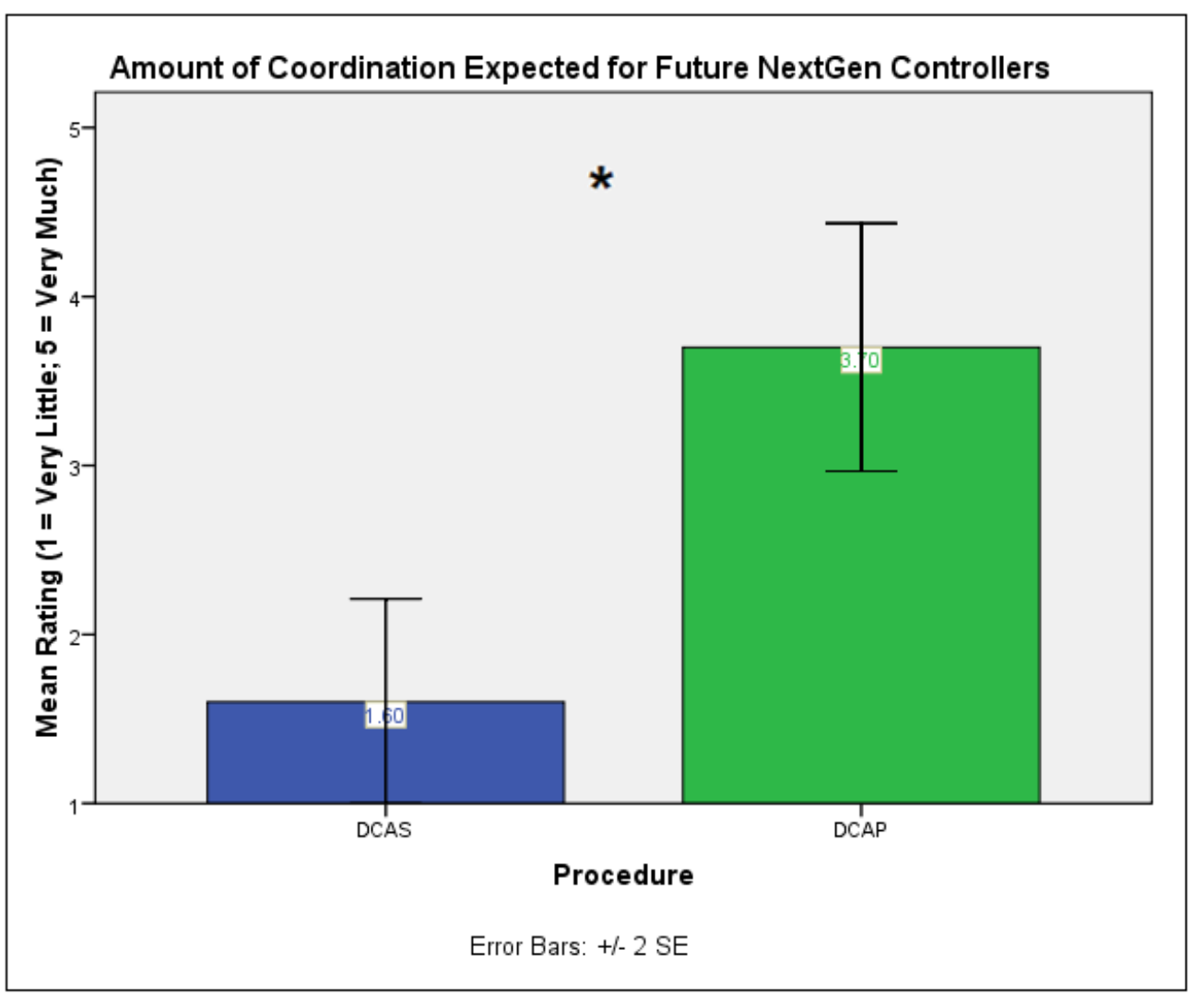

Figure 20. Expected coordination for future significant mean comparison.

IV-a. Likability of amount of coordination (experienced). To gauge their comfort with these levels of coordination participants were asked to rate both their personal likability for these amounts as well as what they expected future NextGen controllers would feel about them. By comparing Figure 21 with Figure 18, these likability rating distributions share strikingly similar distributions and shape to the amount of coordination experienced, enabling a nearly direct comparison. While there were generally more ratings on the lower end of the amount of the coordination amount scale, there were correspondingly more ratings on the favorable end of the likability scale. Furthermore, where the experienced coordination scale spikes at "1" for its 
absence, the likability metric also invariantly follows suit in the DCAS procedure ( $\mathrm{M}=$ $1.00, \mathrm{SD}=.00)$. Overall, where the amount of coordination experienced varied in the DCAP procedure $(\mathrm{M}=2.37, \mathrm{SD}=1.15)$, the likability for those amounts generally decreased in line with the more coordination was reported as experienced.

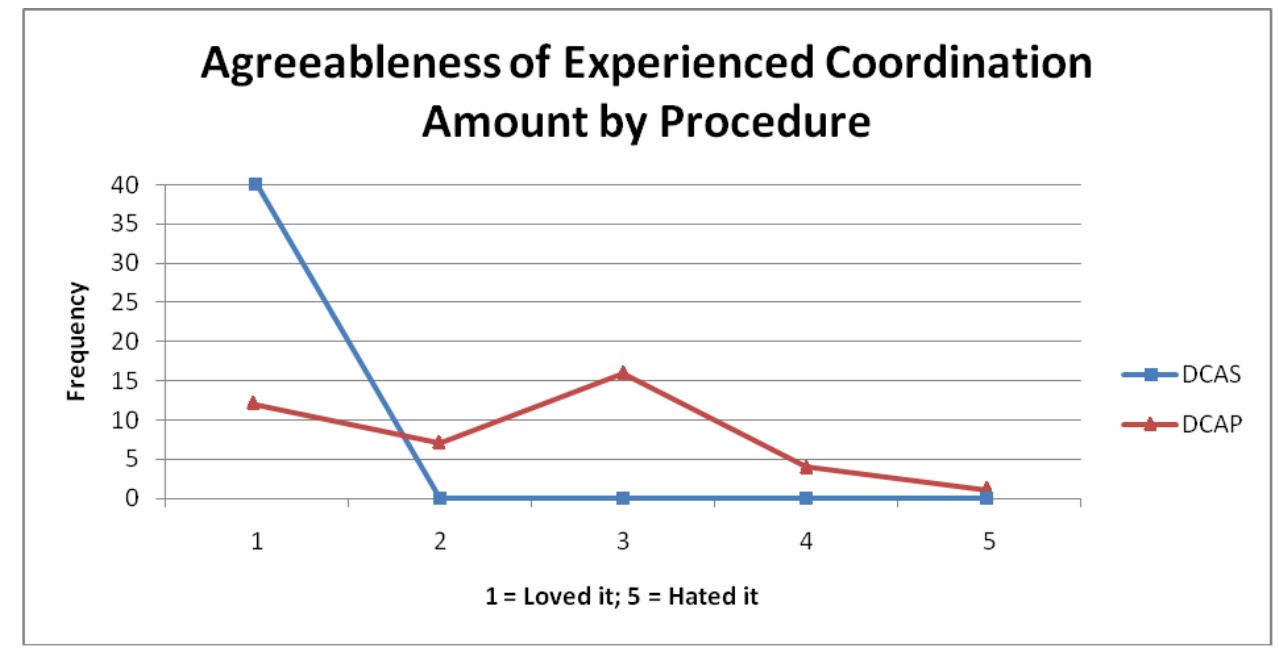

Figure 21. Agreeableness of experienced coordination amount by procedure.

Submitting these data to the analyses returned a significant main effect of procedure with controller participants rating their experienced coordination lower in the DCAS procedure than in the DCAP procedure $[\mathrm{F}(1,76)=62.14, \mathrm{p}<.001]$. This statistic however, is also only provided as a guideline as participants were again invariant in their ratings, and so again in violation of an assumption of homogeneity of variance between conditions. From matching the slopes of the lines in Figure 21 over those in Figure 18, the descriptives clearly suggest a directly inverse relationship between amount and agreeableness of coordination.

Using only the preference ratings where controllers varied in their agreeableness of coordination responses (i.e., DCAP), the traffic density factor was analyzed and failed 
to obtain a significant effect between the $1.7 \mathrm{x}(\mathrm{M}=2.25, \mathrm{SD}=1.07)$ and $2.5 \mathrm{x}$ levels $(\mathrm{M}$ $=2.56, \mathrm{SD}=1.15),[\mathrm{F}(1,38)=.77, \mathrm{p}=.387]$.

IV-b. Likability of amount of coordination (expected). When asked to anticipate how agreeable controllers of NextGen would find the levels of coordination our controllers expected they would experience, none of our controller participants anticipated the minimum level of coordination for the DCAP procedure and likewise none indicated that they would love that amount. On the other hand, 6 ratings expected the minimum level of coordination for the DCAS procedure and there were 5 ratings of "would love." In general, as seen in Figure 22, more ratings were given on the disfavorable side of the scale for the DCAP procedure, and more were given for the DCAS procedure on the favorable extremity.

The analyses found the average expected likability of amount of coordination rating of the DCAS procedure $(\mathrm{M}=1.70, \mathrm{SD}=.82)$ to be more favorable than that of the DCAP procedure $(\mathrm{M}=3.10, \mathrm{SD}=088),[\mathrm{F}(1,18)=13.57, \mathrm{p}<.01]($ see Figure 23$)$.

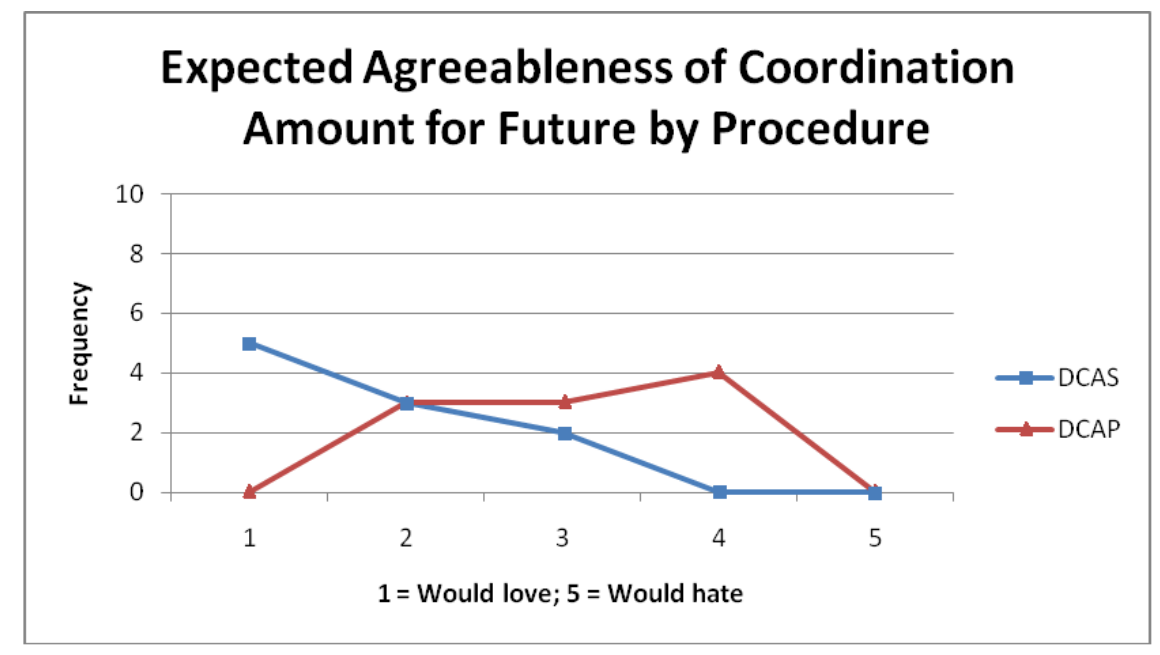

Figure 22. Coordination agreeableness expected for future controllers. 


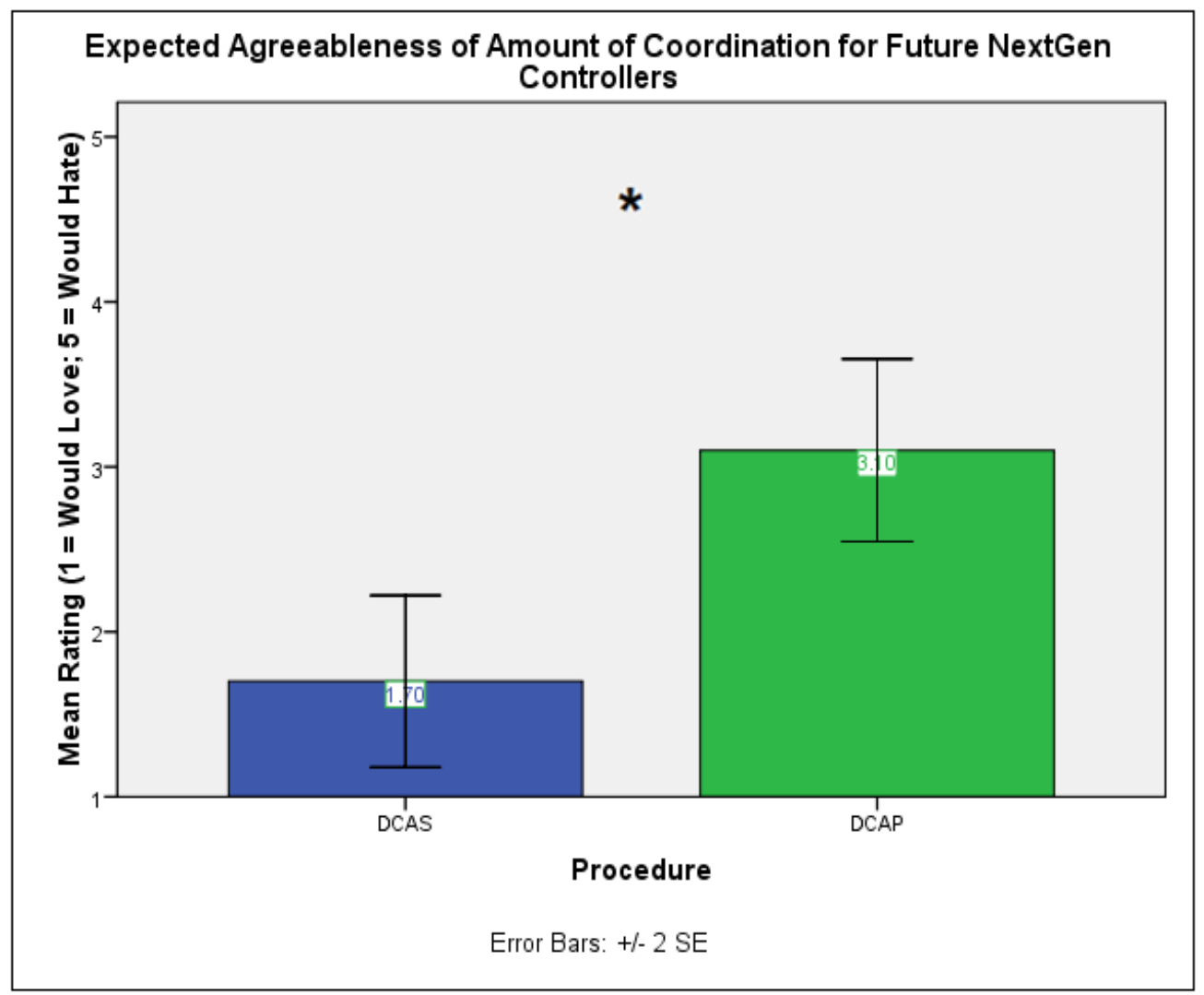

Figure 23. Agreeableness of coordination for future significant mean comparison.

\section{Summary - Controller Experience, Subjective}

As a summary of all the subjective metrics of controller experience, large amounts of differences are seen between the two procedures, with the DCAP procedure producing higher ratings towards the negative ends of the scales than the DCAS procedure both descriptively and inferentially. In regards to traffic density, controller workload was rated significantly higher in the higher traffic density, both by the ratings of controllers working the radar position, as well as by their supervisor's assessment ratings. 


\section{V-a, V-b, V-c. Verbal coordination counts, lengths and \% of run length.}

Subjective amount of coordination experienced ratings by controllers were supported and validated by the objective audio transmission data, which more clearly than anything else, showed no recorded verbal coordination transmissions in the DCAS procedure runs against a multitude in the DCAP procedure runs. Figure 24 presents the audio transmission data where each colored cell (color-coded per participant that initiated the coordination) represents one coordination transmission with the number inside the cell equaling the duration of the transmission in seconds.

\begin{tabular}{|c|c|c|c|c|c|c|c|c|c|c|c|c|c|c|c|c|c|c|c|}
\hline 1.7 & DCAP & run1 & 8 & 9 & 10[ & 10 & 12 & 9 & 11 & 9 & & & & & & & & & \\
\hline 1.7 & DCAS & run1 & & & & & & & & & & & & & & & & & \\
\hline 2.5 & DCAP & run2 & 16 & 11 & 12 & 8 & 9 & 22 & & & & & & & & & & & \\
\hline 1.7 & DCAS & run2 & & & & & & & & & & & & & & & & & \\
\hline 1.7 & DCAP & run3 & $6]$ & 12 & 10] & 11 & & & & & & & & & & & & & \\
\hline 2.5 & DCAS & run3 & & & & & & & & & & & & & & & & & \\
\hline 2.5 & DCAP & run4 & 9 [ & 9 & 9 & 8 & & & & & & & & & & & & & \\
\hline 2.5 & DCAS & run4 & & & & & & & & & & & & & & & & & \\
\hline 2.5 & DCAP & run5 & 15 & 10 & 11 & 10 & 9 & 15 & 16 & 11 & 26 & 22 & & & & & & & \\
\hline 2.5 & DCAS & run5 & & & & & & & & & & & & & & & & & \\
\hline 1.7 & DCAP & run6 & 18 & 16 & 3 & 22 & 9 & 13 & 11 & 4 & & & & & & & & & \\
\hline 2.5 & DCAS & run6 & & & & & & & & & & & & & & & & & \\
\hline 2.5 & DCAP & run7 & 15 & 24 & 22 & 11 & 8 & 14 & 19 & 11 & 3 & 11 & 6 & 2 & 6 & & & & \\
\hline 1.7 & DCAS & run7 & & & & & & & & & & & & & & & & & \\
\hline 1.7 & DCAP & run8 & 9 & 7 & 10 & 24 & 24 & 12 & 15 & 7 & 34 & 9 & 10 & 10 & 7 & 7 & 6 & 12 & 5 \\
\hline 1.7 & DCAS & run8 & & & & & & & & & & & & & & & & & \\
\hline 1.7 & DCAP & rung & 2 & & & & & & & & & & & & & & & & \\
\hline 1.7 & DCAS & rung & & & & & & & & & & & & & & & & & \\
\hline 1.7 & DCAP & run10 & 7 & 7 & 13 & 5 & 10 & 10 & 16 & 7 & & & & & & & & & \\
\hline 1.7 & DCAS & run10 & & & & & & & & & & & & & & & & & \\
\hline
\end{tabular}

Figure 24. Verbal coordination transmissions, color coded by participant and enumerate by length of transmission in seconds.

Ground to ground R-side verbal coordination occurred exclusively within the DCAP runs, with an average of $7.90(\mathrm{SD}=4.65)$ transmissions per run and each lasting on average 10.32 seconds $(\mathrm{SD}=3.44)$. When the participants did verbally coordinate, an 
average of 91.00 seconds or $10.1 \%(\mathrm{SD}=.07)$ of a run was devoted to this coordination task. Calculating the average amount of time each controller actually spent verbally coordinating through the audio transmissions revealed that on average about 43.74 seconds or $4.86 \%$ of their time on position per run was spent handling ground to ground radio coordination. Comparatively, in the DCAS runs all these numbers were nil.

For traffic density, analyses compared the average count of coordination transmissions by run for the $1.7 \mathrm{x}$ density $(\mathrm{M}=7.67, \mathrm{SD}=5.39)$ against that of the $2.5 \mathrm{x}$ density $(\mathrm{M}=8.25, \mathrm{SD}=4.03)$ but did not obtain a significant difference at the $\mathrm{p}<.05$ level $[\mathrm{F}(1,8)=.03, \mathrm{p}=.859]$. The average length of coordination transmissions were also analyzed for the $1.7 \mathrm{x}$ density $(\mathrm{M}=9.20, \mathrm{SD}=3.75)$ against the $2.5 \mathrm{x}$ density $(\mathrm{M}=$ $11.99, \mathrm{SD}=2.44)$ but also did not show a significant difference at the $\mathrm{p}<.05$ level $[\mathrm{F}(1,8)=1.68, \mathrm{p}=.231]$. Lastly as another way of looking at the coordination transmission length data, the proportion of run time coordination transmissions took up in the $1.7 x$ density $(M=.09, S D=.08)$ was analyzed against that in the $2.5 x$ density $(M=$ $.11, \mathrm{SD}=.06)$, and likewise did not show significance at the $\mathrm{p}<.05$ level $[\mathrm{F}(1,8)=.21, \mathrm{p}$ $=.659]$.

Unexpectedly, from analyzing the audio transmission data, it was seen that one set of four adjacent R-side controllers handled their coordination duties in a very different way than the other set of controllers despite working identical problems under identical conditions. As seen in Figure 24, the verbal coordination under the DCAP procedure in runs $1,2,3,4$, and 9 was almost entirely initiated by one single controller. Such a technique resulted in that World transmitting less coordinations than the other World both 
in average counts, length times, and ultimately exhibiting a significant interaction of World and procedure in the amount of time on task spent to resolve a conflict $[F(1,174)=$ 8.12, $\mathrm{p}<.01]$. On average in the DCAP procedure, controllers in World 2 resolved their conflicts faster $(\mathrm{M}=60.55,36.23)$ than World 1 where controllers coordinated more (M $=73.20, \mathrm{SD}=53.22)$, on the other hand in the DCAS procedure where neither World verbally coordinated, World $2(\mathrm{M}=51.28, \mathrm{SD}=46.31)$ took longer than World $1(\mathrm{M}=$ 29.61, $\mathrm{SD}=21.24$ ) to resolve conflicts (see Fig. 25).

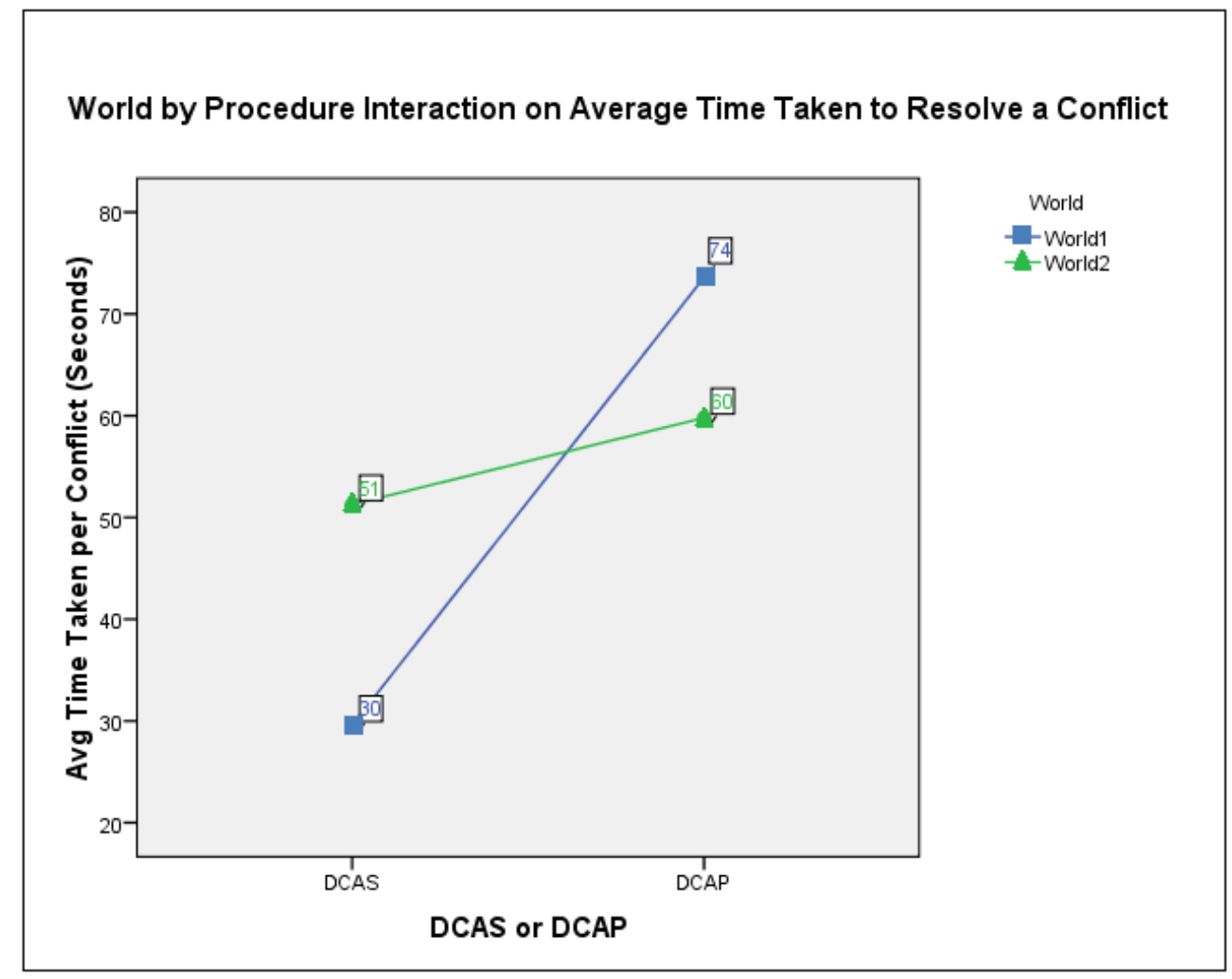

Figure 25. Interaction of world and procedure on time taken to resolve a conflict. Anecdotally, the audio coordination in World 2 (aside from being almost entirely initiated by a single person) were characteristically almost exclusively assertive and to the point (e.g., "AAL691, my control" or "SWA971 and UAL866, I'm taking care of."), 
whereas the recorded verbal coordination transmissions in World 1 tended to entail a larger proportion of more passive type coordination that sometimes opened with a question or a negotiation (e.g., "With the DAL652, was I going to do that one or were you?"). Examination of the factor of World across the other objective data analyses (i.e., Sep Violations, Time until Los, Resolution Attempts, and Heading Changes) however failed to obtain significant main or interaction effects.

VI. Time on task taken to resolve conflicts. For each of the scripted conflicts, a time on task metric was measured as a reflection of how fast or slow a controller resolved a conflict under the different conditions. The start of this measurement began on the nearest whole second when a conflict was first alerted to the R-side (i.e., when the conflict pair appeared for the first time in the conflict table). Time was captured up until either the controller uplinked a resolution clearance to one of the aircraft in the scripted pair or that conflict serendipitously dropped out of the conflict table. In the event that the same conflict pair re-appeared in the conflict table, the process was repeated and each separate period of time that the automation declared the aircraft to be in conflict was added together for a single data point per conflict pair per run.

The analyses showed a significantly lower average time in the DCAS procedure $(M=40.45, S D=37.45)$ than in the DCAP procedure $(M=67.58, S D=46.63)$, $[F(1,170)=20.12, p<.001]$ and is shown in Figure 26. The analyses however did not obtain a significant difference in the average time taken between the $1.7 \mathrm{x}$ density $(\mathrm{M}=$ $54.50, \mathrm{SD}=46.46)$ and the $2.5 \mathrm{x}$ density $(\mathrm{M}=53.24, \mathrm{SD}=42.26),[\mathrm{F}(1,170)=.02, \mathrm{p}=$ 
.887]. Lastly, an unexpected interaction of procedure and world on time taken was found and is described in the previous section with the objective coordination data.

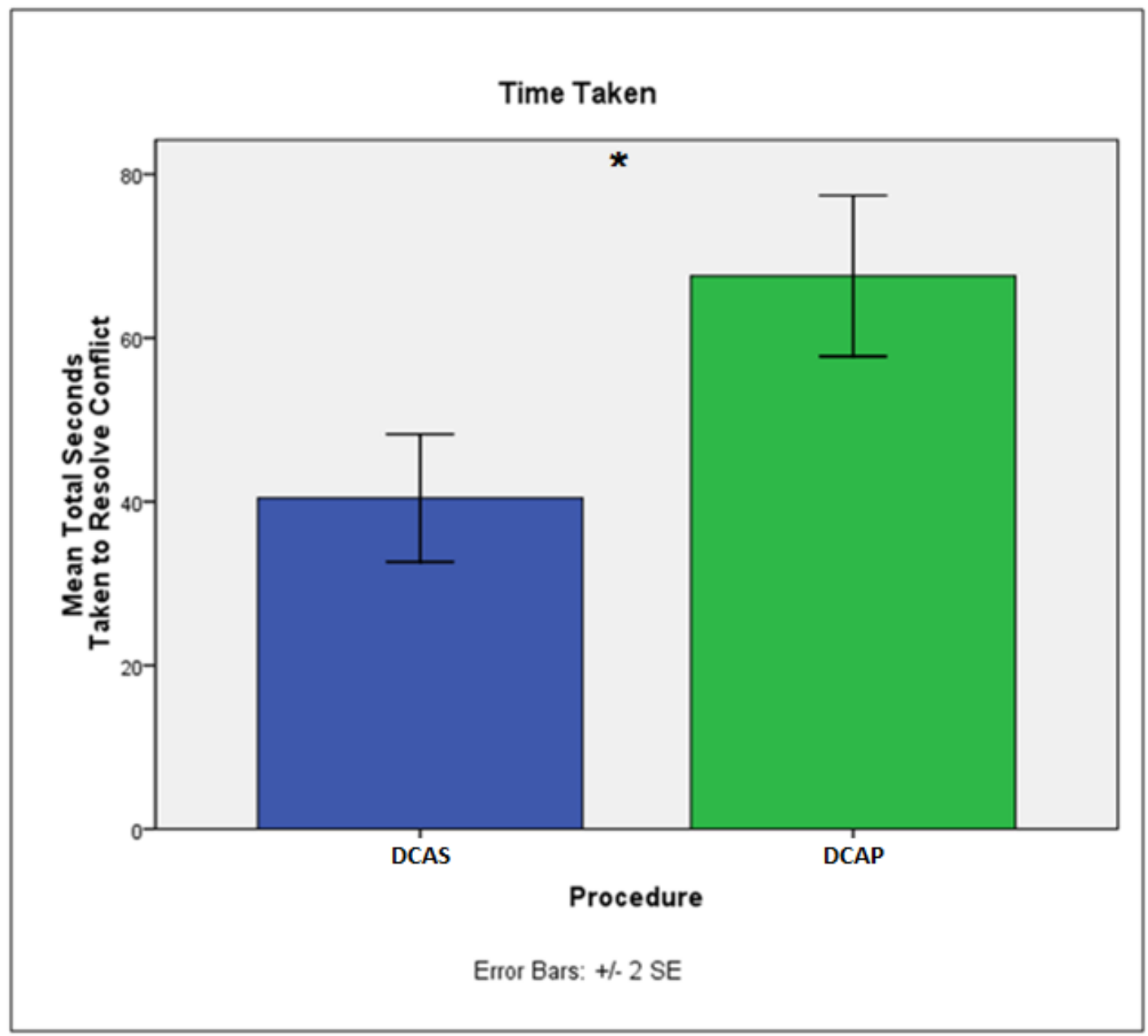

Figure 26. Significant mean comparison of time taken to resolve a scripted conflict.

\section{Summary - Controller Experience, Objective}

To summarize the objective results characteristic of the controller experiences, overall differences were seen between the procedures but not the traffic density. Assumed procedural differences are apparent in the descriptive statistics of the coordination data from the complete lack of coordination in the DCAS procedure. 
Furthermore, when just the existing coordination data (i.e., DCAP) was examined by the factor of traffic density independently from the absences in DCAS, no significant effects of traffic density were obtained. Correspondingly, the time on task metric did find the controller participants to resolve conflicts faster in the DCAS procedure (i.e., where ATCo opted out of verbal coordination for their adjacent sector conflict resolutions) than in the DCAP procedure.

VII. Feasibility of procedure for future. In their post-procedure questionnaires, controller participants were asked to rate each procedure separately on anticipated feasibility for future NextGen controllers on a scale from 1 to 5 ((Entirely Feasible (1) Unfeasible (5)) [DCAP $(\mathrm{M}=2.50, \mathrm{SD}=.97)$, DCAS $(\mathrm{M}=2.10, \mathrm{SD}=.99)]$. The analyses failed to show a significant effect of the manipulation of procedure on anticipated feasibility at the $\mathrm{p}<.05$ level $[\mathrm{F}(1,18)=.83, \mathrm{p}=.375]$. Because both response averages fell on the lower half of the scale as can be visually seen in Figure 27, the controller participants evidently believed both the DCAS and the DCAP procedure to be a workable set of responsibility procedures for the tested NextGen environment without significantly differentiating between the two in terms of feasibility. 


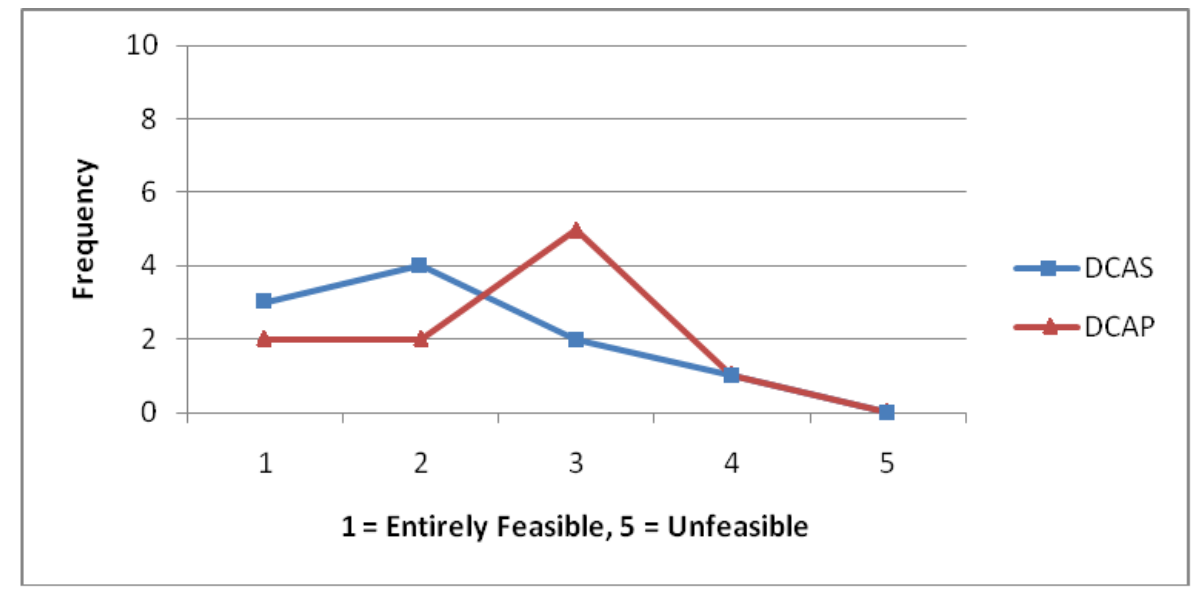

Figure 27. Feasibility ratings by procedure.

VIII-a, VIII-b. Unnecessary plane movement (experienced, expected). In their questionnaires controller participants were asked to rate their levels of concern for unnecessary or counter-productive movement of planes once after each run for what they themselves experienced and once after each procedural block as to what they anticipated concern levels would be for future controllers of NextGen. These ratings were made on a 1 to 5 scale (Not concerned (1) - Very concerned (5)). Averages indicated generally less concern in the DCAS $(M=1.90, S D=1.22)$ than in the DCAP procedure $(M=2.23, S D$ $=1.10)$ in the question of experienced concern as well as of that for expected concern [DCAS $(\mathrm{M}=2.60, \mathrm{SD}=.97), \mathrm{DCAP}(\mathrm{M}=3.40, \mathrm{SD}=1.27)]$ and the distributions for these ratings can be seen in Figures 28 and 29. 


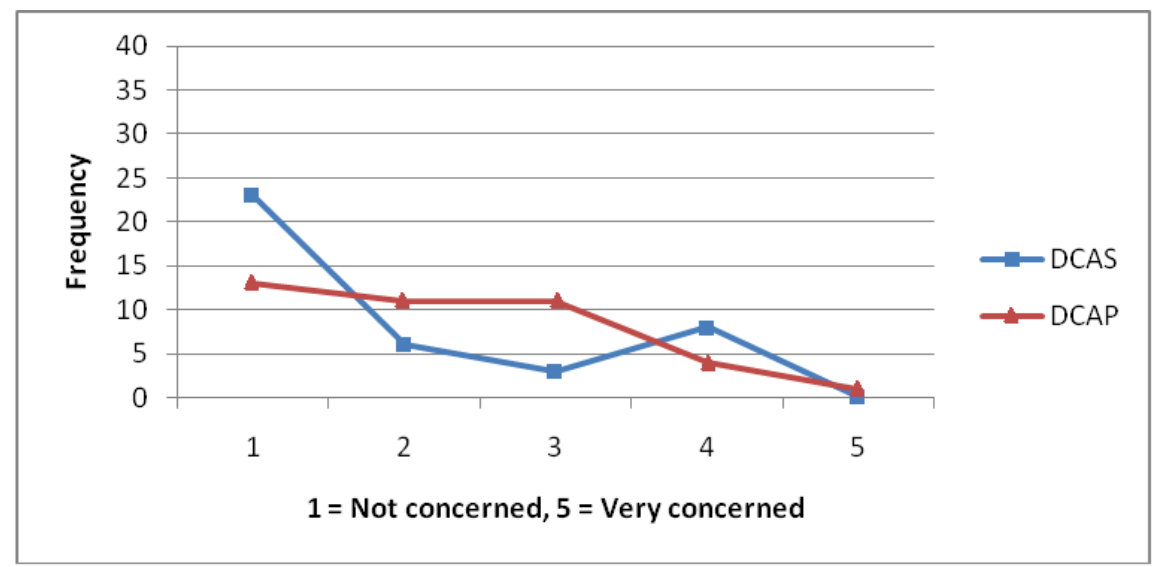

Figure 28. Experienced concern over the unnecessary movement of planes.

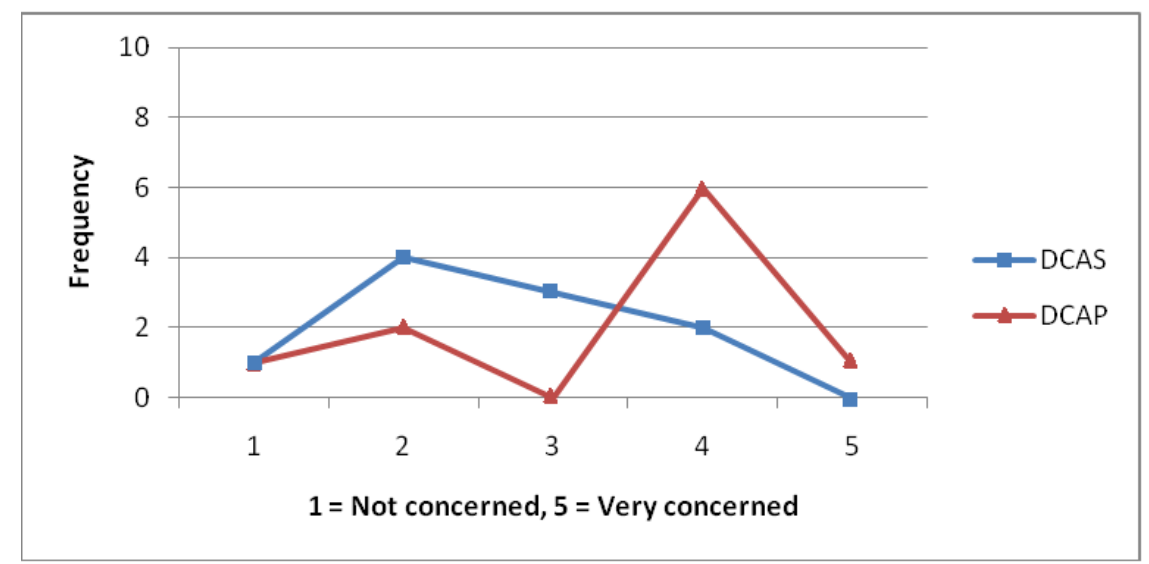

Figure 29. Expected concern for future for unnecessary movement of planes.

While both averages for the experienced concern for either procedure fell on the less concerned side of the scale, only the DCAS procedure expected levels of concern also indicated less rather than more concern over counter-productive plane movement. The analyses, however, did not show a significant effect of the manipulation of procedure at the $\mathrm{p}<.05$ level on experienced concern ratings $[\mathrm{F}(1,76)=1.67, \mathrm{p}=.200]$ nor on those anticipated for the future $[\mathrm{F}(1,18)=2.53, \mathrm{p}=.129]$. Experienced inefficiency concerns 
were also tested between the two traffic densities but also failed to show significance $[\mathrm{F}(1,76)=.96, \mathrm{p}=.330]$ nor an interaction with procedure $[\mathrm{F}(1,76)=.12, \mathrm{p}=.725]$.

\section{Summary - Plane Performance, Subjective}

Overall the subjective ratings of controllers on the plane performance level indicated that they judged either procedure as adequate in terms of feasibility. Furthermore, they also responded with equally low levels of concern for the efficiency of plane movement between DCAS and DCAP, both as to what they experienced themselves, as well as what they anticipated future controllers of NextGen to experience.

IX-a, IX-b, IX-c. Separation Violations (LoS, O.E., Proximity Event). Across all 192 scripted conflicts presented to the participants, there were only two logged instances of a LoS (planes came closer than 5 nautical miles horizontally and 800 feet vertically for longer than 1 second). Under the $2.5 x$ traffic density, one operational error occurred in each procedure, but both were the result of a situation in which the assumption of a timely automated detection alert was not upheld. At the present level of development, the uncertainty associated with border-line transitioning aircraft was too great for the automation algorithms to be able to recognize and compute resolution trajectories in time for either experimental procedure. While not an interpretable part of this study, these anecdotal cases are documented that they might shed light on a separate but related research problem regarding the coordination issues with short-term conflicts.

Each of these two event series are depicted in Figures 30 and 31, for the DCAS and DCAP procedures respectively. In both cases the underlying base scripted conflict was set to occur between COA2985 flying eastward from ZKC 90 into ZID 81 level at an 
altitude of 40,000 ft and UPS234 flying northward through ZID 81 in a climb from 29,000 to $41,000 \mathrm{ft}$. In either procedure the conflict is detected and alerted late with only 3 minutes remaining until LoS. About half a minute after that the short term automation issues a left turn clearance to COA2985. In that time however, the controllers (ZID 81 alone in Figure 30 and ZID 81/ZKC 90 together through a coordinate clearance in Figure 31) determine a resolution to turn UPS 234 to the right. These overlapping clearances by the automation and controllers result in the two planes turning outward away from the initial point of predicted LoS, thus only prolonging the conflict rather than resolving it. Lastly, the short term automation attempts to turn COA2985 behind UPS234, and while collision is avoided, the planes are too close to avoid loss of separation minima. 


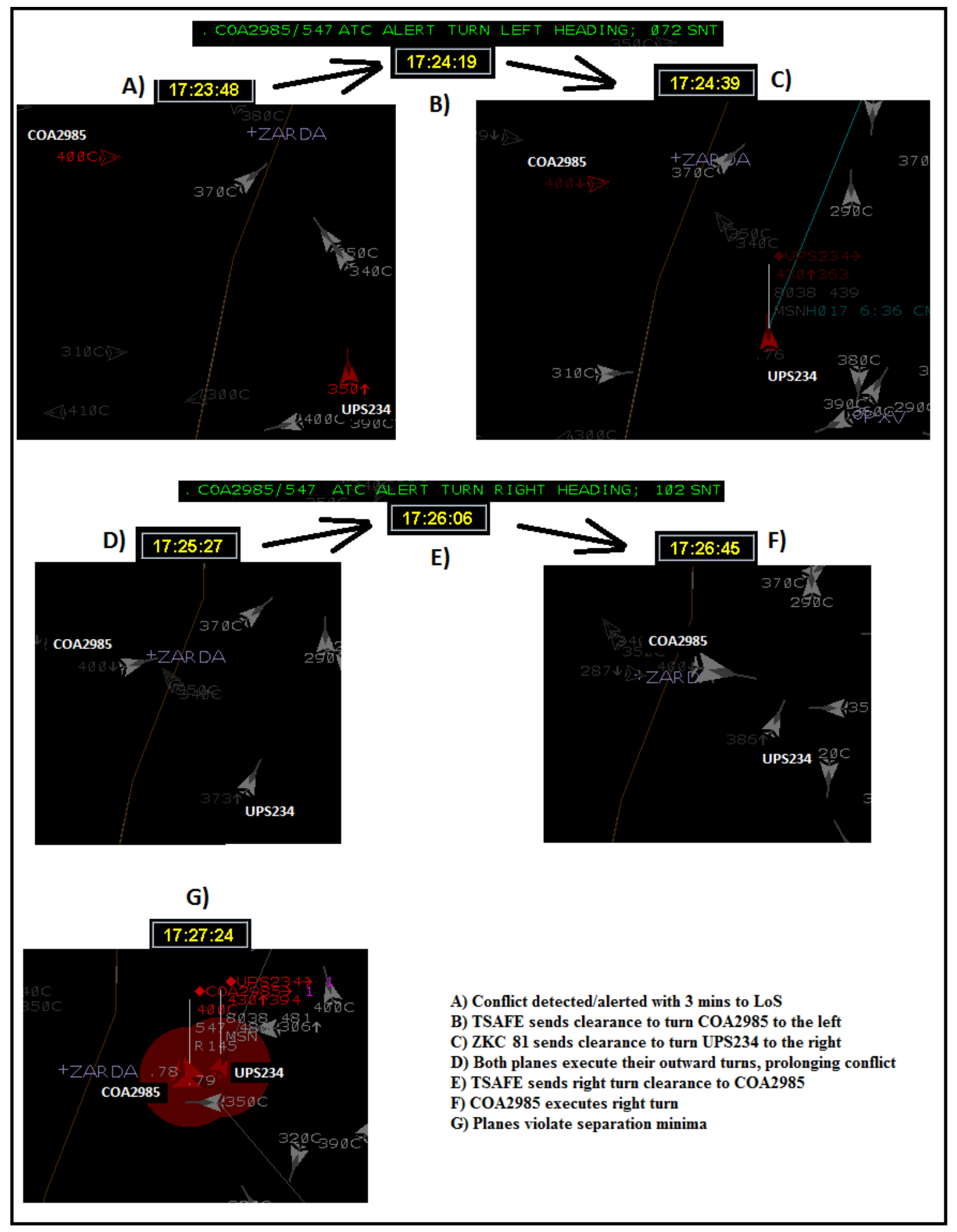

Figure 30. DCAS - Loss of separation due to late conflict detection from automation. 


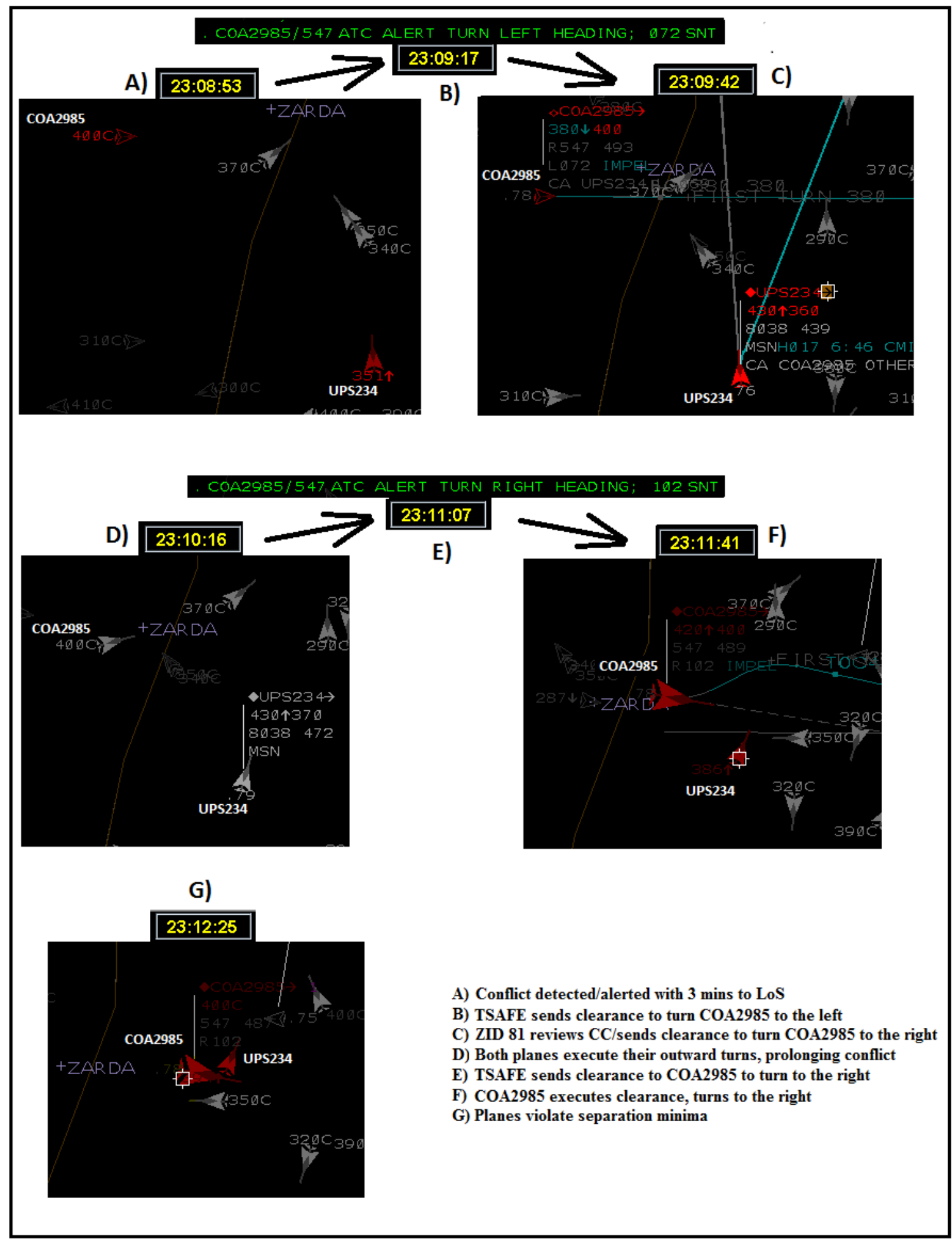

Figure 31. DCAP - Loss of separation due to late conflict detection from automation. 
X. Time until LoS. Every scripted conflict began with an alert from the automation indicating how many minutes were left until a predicted LoS would occur if no action were taken. In the cases where a scripted pair of conflict aircraft came into conflict multiple times with each other, averages of this time until LoS counter were taken for that pair. Overall time until LoS represents how close in time the scripted conflict aircraft came to losing separation. The DCAP procedure showed a slightly lower time until LoS average $(\mathrm{M}=7.14, \mathrm{SD}=1.97)$ than the DCAS procedure $(\mathrm{M}=7.32, \mathrm{SD}=$ 2.26), but the analyses showed no significance in this difference at the $p<.05$ level $[F(1,170)=.22, p=.643]$. Similarly, the differences between the traffic density averages were likewise small and in the anticipated direction of the $2.5 \mathrm{x}$ density have closer in times $(\mathrm{M}=7.14, \mathrm{SD}=2.23)$ than the $1.7 \mathrm{x}$ density $(\mathrm{M}=7.32, \mathrm{SD}=2.01)$ but with no significance $[\mathrm{F}(1,170)=.27, \mathrm{p}=.603]$. No interactive effects were found between procedure and traffic density on the time remaining until $\operatorname{LoS}[\mathrm{F}(1,170)=.41, \mathrm{p}=.523]$.

XI. Resolution attempts per conflict. Even with the aid of conflict-probed automated resolution clearances, scripted conflict pairs were not guaranteed to be kept apart indefinitely. Because of the dynamic and interactive nature of the entire traffic environment, a pair of aircraft might conflict, be issued clearances that kept them apart, only to then at a later time become conflicted again. That average number of resolution attempts that a controller(s) sent for a single scripted conflict pair was highly similar between the DCAP procedure $(\mathrm{M}=1.31, \mathrm{SD}=.61)$ and the DCAS procedure $(\mathrm{M}=1.32$, $\mathrm{SD}=.57)$ and the analyses did not show attributable significance to any difference between $[\mathrm{F}(1,170)=.01, \mathrm{p}=.945]$. The average resolution attempts per scripted conflict 
pair were also highly similar between the $1.7 \mathrm{x}$ density $(\mathrm{M}=1.37, \mathrm{SD}=.64)$ and the $2.5 \mathrm{x}$ density $(\mathrm{M}=1.26, \mathrm{SD}=.53)$ and the analyses also did not show significant differences between them $[\mathrm{F}(1,170)=1.59, \mathrm{p}=.209]$. No, interactive effects were found between procedure and traffic density on the number of resolutions sent to a scripted conflict pair $[\mathrm{F}(1,170)=.01, \mathrm{p}=.921]$

XII. Heading change. Nearly $90 \%$ of the resolution clearances sent to scripted conflict pairs were lateral heading changes. The angles of each of these 197 clearances were collected as a measure of how far off a plane was moved from its present relative heading $\left(0^{\circ}\right)$ to avoid the predicted LoS. The average magnitude of path change angle was slightly less in the DCAS procedure $\left(\mathrm{M}=25.85^{\circ}, \mathrm{SD}=12.76^{\circ}\right)$ than in the DCAP procedure $\left(\mathrm{M}=26.57^{\circ}, \mathrm{SD}=14.63^{\circ}\right)$. However, the analyses did find these differences to be significant $[\mathrm{F}(1,185)=.28, \mathrm{p}=.595]$. In regards to traffic density, the $1.7 \mathrm{x}$ density heading change average $\left(\mathrm{M}=26.16^{\circ}, \mathrm{SD}=12.52^{\circ}\right)$ was highly similar to that of the $2.5 \mathrm{x}$ density $\left(\mathrm{M}=26.27^{\circ}, \mathrm{SD}=14.81^{\circ}\right)$ again with the analyses not yielding a significant difference $[\mathrm{F}(1,185)=.07, \mathrm{p}=.792]$. No interactive effect was found between procedure and traffic density on average heading change $[\mathrm{F}(1,185)=2.02, \mathrm{p}=.157]$.

\section{Summary - Plane Performance, Objective}

To summarize the objective results characteristic of the plane performance (or service rendered to planes), overall differences were not found between the DCAS and DCAP procedures nor between the $1.7 x$ and $2.5 x$ density levels. In all but two cases, planes were kept safely apart with adequate time remaining until LoS. Furthermore, 
planes were also equivalently handled in terms of efficiency, i.e., without difference in the number or size of clearances sent to the aircraft to keep them apart from one another. 


\section{DISCUSSION}

The purpose of this study was to investigate the between-ATCo dynamic of adjacent en-route sectors for the resolution of conflicts that span sector boundaries under an advanced NextGen automated separation assurance environment. Under two different anticipated future levels of air traffic density (1.7x and $2.5 \mathrm{x})$, effects on controllers and effects on planes were measured and compared between two general procedures that differed in terms of who should be required to plan and implement deconfliction clearances for aircraft conflicts that are predicted to lose separation in a sector beyond where they are initially detected. Under the de-conflicting airplanes (DCAP) procedure, the guiding rule was that aircraft ownership (as with today's methods) underlies conflict resolution responsibility. In such a system, for any given amount of time, a single ATCo "owns" an aircraft and is responsible for safe-guarding it against losing separation with other owned aircraft and at sector boundaries, works as a team with other ATCo owners of aircraft to assure the safe transition of the aircraft. Under the de-conflicting airspace (DCAS) procedure, the guiding rule shifts the focus from planes to an area of space which must be kept conflict free. Where a pair of aircraft are predicted to lose separation then dictates who ought to be planning and implementing resolutions rather than where the aircraft presently are at the time of conflict detection.

Because the DCAS procedure reduces the number of ATCo involved in any inter-sector conflict geometry to just one (and hence eliminates potential for temporary ambiguity of responsibility), it was hypothesized that the procedure would show positive advantages over DCAP in the effects it had on the experiences of the controllers. 
Furthermore, it was anticipated that this advantage would carry over to an observable improvement in the controllers' performance with resolution clearances that would be safer from LoS and more efficient than in DCAP. Additionally, while either procedure was expected to work as well in lower traffic densities, when controllers aren't under as much stress or strain, it was anticipated that more densely trafficked airspace would more strongly exhibit differences between the deconfliction procedures.

\section{Procedure Main Effects: Differences}

Overall the results showed support for the first general hypothesis indicating differences in behavior and more favorable experiences by the controllers when operating under the DCAS procedure when compared to the DCAP procedure.

Objectively, it was seen that the controllers did not verbally coordinate their intersector resolution clearances under a procedure that did not require this of them; there were zero recorded verbal coordination transmissions under DCAS. Notably, the responsibility to coordinate the movement of a plane outside of their own sector with the ATCo of the sector that presently owned the aircraft was left up to their discretion; if at any time they felt the need to coordinate their resolutions with one another, they were encouraged to do so. Objectively, it was also shown that the controllers were faster at resolving their conflicts under DCAS than DCAP. Taken together, it is easy to imagine that the presence of coordination tasks increased controllers' time spent resolving conflicts.

Subjectively, controllers were well aware of their behavioral differences between the two procedures and ranked their perceived amounts of verbal coordination in line 
with their actual levels (i.e., at minimum in DCAS and as some amount in DCAP). Importantly, in their predictions of coordination levels for future NextGen controllers, their average ratings indicated their knowledge of the possibility of verbal coordination under DCAS. Preference ratings for those levels of verbal coordination evidenced that they in fact liked both amounts of coordination more than they disliked them, and that they expected the same to be true for future controllers as well. Still, their likability ratings (again for both actual and what they expected of others) showed a statistically greater preference under the DCAS procedure (where coordination amount was both objectively and subjectively less). Overall, regarding the procedures as a whole, controllers rated their workload as lower in DCAS than DCAP and indicated greater preference for the former over the later.

A caveat should be noted however, that there is some potential that the obtained subjective differences in these metrics might in part be due to exceptions involving the smooth transition of aircraft ownership/communication pairings across the sector boundaries. Per an individual aircraft, a discrepancy between its geographic location and ownership status (i.e., due to an errant hand-off) confuses the transparency of conflict alerting and resolution responsibility, both for automation and controller alike, and ultimately would have been systematically more aversive in the DCAP procedure than in the DCAS procedure. An analysis of the exact extent to how often such exceptions did in fact occur and might have contributed to controller's rating of their experiences has not yet been undertaken. 


\section{Procedure Main Effects: Similarities}

The results did not support the expectation that controllers would differentiate the two procedures in the performance of their duties (i.e., services rendered to the planes). In spite of reduced coordination, time on task, and workload with the DCAS procedure (as well as greater preferences therein), controllers did not significantly differ in their ratings of concern and feasibility for the two procedures.

Subjectively, controllers did not express concern in either procedure for inefficient movement of planes in both their own experiences and those expected of future controllers. Notably, it was assumed that a cost associated with a reduction in ATCo coordination might be an increased risk of controllers working against one another. For example, a plane might be moved for one ATCo's purpose only to be moved again by another ATCo for a different purpose, whereas through coordination, the plane might have been moved but once in a way that would have achieved both purposes. However, this perceived risk was not expressed by the participant controllers, as their rated concerns of unnecessary or counter-productive plane movement were not statistically different for the two procedures. Furthermore, both procedures were rated

overall as more feasible than not feasible with neither being statistically rated as more feasible than the other.

The similarities of controller procedural performance ratings are substantiated by apparent equivalencies in objective safety and efficiency metrics. Under either procedure planes were in fact kept safely apart. Discounting an equivalent conflict in both procedures where controllers and the short term automation worked against one another, 
there were no losses of separation under either procedure. Nominally, adequate amounts of time remained before a predicted LoS might have occurred (i.e., on average greater than seven minutes remaining per conflict) in both DCAS and DCAP. On par with the subjective perceptions of similar efficiency under each procedure, the controllers objectively did not in fact issue more numerous nor larger clearances in resolution of their conflicts.

\section{Traffic Density Main Effects: Differences and Similarities}

The only place where the results showed a main effect of traffic density was on the workload metric (both as self-rated by the controllers as well as observed by the supervisor positions) where higher workload ratings were associated with the higher traffic density of $2.5 x$ over that of $1.7 x$. Despite this relative difference, workload rating averages in the absolute were all well within tolerable levels. On all other metrics where traffic density was a factor in the analysis, no statistical differences were obtained.

\section{Interactions of Procedure and Traffic Density}

No significant interactions were obtained between the procedure and traffic density factors on any measured data. As seen from Table 3 in the results section, while support was found to substantiate the interaction hypothesis where either DCAS or DCAP would be both subjectively acceptable and objectively manageable under the lower traffic density of $1.7 \mathrm{x}$, results were not obtained to support the expectation that would indicate the DCAS procedure to be exclusively manageable at the higher traffic density level of $2.5 x$. Instead the only subgroup procedural average within the $2.5 x$ data that stands out in Table 3 (departing from its corresponding 1.7x average at greater than a 
full standard deviation and highest among its sub-groups) is the supervisor observed workload rating of 4.00 for the $2.5 x-D C A P$ conditions.

\section{Lessons Learned}

When initially introduced to the DCAS procedure, controller participants were wary of the idea of planes being moved by others within their sector without the requirement of first obtaining their direct acknowledgement. As they were reminded of and were able to trust the notion that these movements would be actively probed for conflicts, they seemed more interested in giving it a try. Evidently, in practice with the present levels of automated separation assurance and the shift of focus from airplanes to an area of airspace, controllers did take advantage of opportunities not to verbally coordinate inter-sector resolution clearances with one another, solved the scripted conflicts faster, with less workload, and in a more likable manner.

Interestingly, in spite of their greater positive experiences under the DCAS procedure, participants' ability to perform under both procedures was similar and effective; planes were kept apart and in efficient manner. Furthermore they seemed similarly un-phased by the increase of traffic density from the $1.7 x$ to the $2.5 x$ level save for subjective workload assessments. At first, the overall results taken as a whole appear at odds with general usability theory which assumes that user experience drives and determines user performance. Considering the nature of this specific population of participants (in league with that of emergency personnel like firefighters or bomb-squads where performance can be tied directly to human life and/or immense property value), however, it is clear how important it is for them to separate their own personal preference 
or ease of use from the ultimate performance of their critical duties. Thus, it appears that within the presently simulated NextGen separation assurance environment, our controller participants were able to internalize and absorb whatever differences in usability they experienced between these manipulated procedures and traffic densities, ultimately not letting the differences affect their work.

\section{Limitations and Future Research}

Follow-on research would look to improve upon the limitations of the present study in at least three different general avenues. First, it would be useful to examine the sixteen runs of training data for emergent or developed differences in experience and performance under the different conditions. Of key interest would be whether or not their undifferentiated performance was evident from the beginning or developed over exposure and in what ways. For example, how long it took the controllers to accept and adapt to each of the new operational procedures in their training runs would shed more light on their overall comfort levels with either procedure. Second, safety and performance differences not obtained at present might be evidenced at higher levels of traffic density or increased complexity. In other words, a "ceiling"/"floor" effect can be recognized from the workload ratings received where participant average ratings (although higher in some conditions than others) were yet still all within the workload spectrum of "in the groove" spectrum and below that of "overloaded." It would be pertinent to determine where, if within reason, a breaking point between the two procedures might exist, especially in light of other obtained subjective differences of preference. Finally providing the time and resource, a more comprehensive study would include analyzing 
all the aircraft data, extending the investigation beyond just the scripted conflict subset. From observing the experiment as it unfolded, numerous un-scripted conflicts emerged in the runs and it would be important to determine how representative their treatment of the scripted conflicts was of their treatment of all the planes. While they were not given any indication as to which were scripted and which were not, it would be important to ensure that their measured levels of service were not drawn at the cost of those not measured.

\section{Conclusion}

While the DCAS procedure lowered controller workload, coordination, time on task, and was more favorable for controllers in comparison with the DCAP procedure, the levels for these aspects were still also very good for DCAP. Furthermore, in terms of the service rendered to the planes, neither procedure departed from the other indicating that regardless of what differences the controllers themselves experienced, they were able to intercept these differences and prevent them from transpiring on their scopes, i.e., meeting their goals of safe and efficient travel. In general, because the traffic densities represented much higher demand levels than those required today, it is very encouraging for the ground-based automated separation assurance concept that our controller participants were able to effectively work with each other and the automation to manage these sector to sector conflicts under either procedure and either traffic level. 


\section{REFERENCES}

Airspace Operations Laboratory (2008). The Multi Aircraft Control System (MACS). Retrieved August 13, 2010, from

http://humansystems.arc.nasa.gov/groups/AOL/technologies/macs.html

Barhydt, R. and Kopardekar, P. (2005) Joint NASA Ames/Langley Experimental Evaluation of Integrated Air-Ground Operations for En Route Free Maneuvering. Sixth USA/Europe Air Traffic Management Research and Development Seminar. Baltimore, MD. Retrieved August 13, 2010, from

http://www.atmseminar.org/seminarContent/seminar6/papers/p_084_AGC.pdf

Barnett, A. (2001). Air Safety: End of the golden age? The Journal of the Operational Research Society, 52(8), 849-854.

Boeing (2009). Commercial Safety. Retrieved September 25, 2009 from http://www.boeing.com/commercial/safety/pf/pf_howsafe.html

Bureau of Transportation Statistics. (2009). On-Time performance - Flight delays at a glance. Research and Innovative Technology Administration. Retrieved August 13, 2009 from http://www.transtats.bts.gov/HomeDrillChart.asp

Cooper, G., White, M., \& Lauber, J. (1980). Resource Management on the Flightdeck: Proceedings of a NASA/Industry Workshop. (NASA CP-2120). Moffett Field, CA: NASA-Ames Research Center.

Erzberger, H. (2006). Automated conflict resolution for air traffic control. Proceedings of the $25^{\text {th }}$ International Congress of the Aeronautical Sciences (ICAS). Hamburg, Germany, September 3-8. Retrieved August 13, 2010, from http://www.aviationsystemsdivision.arc.nasa.gov/publications/tactical/erzberger_09_06.p df

Erzberger, H. and Heere, K. (2008). Algorithm and operational concept for resolving short range conflicts. Proceedings of the $26^{\text {th }}$ International Congress of the Aeronautical Sciences (ICAS). Anchorage, Alaska, September 14 - 19. Retrieved August 13, 2010, from http://pep.metapress.com/content/133143x0354h5281/fulltext.pdf

Erzberger, H., Lauderdale T., \& Chu, Y-C. (2010). Automated conflict resolution, arrival management and weather avoidance for air traffic management. Proceedings of the $27^{\text {th }}$ International Congress of the Aeronautical Sciences (ICAS). Nice, France, September 19 -24 .

Farley, T. \& Erzberger, H. (2007). Fast-time simulation evaluation of a conflict resolution algorithm under high air traffic demand. Seventh FAA/Eurocontrol Research and Development Seminar. Barcelona, Spain. Retrieved August 13, 2010, from http://www.aviationsystemsdivision.arc.nasa.gov/publications/tactical/farley_atm2007_1. pdf 
Federal Aviation Administration (2007). The operational evolution partnership. Retrieved October 13, 2009, from

http://www.faa.gov/about/office_org/headquarters_offices/ato/publications/oep/partnershi $\mathrm{p} /$

Federal Aviation Administration (2008a). Order JO 7110.65S: Air traffic control. Washington DC: U.S. Department of Transportation.

Federal Aviation Administration (2008b). Order JO 7210.3V: Facility operation and administration. Washington DC: U.S. Department of Transportation. Retrieved October 13, 2009, from http://www.faa.gov/air_traffic/publications/atpubs/FAC/Ch17/s1708.html

Federal Aviation Administration. (2009a). FAA aerospace forecast: fiscal years 2009-2025. Washington, DC: U.S. Department of Transportation.

Federal Aviation Administration. (2009b). Air Traffic - NextGen Briefing. Washington, DC: U.S. Department of Transportation. Retrieved August 13, 2009 from http://www.faa.gov/air_traffic/briefing/

Helmreich, R. L. \& Foushee, H. C. (2010). Why CRM? Empirical and theoretical bases of human factors training. In B. G. Kanki, R. L. Helmreich, \& J. Anca (Eds.), Crew Resource Management $\left(2^{\text {nd }}\right.$ ed., pp. 3 - 57). San Diego, USA: Elsevier.

Homola, J. (2008). Analysis of human and automated separation assurance at varying traffic levels. (Master's thesis, San Jose State University). Available from ProQuest Dissertations \& Theses database. (UMI No. 1459700).

Jaccard, J. and Wan, C. (1996). LISREL Approaches to Interaction Effects in Multiple Regression. Thousand Oaks, Ca: Sage Publications. Retrieved as reference August 13, 2009 from http://www.listserv.uga.edu/cgi-bin/wa?A2=ind0506\&L=spssx-1\&P=37560

Joint Planning and Development Office (2009). Concept of operations for the next generation air transportation system v. 3.0. Retrieved August 13, 2010 from http://www.jpdo.gov/library/NextGen_ConOps_v3\%200.pdf

Leiden, K., \& Green, S. (2000). Trajectory Orientation: A technology-enabled concept requiring a shift in controller roles and responsibilities. Third USA/Europe Air Traffic Management Research and Development Seminar. Napoli, Italy, June.

MacNeil/Lehrer Productions (2000, July 19). The NewsHour with Jim Lehrer [Television broadcast]. New York and Washington, DC: Public Broadcasting Service. Transcript retrieved August 13, 2009 from http://www.pbs.org/newshour/bb/transportation/july-dec00/delays_7-19.html

McNally, D. \& Thipphavong, D. (2008). Automated separation assurance in the presence of uncertainty. Proceedings of the $26^{\text {th }}$ International Congress of the Aeronautical Sciences (ICAS). Anchorage, Alaska, September 14 - 19. Retrieved August 13, 2010, from 
http://www.aviationsystemsdivision.arc.nasa.gov/publications/strategic/McNallyICAS2008-581.pdf

Mainini, M. (2009). En route air traffic control input devices for the next generation. (Master's thesis, San Jose State University).

Manning, J. (2000). The air traffic controllers' strike. Material Things: An encyclopedia of the 1980's. Retrieved October 13, 2009, from

http://eightiesclub.tripod.com/id296.htm

Mathieu, J., Heffner, T., Goodwin, G., Salas, E., \& Cannon-Bowers, J. (2000). The influence of shared mental models on team process and performance. Journal of Applied Psychology, $85(2), 273-285$.

Mohler, G. (2007). How OEP will lead FAA through the NextGen transformation. IEEE Conference Proceeding: Integrated Communications, Navigation and Surveillance Conference. Virginia, USA. May $1-3$.

Mohler, G. (2008). Airport capacity planning and NextGen. Eastern Region Airport Conference, March 2008. Retrieved August 13, 2009, from http://www.faa.gov/airports/eastern/airports_news_events/hershey/media_08/D4Giselle.pdf

Murphy, M. (1980). Review of aircraft incidents. Cited in Cooper. et al.

National Air Traffic Controllers Association. (n.d.) Where do air traffic controllers work? Air Traffic Control: By the Numbers. Retrieved August 13, 2010, from http://www.natca.org/mediacenter/bythenumbers.msp

Nolan, M.S. (2004). Fundamentals of air traffic control ( $4^{\text {th }}$ ed.). California: Brooks/ColeThomson Learning.

Office of the Secretary of Transportation (2009). Treatment of the economic value of a statistical life in departmental analyses. Retrieved August 13, 2010, from http://ostpxweb.dot.gov/policy/reports/VSL\%20Guidance\%20031809\%20a.pdf

Orasanu, J. M. (2010). Flight crew decision-making. In B. G. Kanki, R. L. Helmreich, \& J. Anca (Eds.), Crew Resource Management (2 ${ }^{\text {nd }}$ ed., pp. 147 - 180). San Diego, USA: Elsevier.

Payne, S. J. (2008). Mental models in human-computer interaction. In A. Sears \& J. A. Jacko (Eds.), Human-computer interaction handbook ( $2^{\text {nd }}$ ed., pp. $\left.63-76\right)$. New York: Lawrence Erlbaum Associates.

Prevot, T., Homola, J., \& Mercer, J. (2008). Human-in the-Loop evaluation of ground-based automated separation assurance for NextGen. Proceedings of the $26^{\text {th }}$ International Congress of the Aeronautical Sciences (ICAS). Anchorage, Alaska, September 14 - 19. Retrieved August 13, 2010, from http://humansystems.arc.nasa.gov/publications/AIAA-2008-8885-328.pdf 
Prevot, T., Homola, J., Mercer, J., Mainini, M., \& Cabrall, C. (2009). Initial evaluation of NextGen air/ground operations with ground-based automated separation assurance. Eighth USA/Europe Air Traffic Management Research and Development Seminar. Napa, California. Retrieved August 13, 2010, from

http://humansystems.arc.nasa.gov/groups/AOL/1_publication_view.php?publication_id=1 824

Prevot, T., Lee, P., Callantine, T., Mercer, J., Homola, J., Smith, N. \& Palmer, E. (2010). HumanIn-the-Loop evaluation of NextGen concepts in the airspace operations laboratory. AIAA Modeling and Simulation Technologies Conference. Toronto, Canada.

Wing, D., Prevot, T., Murdoch, J., Cabrall, C., Chamberlain, J., Chartrand, R., Consiglio, M., Hoadley, S., Homola, J., Mercer, J., \& Palmer, M. (2010). Comparison of airborne and ground-based functional allocation concepts for NextGen using human-in-the-loop simulations. Tenth AIAA Aviation Technology, Integration, and Operations Conference. Dallas Fort-Worth, Texas. 
APPENDICES 


\section{Appendix A}

\section{Human Subjects - IRB Approval}

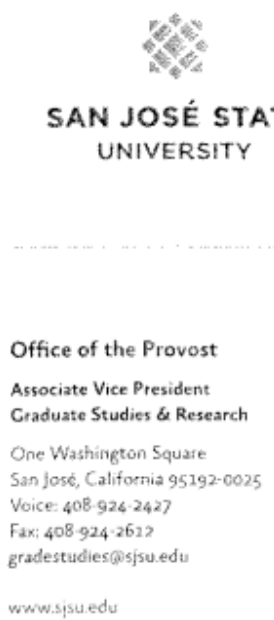

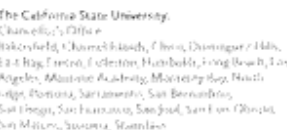

To: Christopher Donald Douglas Cabrall

From: Pamela Stacks, Ph.D. Associate Vice President Graduate Studies and Research

Date: November 3, 2009

The Human Subjects-Institutional Review Board has approved your request to use human subjects in the study entitled:

"Aircraft conflict resolution responsibility in NextGen separation assurance"

This approval is contingent upon the subjects participating in your research project being appropriately protected from risk. This includes the protection of the confidentiality of the subjects' identity when they participate in your research project, and with regard to all data that may be collected from the subjects. The approval includes continued monitoring of your research by the Board to assure that the subjects are being adequately and properly protected from such risks. If at any time a subject becomes injured or complains of injury, you must notify Dr. Pamela Stacks, Ph.D. immediately. Injury includes but is not limited to bodily harm, psychological trauma, and release of potentially damaging personal information. This approval for the human subject's portion of your project is in effect for one year, and data collection beyond November 3, 2010 requires an extension request.

Please also be advised that all subjects need to be fully informed and aware that their participation in your research project is voluntary, and that he or she may withdraw from the project at any time. Further, a subject's participation, refusal to participate, or withdrawal will not affect any services that the subject is receiving or will receive at the institution in which the research is being conducted.

If you have any questions, please contact me at (408) 924-2427.

Protocol \#S0904ii

cc. Kevin Jordan 0120 


\section{Appendix B}

\section{Consent Form}

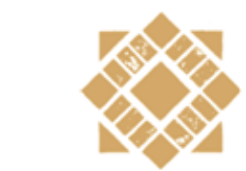

San José State

UNIVERSITY

Department of Industrial \& Systems Engineering Engr 485

One Washington Square San Jose. CA $95192-1020$ Voice: $408-924-3301$ Fax: 408-924-4040 www.engr.sjsu.edu

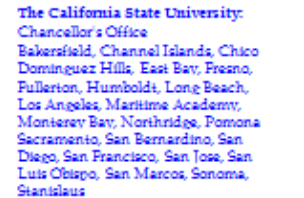

\section{AGREEMENT TO PARTICIPATE IN RESEARCH AT SAN JOSE STATE UNIVERSITY}

Responsible Investigator(s): Christopher Cabrall

Title of Protocol: Aircraft Deconfliction Responsibility across En-Route Sectors in NextGen Separation Assurance

1. You have been asked to participate in a research study investigating the aircraft conflict resolution strategies and responsibilities of air traffic control operators and an automated algorithm.

2. You will be asked to manage simulated air traffic at an air traffic control workstation. This study will be conducted at the NASA Ames Research Center's Airspace Operations Laboratory between the dates of $\operatorname{Dec} 1,2009$ and February 28, 2010. Your participation will involve 15 minute sessions, run across 1.5 days, with frequent breaks for refreshment and lunch.

3. There will not be any risks present in this study outside of what are present in daily life.

4. Direct benefits from participation in this study may include skill maintenance and the gaining of greater insight into the possible advances in the air transportation system. An indirect benefit may be the feeling of reward gained from the knowledge that your participation may be contributing to these advances.

5. Although the results of this study may be published, no information that could identify you will be included. The data collected from your participation will also be stored on password protected computers, with access granted only to those with the password.

6. Compensation for your participation will be provided for by Perot Systems based on your qualifications and task.

7. Questions about this research may be addressed to Christopher Cabrall,

Christopher.D.Cabrall@nasa.gov. Complaints about the research may be presented to Dr. Kevin Jordan, Ph.D., Professor of Psychology, SJSU, (408) 924-5626. Questions about a research subjects' rights, or research-related injury may be presented to Pamela Stacks, Ph.D., Associate Vice President, Graduate Studies and Research, at (408) 9242427.

8. No service of any kind, to which you are otherwise entitled, will be lost or jeopardized if you choose to not participate in the study.

9. By signing this document, you acknowledge that your consent is being given voluntarily. You may refuse to participate in the entire study or in any part of the study. If you decide to participate in the study, you are free to withdraw at any time without any negative effect on your relations with San Jose State University or with any other participating institutions or agencies.

10. At the time that you sign this consent form, you will receive a copy of it for your records, signed and dated by the investigator.

Your signature on this document indicates agreement to participate in the study and your consent to the anonymous video and audio recording of yourself for data analysis or illustrative purposes. The signature of a researcher on this document indicates agreement to include the below signed subject in the research and attestation that the subject has been fully informed of his or her rights.

Signature
Investigator's Signature




\section{Appendix C}

\section{Post-Run Questionnaire}

\section{Post-Run Survey}

Your thoughtful feedback is a valuable part of this research. Thank you for your participation!

$$
\text { R-SIDES (World?_ _ Station ID?__ }
$$

1. Please rate how much coordination you experienced in the last run:
1
2
3
4

Very Little

Very much

Rating \#

2. How agreeable/disagreeable was that amount of coordination?:

1

Love it
2

3

4

5

Hate it

Rating \#

3. How concerned are you that planes were moved un-necessarily or counterproductively?:

1

2

Not concerned
3

4

5

Very concerned

Rating \#

4. Please describe/list any aircraft that you felt behaved unusually or unexpectedly: 
5. Do you feel these aircraft negatively impacted your ability to perform your duties?:

6. Please describe any problems you might have experienced with any equipment (i.e., DSR keyboard, DSR mouse, PC keyboard, PC mouse, Headset, Tablet PC, etc.) in the last run:

Thank you! 


\section{Post-Procedure Questionnaire}

\section{Post-Procedure Survey}

Your thoughtful feedback is a valuable part of this research. Thank you for

Remember in the DCAP procedure, controllers would be responsible for any conflict in which at least one of the conflicting aircraft was under their ownership, regardless of where the other aircraft is and regardless of where the predicted loss of separation would occur (i.e., could be predicted to occur in an adjacent sector).

\section{Or}

Remember in the DCAS procedure, controllers would protect an area of space from the occurrence of predicted Losses of Separations regardless of ownership of aircraft they would send clearances to.

(World?__ Station ID? _ _ )

1. If the ?X? procedure were adopted as common practice, please rate how much coordination you would expect the future NEXTGEN controllers to experience during a typical day:
1
2
3
4
5

Very Little

Very much

Rating \#

2. How would the future NEXTGEN controllers within ?X? find that level of coordination to be?:

1

Would Love
2

3

4

5

Would Hate 
Rating \#

3. How concerned do you think the future NEXTGEN controllers would be that planes controlled under a ?X? procedure would be moved un-necessarily or counter-productively?:
1
2
3
4
5

Not concerned

Very concerned

Rating \#

4. How feasible do you think a ?X? procedure might be for future NEXTGEN controllers?:
1
2
3
4
5

Entirely Feasible

Unfeasible

Rating \#

5. Please rate your overall Situation Awareness under the ?X? procedure:

1

2

3

4

5

Very High

Very Low

Rating \#

6. Please describe any of the thoughts or opinions you have regarding the ?X? procedure: 
Post-Study Questionnaire

\section{Post-Simulation Questionnaire}

Your thoughtful feedback is a valuable part of this research. Thank you for your participation!

$$
\text { (World ?__, Station ID?__ })
$$

1. Please rate the two controller responsibility procedures for NextGen separation assurance based on likability from your experience with them today only:

Point of Detection* Procedure (Track Control/Ownership Based Concept; Being responsible for conflicts involving planes under my ownership):
1
2
3
4
5

Love it

Hate it

Rating \#

Point of Conflict* Procedure (Loss of Separation Based Concept; Being responsible only for conflicts that are predicted to occur within my area regardless of ownership):
1
2
3
4
5

Love it

Hate it

Rating \# 
2. If you rated one procedure higher than the others, what made you rate it higher?

3. If you rated one configuration lower than the others, what made you rate it lower?

\section{Additional Comments?}

*During the simulation the procedures were referred to as Point of Detection and Point of Confliction but were changed to Deconflicting AirPlanes (DCAP) and Deconflicting AirSpace (DCAS) respectively for clarification during publication. 


\section{Appendix D}

\section{Workload Rating Scale}

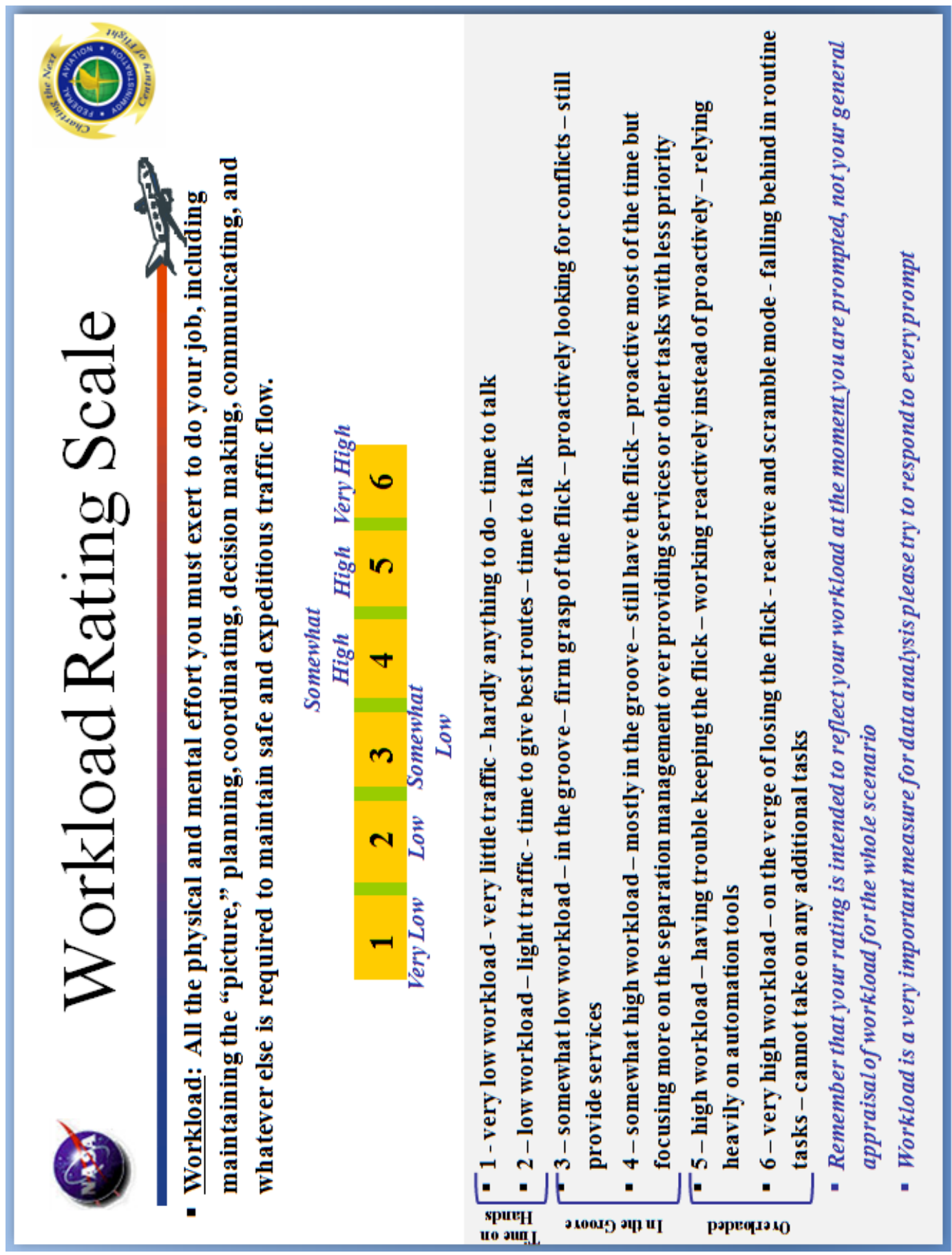

